\title{
Recent advances in noble metal free doped graphitic carbon nitride based nanohybrids for photocatalysis of organic contaminants in water :A Review
}

Vasudha Hasija ${ }^{a}$, Pankaj Raizada ${ }^{a *}, b$, Anita Sudhaik ${ }^{a, b}, K_{i r t i}$ Sharma $^{a}$, Pardeep Singh $^{a, b}$, Sreekantha B. Jonnalgadda ${ }^{c}$, Vijay Kumar Thakur ${ }^{d}$

${ }^{a}$ School of Chemistry, Faculty of Basic Sciences, Shoolini University, Solan (HP), India--173229

${ }^{b}$ Himalayan Centre for Excellence in Nanotechnology, Shoolini University. Solan (HP) India-173229

${ }^{c}$ School of Chemistry, Westville Campus, University of KwaZulu-Natal, P Bag X 54001, Durban 4000, South Africa

${ }^{d}$ Enhanced Composites and Structures Center, School of Aerospace, Transport and Manufacturing, Cranfield University, Bedfordshire MK43 OAL, UK

*Corresponding Author

Tel: +91-1792-308000,

Fax: $+91-1792-30800$

Email:*pankajchem1@gmail.com 


\section{Abstract}

Extensive contamination of water bodies by textile dyeing industries, organic pollutants and agricultural waste has emerged water pollution as one of the major global environmental crisis. The effect of this gross negligence is posing serious threats to human health therefore today; conserving water resources for the essence of life is of grave concern. Recently, advancements in photocatalytic properties of graphitic carbon nitride $\left(\mathrm{g}-\mathrm{C}_{3} \mathrm{~N}_{4}\right)$ for wastewater treatment have gained tremendous interest in research. However, pristine $\mathrm{g}-\mathrm{C}_{3} \mathrm{~N}_{4}$ suffers from bottlenecks such as low surface area, rapid recombination of photo-generated electron-hole pairs and insufficient light absorption which thereby, reduces the photocatalytic degradation activity. Hitherto, noble metals have been widely utilized as dopants but are cost ineffective, rarely found and are difficult to recover. In this updated and allinclusive review we have briefly discussed photocatalysis mechanism, primarily focused on nonprecious elemental doping via various synthesis techniques of noble metal free doped $\mathrm{g}-\mathrm{C}_{3} \mathrm{~N}_{4}$ photocatalysts. Typically metal, non-metal, rare earth metal doping and co-doping have been explored, which demonstrates the synergistic behavior of the doped nanocomposites in modulation of electronic structure, broaden the visible light absorption range, enhancement in photocatalytic wastewater remediation ability to obtain maximum pollutant eradication. Summary remarks conclude the review with valuable knowledge of noble metal free doped $\mathrm{g}_{-} \mathrm{C}_{3} \mathrm{~N}_{4}$ photocatalysts for water purification and sheds light on current challenges and crucial issues associated with its commercialization. The future aspect aims at designing of efficient solar light driven photocatalysts for application in various domains i.e. production of $\mathrm{H}_{2}$ and $\mathrm{O}_{2}$, reduction of $\mathrm{CO}_{2}$, practical use of solar cells, treatment of wastewater, air purification and environmental conservation.

Keywords: Graphitic carbon nitride $\left(\mathrm{g}-\mathrm{C}_{3} \mathrm{~N}_{4}\right)$; Inherent drawbacks of $\mathrm{g}-\mathrm{C}_{3} \mathrm{~N}_{4}$ as photocatalyst; Noble metal free doping of $\mathrm{g}_{-} \mathrm{C}_{3} \mathrm{~N}_{4}$; Improved photocatalytic activity; Wastewater treatment 


\section{Contents}

1. Introduction............................................................00

1.1 Noble metal free doping of $\mathrm{g}-\mathrm{C}_{3} \mathrm{~N}_{4}$ : Potential strategy for enhanced photocatalytic activity .00

2. Synthesis routes for preparation of noble metal free doped $g-C_{3} \mathbf{N}_{4} \ldots \ldots \ldots \ldots \ldots \ldots$

2.1 High temperature assisted synthesis (Thermal condensation, pyrolysis and calcination)

2.2 Thermal polymerization Method

2.3 Hydrothermal Method ..................................................00

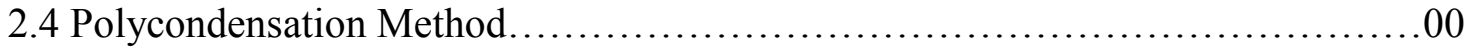

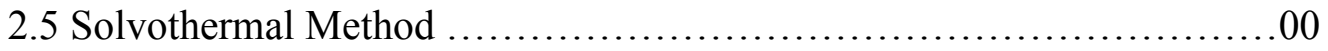

3. Noble metal free doped $g-\mathrm{C}_{3} \mathbf{N}_{4}$ photocatalyst for water purification .............00

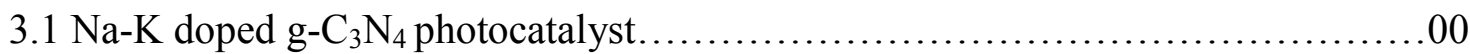

3.2 Transition metal doped $g-\mathrm{C}_{3} \mathrm{~N}_{4}$ photocatalyst...........................00

3.3 Rare earth metal doped $\mathrm{g}-\mathrm{C}_{3} \mathrm{~N}_{4}$ photocatalyst........................... 00

4. Non-metal doping $g-C_{3} \mathbf{N}_{4}$ photocatalyst for water purification $\ldots \ldots \ldots \ldots \ldots \ldots 00$

4.1 Phosphorus doped g- $\mathrm{C}_{3} \mathrm{~N}_{4}$ photocatalyst................................. 00

4.2 Sulfur doped $\mathrm{g}-\mathrm{C}_{3} \mathrm{~N}_{4}$ photocatalyst.....................................

4.3 Oxygen doped $g-\mathrm{C}_{3} \mathrm{~N}_{4}$ photocatalyst.................................. 00

4.4 Nitrogen, carbon, boron and halogen doped $g-\mathrm{C}_{3} \mathrm{~N}_{4}$ photocatalyst...............00

5. Metal/nonmetal co-doping of $g-\mathrm{C}_{3} \mathbf{N}_{4}$ photocatalyst for water purification..........00

6. Other potential applications of modulated $\mathrm{g}-\mathrm{C}_{\mathbf{3}} \mathbf{N}_{\mathbf{4}} \ldots \ldots \ldots \ldots \ldots 0$

7. Conclusion and future aspects................................... 00 


\begin{abstract}
Abbreviations:
AOP, Advanced oxidation process; AEP, 2-aminoethylphosphonic acid; AAS, atomic absorption spectroscopy; BPA, bisphenol A;BET, Brunauer-Emmett-Teller; CQDs, carbon quantum dots; CN, Concentration; CB, conduction band; DFT, density function theory; 2,4-DCP, 2-4 dichlorophenol; DCDA, dicyandiamide; DRS, diffuse reflectance spectra; $\mathrm{e}^{-}-\mathrm{h}^{+}$pair, EHP; $\mathrm{e}^{-}$, electron; EDX, energy dispersive X-ray analysis; $\mathrm{Fe}_{2} \mathrm{O}_{3}$, ferric oxide; FESEM, field emission spectroscopy; $\mathrm{g}-\mathrm{C}_{3} \mathrm{~N}_{4}$, graphitic carbon nitride; HRTEM, high resolution transmission electron microscopy; $\mathrm{h}^{+}$, hole; IC, indigo caramine; IFCT, interfacial charge transfer effect; mp, mesoporous; $\mathrm{MO}$, methyl orange; $\mathrm{MB}$, methylene blue; $\mathrm{NO}$, nitrous oxide; $\mathrm{Cl}_{6} \mathrm{~N}_{3} \mathrm{P}_{3}$, phosphonitrilic chloride trimer; photoelectrochemical (PEC); PL, photoluminescence; polymeric carbon nitride $(\mathrm{PCN})$; KI, potassium iodide; PDOS, project density states plot; $\mathrm{P}^{31} \mathrm{NMR}$, solid state phosphor nuclear magnetic resonance; QC, quantum confinement; ROS, reactive oxygen species; RhB, rhodamine B; TOC, total organic carbon; TTCA, tri-thiocyanuric acid; VB, valence band; XRD, Xray diffraction; XPS, X-ray photoelectron spectroscopy; ZnTNPc, zinc phthalocyanines
\end{abstract}




\section{Introduction}

The growing process of industrialization, modern civilization and excessive utilization of available resources by mankind has emerged water pollution as one of the global environmental issues. There is a rapid increase in the discharge of organic pollutants such as crude oil, antibiotics and chlorinated products which are persistent and toxic [1-8]. Similarly, agricultural runoff carrying inorganic fertilizers and pesticides decrease oxygen level for aquatic ecosystem. Indeed various water remediation techniques such as biological methods, precipitation, coagulation, flocculation, ion exchange, membrane filtration and reverse osmosis have been developed for the removal of pollutants including organic acids, nitrates, phosphates, toxic heavy metals, dyes etc [912].There are certain limitations of these techniques for instance; they have low removal efficiency, cost ineffective, time consuming, high production of sewage sludge, applicable at small scale and generation of toxic by-products which gets accumulated into the environment . In this scenario, the approach of green chemistry is the key to alleviate water pollutants and an essential necessity for sustainable development of human society $[13,14]$. For achieving complete abatement and mineralization of pollutants, advanced oxidation processes (AOP's) are considered to be highly efficient in the oxidation of persistent organic contaminants into harmless products $[15,16]$.The common characteristic feature of all AOP's is in-situ formation of highly reactive hydroxyl radical $(\cdot \mathrm{OH})$ that causes non-selective oxidation of organic pollutants to $\mathrm{CO}_{2}, \mathrm{H}_{2} \mathrm{O}$ and particular inorganic ions [17]. The versatility of AOP's is attributed to its highly selective nature of attack, high oxidation potential of $\mathrm{OH} \cdot\left(\mathrm{E}^{\circ}=2.80 \mathrm{eV}\right)$ and by the different possible ways for $\mathrm{OH} \cdot$ radical production which allow a better fulfillment with respect to waste water treatment requirements $[18,19]$. Due to combination of various processes the classification of AOP's is vast that includes Fenton's reagent $\left(\mathrm{H}_{2} \mathrm{O}_{2} / \mathrm{Fe}^{+2}\right)$, photo- Fenton $\left(\mathrm{Fe}^{+2} / \mathrm{H}_{2} \mathrm{O}_{2} / \mathrm{UV}\right)$ and sono-Fenton $\left(\mathrm{Fe}^{+2} / \mathrm{H}_{2} \mathrm{O}_{2} / \mathrm{US}\right)$, ozone and ozone-hybrids $\left(\mathrm{O}_{3}, \mathrm{O}_{3} / \mathrm{H}_{2} \mathrm{O}_{2}, \mathrm{O}_{3} / \mathrm{H}_{2} \mathrm{O}_{2} / \mathrm{UV}\right)$, photocatalytic degradation $\left(\mathrm{TiO}_{2} / \mathrm{UVandTiO}_{2} / \mathrm{H}_{2} \mathrm{O}_{2} / \mathrm{UV}\right)$ [20-22]. The foremost drawbacks associated with AOP's includes 
the use of expensive catalysts like $\mathrm{H}_{2} \mathrm{O}_{2}, \mathrm{O}_{3}$, high operating costs, requirement of sophisticated equipment's, incomplete degradation of pollutants and formation of highly toxic secondary products that adds on to deteriorate environmental implications [23]. Photocatalysis is a promising AOP which has deemed to be an excellent solar energy conversion technology operating at ambient temperature and pressure in the domain of pollutant removal. This process makes use of a semiconductor metal oxide as catalyst which on absorption of light photons leads to the formation of holes $\left(\mathrm{h}^{+}\right)$and electrons ( $\left.\mathrm{e}^{-}\right)$in valence and conduction band edge, respectively. The proposed mechanism involves reaction of photoexcited electron with oxygen in the conduction band (CB) and $\mathrm{h}^{+}$participate in oxidation process in the valence band (VB) consequently, generating superoxide or hyperoxide radicals $\left(\mathrm{O}_{2}^{-} / \mathrm{HO}_{2}, \mathrm{H}_{2} \mathrm{O}_{2}\right)$ and $(\mathrm{OH})$. The activation of dissolved $\mathrm{O}_{2}$ and/or $\mathrm{H}_{2} \mathrm{O} / \mathrm{OH}$ results in release of reactive oxygen species (ROS) and $\mathrm{h}^{+}$(electronic vacancies) which effectively oxidize persistent organic/inorganic contaminants present in wastewater $[23,24]$. A brief diagrammatic representation of photocatalytic mechanism is depicted in (Fig.1). The photocatalytic research came into light in early 1970's; Formenti et al., Fujishima and Honda studied the process of decomposition of water, hydrogen reduction using solar energy and titanium dioxide $\left(\mathrm{TiO}_{2}\right)$ as photocatalyst $[25,26] . \mathrm{TiO}_{2}$ has widely been used as they are non-toxic, reproducible in nature due to their extensive chemical stability and highly inert nature in aqueous medium. However, there is less quantum yield and low absorption of ultraviolet light due to wide band gap $(3.2 \mathrm{eV})$ which restricts its utilization in visible light range [27]. The photocatalytic technology has also focused on catalytic activity of many other semiconductor metal oxides including $\mathrm{ZnO}, \mathrm{CaO}, \mathrm{ZnWO}_{4}, \mathrm{WO}_{3}, \mathrm{Nb}_{2} \mathrm{O}_{5}, \mathrm{BiTiO}_{3}, \mathrm{SrTiO}_{3}, \mathrm{Fe}_{2} \mathrm{O}_{3}, \mathrm{Ag}_{2} \mathrm{CO}_{3}, \mathrm{BiOBr}, \mathrm{BiOCl}, \mathrm{BiOI}$, $\mathrm{BiVO}_{4}, \mathrm{Ag}_{3} \mathrm{PO}_{4}, \mathrm{ZrO}_{2}, \mathrm{CaFe}_{2} \mathrm{O}_{4}, \mathrm{MnFe}_{2} \mathrm{O}_{4}, \mathrm{ZnFe}_{2} \mathrm{O}_{4}, \mathrm{BiFe}_{2} \mathrm{O}_{4}, \mathrm{CoFe}_{2} \mathrm{O}_{4}, \mathrm{Bi}_{2} \mathrm{WO}_{6}, \mathrm{Bi}_{20} \mathrm{~T}_{20}, \mathrm{TaON}$, etc [28-42]. Certain metal sulphides and metal nitrides i.e. $\mathrm{CdS}, \mathrm{ZnS}, \mathrm{NiS}$, and $\mathrm{Ta}_{3} \mathrm{~N}_{5}$ etc. are also efficient photocatalyst because of narrow band gap and CB edge position. Nevertheless, their photocatalytic performance is strongly reduced by wide band gap, rapid recombination rate of 
photogenerated $\mathrm{e}^{-}-\mathrm{h}^{+}$pair (EHP), low solar light energy utilization efficiency and photo corrosion issues remains the "bottleneck" of the semiconductor based photocatalysts for the objective of pollutant removal and various other practical applications $[43,44]$.

Currently, a vital research topic is to design a robust, commercially available competent photocatalyst with narrow band gap, rapid charge transfer, anti-photo-corrosion properties and high visible light quantum efficiency. In recent years remarkable attention has been gained by metal free polymeric semiconductor carbon nitride $\left(\mathrm{C}_{3} \mathrm{~N}_{4}\right)$. The compositional unit of carbon nitride materials consists of one of the stacked two dimensional (2D) sheets of triazine $(1,3,5-$ triazine), $\mathrm{C}_{3} \mathrm{~N}_{3}$ and the heptazine (1,3,4,6,7,9,9b-heptaazaphenalene), $\mathrm{C}_{6} \mathrm{~N}_{7}$ rings [45]. A synthetic pathway for formation of various carbon and nitrogen containing molecules is temperature assisted i.e.; heating of melamine to $317 \square$ forms melam $\left[\left(\mathrm{H}_{2} \mathrm{~N}\right)_{2}\left(\mathrm{C}_{3} \mathrm{~N}_{3}\right)_{2}\right] \mathrm{NH}$ that further reacts at above $360 \square$ to form melem (triamino-heptazine) $\mathrm{C}_{6} \mathrm{~N}_{7}\left(\mathrm{NH}_{2}\right)_{3}[46]$. Melem condenses above $520 \square$ to form a yellow-orange powder poly (amino imino) heptazine, which is termed as Liebig's melon [47]. Whereas, condensation of melem at below $520 \square$ leads to formation of triazine based graphitic carbon nitride $\left(\mathrm{g}-\mathrm{C}_{3} \mathrm{~N}_{4}\right)$. The hierarchical precursor of $\mathrm{g}-\mathrm{C}_{3} \mathrm{~N}_{4}$, melon shows resemblance and is mistakenly termed as $\mathrm{g}-\mathrm{C}_{3} \mathrm{~N}_{4}$, due to its X-ray powder diffraction pattern with a pseudo graphitic peak [48]. However, they are completely different as the п-п stacking is shared by all heptazine atoms, unlike graphite which is covalently-linked [49]. Theoretically, it was confirmed that nitrogen $(\mathrm{N})$, carbon $(\mathrm{C})$ atoms $2 \mathrm{p}$ orbital overlap and forms $\mathrm{VB}$ and $\mathrm{CB}$ of $\mathrm{g}-\mathrm{C}_{3} \mathrm{~N}_{4}$. Furthermore, it is also reported that lone pair electrons of $\mathrm{N}$ atom are mainly responsible for formation of VB and electronic structure. The $\mathrm{CB}$ and VB potentials of $\mathrm{g}-\mathrm{C}_{3} \mathrm{~N}_{4}$ are located at -1.09 and $+1.56 \mathrm{eV}$, respectively with mid-way band gap $(\sim 2.7 \mathrm{eV})$ which enables it to initiate photocatalytic reaction on absorption of light over extended range of wavelengths in visible region $[17,24]$. This n-type (electron rich) semiconductor is a promising visible-light responsive photocatalyst for water purification since 2009 [50,51]. 
The key property determining the photocatalytic performance of $g-\mathrm{C}_{3} \mathrm{~N}_{4}$ is tunable band gap ( $2.7 \mathrm{eV}$ ) corresponding to an optical wavelength of $460 \mathrm{~nm}$ which promotes the utilization of renewable solar energy [52].The other potential properties includes nontoxic nature, high chemical resistance and backbone comprising of earth abundant elements of $\mathrm{C}$ and $\mathrm{N}$ that enable low cost, facile fabrication methods. The most commonly used synthesis techniques are via thermal polycondensation, solvothermal, template assisted, electrochemical, ultrasonic assisted exfoliation, ionothermal and sol gel methods [17,53,54]. Consequently, $\mathrm{g}-\mathrm{C}_{3} \mathrm{~N}_{4}$ has been reported as an intriguing photocatalyst for degradation of persistent and emerging waterborne contaminants and pathogen inactivation which promotes sustainable water and wastewater treatment.

\subsection{Noble metal free doping of $\mathrm{g}-\mathrm{C}_{3} \mathrm{~N}_{4}$ : Potential strategy for enhanced photocatalytic activity}

Despite of $\mathrm{g}_{-} \mathrm{C}_{3} \mathrm{~N}_{4}$ as a potential photocatalyst, it is also associated with some pitfalls such as small specific surface area, poor visible light absorption and fast recombination of photo induced EHP which lowers quantum efficiency. Moreover, time consuming process, centrifugation or filtration is carried out for the separation of $\mathrm{g}-\mathrm{C}_{3} \mathrm{~N}_{4}$ from reaction solution which involves wastage of photocatalyst [17].To overcome these limitations of $\mathrm{g}-\mathrm{C}_{3} \mathrm{~N}_{4}$ various pivotal strategies have been explored including fabrication of mesoporous structure (texture modification), heterojunction with other semiconductors, elemental and molecular doping, coupling with magnetic materials and copolymerization $[23,55]$. Amongst these strategies, doping is a suitable and effective technique to modulate band gap, reduce large interlayer resistance and to enhance photocatalytic activity of g$\mathrm{C}_{3} \mathrm{~N}_{4}$ for water purification. Doping has been a 'rising star' technique to overcome limitations offered by pristine $\mathrm{g}-\mathrm{C}_{3} \mathrm{~N}_{4}$ as reported in more than 6051 research articles since 2010 till 2019 as depicted in (Fig. 2).

Doping of $\mathrm{g}_{-} \mathrm{C}_{3} \mathrm{~N}_{4}$ with alkali metals (Na, K), non-metals (B, C, N, O, P, S, Cl, and $\mathrm{Br}$ etc), transition elements ( $\mathrm{Fe}, \mathrm{Cd}, \mathrm{Co}, \mathrm{Mo}$, and $\mathrm{V}$ etc) and rare earth metals ( $\mathrm{Ce}, \mathrm{Eu}, \mathrm{Se}, \mathrm{Y})$ induces band gap reduction and shift in the photocatalytic response towards visible region of solar spectrum 
[24,56]. As displayed in (Fig. 3) $\mathrm{CB}$ and VB of various elements doped $\mathrm{g}-\mathrm{C}_{3} \mathrm{~N}_{4}$ confirms decrease in band gap in comparison to bare $\mathrm{g}-\mathrm{C}_{3} \mathrm{~N}_{4}$. Researchers have explored doping to be either substitutional or interstitial depending upon the in-planar, inter-planar distance of host lattice and also on the ionic radii of dopant. For example, halogen dopants fluorine $(\mathrm{F})$ and chlorine $(\mathrm{Cl})$ undergo interstitial addition as they have moderate atomic radii of 0.41 and $0.78 \AA$ whereas bromine (Br) and iodine (I) substitute host atoms as they have larger radii of 1.03 and $1.39 \AA$ as compared to those of $\mathrm{N}$ and $\mathrm{C}$ atoms (0.54 and $0.65 \AA)$ [57]. Many researchers have focused on the study of synthesis and modification of $\mathrm{g}_{-} \mathrm{C}_{3} \mathrm{~N}_{4}$ but there are limited reports on the fabrication of $\mathrm{g}-\mathrm{C}_{3} \mathrm{~N}_{4}$ based photocatalysts by noble metal free doping. Elemental doping is considered as a versatile and capable strategy to tailor band gap, promote targeted application via incorporation of cations, anions or co-doping. Due to doping, absorbed light can be easily converted into charge carriers and ultimately reactive species.

Here in this review our perspective aims to shed light on recent progress in the synthesis and design of noble metal free doped $\mathrm{g}-\mathrm{C}_{3} \mathrm{~N}_{4}$ nanohybrids. The highlighted compilation of enlightened idea is to accelerate its development in various realms such as photocatalytic degradation of pollutants in wastewater by doping method. In (Fig. 4) pie chart illustrates diversifying application scope of non-precious metal doped $\mathrm{g}_{-} \mathrm{C}_{3} \mathrm{~N}_{4}$ in water application. We believe that this review would help address the challenges and crucial issues for the widespread utilization of element doped g$\mathrm{C}_{3} \mathrm{~N}_{4}$ photocatalyst as a renewable, economical, sustainable energy and water purification source for future researches.

\section{Synthetic routes for preparation of noble metal free doped $g-C_{3} N_{4}$ for water purification}

To date, various synthesis strategies have been explored to overcome the photocatalytic limitations. Currently, many attempts have been carried out to design desired $\mathrm{g}-\mathrm{C}_{3} \mathrm{~N}_{4}$, among them doping has been considered as the most favorable technique. The precursor type and method opted for synthesis plays key role for achieving desirable physical and chemical properties of 
nanohybrids. In the field of research, it has been reported that doped $\mathrm{g}-\mathrm{C}_{3} \mathrm{~N}_{4}$ is more efficient than pristine $\mathrm{g}-\mathrm{C}_{3} \mathrm{~N}_{4}$. The flow charts (Fig. 5 and 6) clearly show a broad classification of methods and detailed synthesis procedure for preparation of noble metal free doped $\mathrm{g}-\mathrm{C}_{3} \mathrm{~N}_{4}$.

\subsection{High temperature assisted synthesis (Thermal condensation, pyrolysis and calcination)}

A range of temperature from $400-610{ }^{\circ} \mathrm{C}$ is used for synthesis of porous $\mathrm{g}-\mathrm{C}_{3} \mathrm{~N}_{4}$ employing melamine, urea, thiourea, triazoles, dicyandiamide (DCDA) precursors via thermal condensation method [58]. The addition of various dopants using this method has been summarized in (Table 1). Tao et al. designed iron ( $\mathrm{Fe}$ ) doped $\mathrm{g}-\mathrm{C}_{3} \mathrm{~N}_{4}$ composite by thermal condensation of melamine and iron nitrate nonahydrate precursors. The synthesized Fe doped $\mathrm{g}-\mathrm{C}_{3} \mathrm{~N}_{4}$ nanocomposite showed 99.5\% degradation of Rhodamine $\mathrm{B}(\mathrm{RhB})$ dye [59]. Raizada et al. fabricated $\mathrm{P}$ and $\mathrm{S}$ co-doped g$\mathrm{C}_{3} \mathrm{~N}_{4}$ via precursors hexa-chloro-triphosphazene and thiourea. The results exemplified photodegradation and mineralization of phenol in $6 \mathrm{hr}$ and significant antibacterial activity for disinfection of E.coli bacteria [60]. Similarly a controllable synthesis were performed for eradication of methylene blue (MB) and methyl orange (MO) dyes using thiourea as source $[61,62]$. $\mathrm{Qu}$ et al. prepared oxygen $(\mathrm{O})$ doped $\mathrm{g}-\mathrm{C}_{3} \mathrm{~N}_{4}$ by condensing urea at high temperature of $550^{\circ} \mathrm{C}$ and supplying a constant flow of $\mathrm{O}_{2}\left(60 \mathrm{ml} \mathrm{min}^{-1}\right)$ flow rate. The photocatalytic degradation was performed on $\mathrm{RhB}$ dye with degradation rate of $52 \%$ for $\mathrm{O}$ doped $\mathrm{g}_{-} \mathrm{C}_{3} \mathrm{~N}_{4}$ whereas, only $22 \%$ for bulk $g-\mathrm{C}_{3} \mathrm{~N}_{4}$. According to BET surface area calculation there is an increase in surface area from 9.2

$\mathrm{m}^{2} / \mathrm{g}$ to $12.8 \mathrm{~m}^{2} / \mathrm{g}$ of $\mathrm{O}$ doped $\mathrm{g}-\mathrm{C}_{3} \mathrm{~N}_{4}$ and bulk g- $\mathrm{C}_{3} \mathrm{~N}_{4}$, respectively [63]. For the first time a novel triazole ring-based $\mathrm{g}-\mathrm{C}_{3} \mathrm{~N}_{4}$ is fabricated by heat assisted condensation of sodium hydroxide $(\mathrm{NaOH})$ and 3-amino-1,2,4-traizole precursor. The effective photocatalytic degradation of $\mathrm{MO}, \mathrm{MB}$ and $\mathrm{RhB}$ dyes is ascribed to narrowed band gap of $2.0 \mathrm{eV}$ [64]. Yan et al. synthesized boron (B) doped g- $\mathrm{C}_{3} \mathrm{~N}_{4}$ for the photodegradation of $\mathrm{RhB}$ and $\mathrm{MO}$ dyes. They used melamine and boron oxide as precursors for the preparation of $\mathrm{B}$ doped $\mathrm{g}-\mathrm{C}_{3} \mathrm{~N}_{4}$. The results indicated large increase in $\mathrm{BET}$ specific surface area from $10 \mathrm{~m}^{2} / \mathrm{g}$ to $30 \mathrm{~m}^{2} / \mathrm{g}$ at $600^{\circ} \mathrm{C}$ thus confirmed heavy degradation process 
[65]. In another work a benign one-pot thermal polycondensation of DCDA with ammoniotrihydroborate led to synthesis of $\mathrm{B}$ doped $\mathrm{g}-\mathrm{C}_{3} \mathrm{~N}_{4}$ for synergistic $\mathrm{H}_{2}$ evolution under visible light [66]. Hangarra prepared sodium-doped g- $\mathrm{C}_{3} \mathrm{~N}_{4}\left(\mathrm{Na}-\mathrm{g}-\mathrm{C}_{3} \mathrm{~N}_{4}\right)$ through a facile solid state technique based on thermal condensation of urea (precursor) in presence of sodium chloride $(\mathrm{NaCl})$ and ammonium chloride $\left(\mathrm{NH}_{4} \mathrm{Cl}\right)$. The structural analysis studied from XRD pattern revealed that $\mathrm{Na}$ species are incorporated both in interlayer spacing and in nitride pores. The interstitial addition of $\mathrm{Na}$ as dopant is because the atomic radii of $\mathrm{Na}\left(\sim 1^{\circ} \mathrm{A}\right)$ is greater than those of $\mathrm{N}\left(\sim 0.65^{\circ} \mathrm{A}\right)$ and $\mathrm{C}$ $\left(\sim 0.7^{\circ} \mathrm{A}\right)$. The $\mathrm{Na}$ doping has proven to be effective in mineralization of $17 \alpha$-ethynyl estradiol (EE2), a major component of the oral contraceptive pill, commonly released in water bodies. The proposed step-wise mechanism as shown in (Fig. 7) and following equations describe the role of $\operatorname{ROS}\left(\mathrm{O}_{2}^{-}, \mathrm{e}^{-}, \mathrm{OH}\right.$ and $\left.\mathrm{h}^{+}\right)$. The initiation (equation i) constitutes of photon absorption by Na doped g- $\mathrm{C}_{3} \mathrm{~N}_{4}$ with migration of $\mathrm{e}^{-}$from $\mathrm{VB}$ to $\mathrm{CB}$ that results in formation of electronic vacancy $\mathrm{h}^{+}$in VB. There is a series of reduction reaction of $\mathrm{O}_{2}$ and $\mathrm{H}_{2} \mathrm{O}_{2}$ (equation ii, iv) and oxidation reactions of $\mathrm{H}_{2} \mathrm{O}$ and $\mathrm{OH}^{-}($equation iii, v) as represented. Thereby, leads to formation of ROS, which causes degradation of EE2 (equation vi, vii, viii). The degradation products of EE2 molecule was firstly converted into semiquinone and finally removed in the form of organic acids and small molecules (equation ix).

$$
\begin{aligned}
& \mathrm{Na}+\mathrm{g}-\mathrm{C}_{3} \mathrm{~N}_{4}+\rightarrow e_{(C B)}^{-}+h_{(V B)}^{+} \\
& \mathrm{O}_{2}+e_{(C B)}^{-} \rightarrow \mathrm{O}_{2}^{-} \\
& \mathrm{H}_{2} \mathrm{O}+h_{(V B)}^{+} \rightarrow \mathrm{OH}^{\cdot}+\mathrm{H}^{+} \\
& \mathrm{H}_{2} \mathrm{O}_{2}+e_{(C B)}^{-} \rightarrow(\mathrm{OH})^{\cdot}+\mathrm{OH}^{-} \\
& \mathrm{OH}^{-}+h_{(V B)}^{+} \rightarrow \mathrm{OH}^{\cdot} \\
& \mathrm{EE2}+\mathrm{OH}^{-} \rightarrow \mathrm{EE}^{-}+\mathrm{H}_{2} \mathrm{O} \rightarrow \text { EE2 degradation products }+\mathrm{CO}_{2}+\mathrm{H}_{2} \mathrm{O} \\
& \mathrm{EE2}+h_{(V B)}^{+} \rightarrow E E 2^{+} \rightarrow E E 2 \text { degradation products }+\mathrm{CO}_{2}+\mathrm{H}_{2} \mathrm{O} \\
& \mathrm{EE2}+e_{(C B)}^{-} \rightarrow \mathrm{EE2}^{-} \rightarrow \text { EE2 degradation products }+\mathrm{CO}_{2}+\mathrm{H}_{2} \mathrm{O}
\end{aligned}
$$


Analysis of PL spectra in (Fig. 8) is significant to study the recombination rate of ROS generated during photocatalytic process. The PL spectra in (Fig. 8a) exhibited restricted ROS recombination due to lowered PL intensity. Compared to bare $\mathrm{g}-\mathrm{C}_{3} \mathrm{~N}_{4}, \mathrm{Na}$ doped $\mathrm{g}-\mathrm{C}_{3} \mathrm{~N}_{4}$ possessed smaller grain size and an increased surface area of bare $\mathrm{g}-\mathrm{C}_{3} \mathrm{~N}_{4}\left(12.5 \mathrm{~m}^{2} / \mathrm{g}\right), 0.6 \mathrm{Na} g-\mathrm{C}_{3} \mathrm{~N}_{4}(18.5$

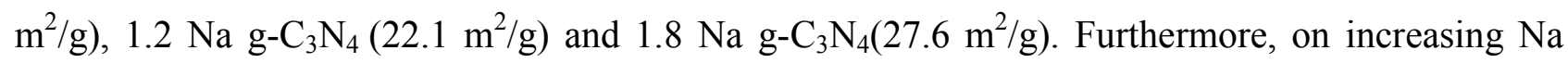
content, band gap energy reduces from $2.85 \mathrm{eV}$ for bare $\mathrm{g}-\mathrm{C}_{3} \mathrm{~N}_{4}$ to $2.77,2.76$, and $2.75 \mathrm{eV}$ for $0.6 \mathrm{Nag}-\mathrm{C}_{3} \mathrm{~N}_{4}, 1.2 \mathrm{Na}$ g- $\mathrm{C}_{3} \mathrm{~N}_{4}$, and $1.8 \mathrm{Nag}-\mathrm{C}_{3} \mathrm{~N}_{4}$, respectively. The prepared $\mathrm{Na}$ doped $(0.6 \%) \mathrm{g}-$ $\mathrm{C}_{3} \mathrm{~N}_{4}$ displayed $95.7 \%$ photodegradation ability for EE2 as compared to bare $\mathrm{g}-\mathrm{C}_{3} \mathrm{~N}_{4}$ with $23.5 \%$ degradation activity. The crystallographic structure of synthesized doped $g-\mathrm{C}_{3} \mathrm{~N}_{4}$ is determined via XRD technique as displayed in (Fig.9) XRD pattern (Fig. 9a) shows minor peak at (100) plane and prominent peak at (002) planes attributed to in-plane structural repeating units of triazine $\mathrm{g}-\mathrm{C}_{3} \mathrm{~N}_{4}$ and interlayer stacking of conjugated aromatic ring, respectively [67].

The pyrolysis technique has been, during last three decades one of the major synthesis method. Jet spray pyrolysis has a wide variety of applications and has been examined as a cheap and reliable preparation technique. Recent studies by E.Sindhuja and co-workers successfully demonstrated photocatalytic ability of Mo doped $\mathrm{g}-\mathrm{C}_{3} \mathrm{~N}_{4}$ by a jet nebulizer spray pyrolysis technique. For the preparation, urea and ammonium heptamolybdatetetrahydrate (source material for Mo) was used. The photostability experiment results revealed that at $1 \%$ Mo CN in doped g$\mathrm{C}_{3} \mathrm{~N}_{4}$ degradation for $98 \% \mathrm{MB}$ and $78 \% \mathrm{RhB}$ dye was obtained. Whereas, pristine $\mathrm{g}-\mathrm{C}_{3} \mathrm{~N}_{4}$ causes only $78 \%, 53 \%$ of $\mathrm{MB}$ and $\mathrm{RhB}$ dye degradation, respectively [68]. Wang et al. synthesized titanium (Ti) doped $\mathrm{g}-\mathrm{C}_{3} \mathrm{~N}_{4}$ through a cost-effective pyrolysis method by urea as reactant molecules and tetra butyl titatnate as $\mathrm{Ti}$ (source). As shown in (Fig. 9b) the XRD pattern of Ti doped g- $\mathrm{C}_{3} \mathrm{~N}_{4}$ depicted no extra significant peak thus suggesting completed incorporation of Ti dopant into layered lattice of $\mathrm{g}-\mathrm{C}_{3} \mathrm{~N}_{4}$. BET surface area of optimized $\mathrm{CN} 0.75$ Ti doped $\mathrm{g}-\mathrm{C}_{3} \mathrm{~N}_{4}$ is $131.6 \mathrm{~m}^{2} / \mathrm{g}$ 
higher than bare $\mathrm{g}-\mathrm{C}_{3} \mathrm{~N}_{4} 124.7 \mathrm{~m}^{2} / \mathrm{g}$ also bimodal pore size centered at (3.9 and $24 \mathrm{~nm}$ ) and large pore volumes $\left(1.008-1.472 \mathrm{~cm}^{3} / \mathrm{g}\right)$ have been possessed in doped photocatalyst. The incorporation of $\mathrm{Ti}$ into $\mathrm{g}-\mathrm{C}_{3} \mathrm{~N}_{4}$ showed extended spectral response from UV to visible region ascribed to increased surface area, hierarchical porosity and reduced band gap from 2.71 to $2.55 \mathrm{eV}$. Because of the obtained properties, $0.75 \mathrm{Ti}$ doped $\mathrm{g}-\mathrm{C}_{3} \mathrm{~N}_{4}$ exhibited effective $100 \% \mathrm{RhB}$ degradation within 50 min of light irradiation [69]. Das et al. synthesized cobalt (Co) doped $\mathrm{g}_{-} \mathrm{C}_{3} \mathrm{~N}_{4}$, using urea and cobalt nitrate hexahydrate. The detailed topographical and surface structural information is obtained from scanning electron microscopy (SEM) technique as illustrated in (Fig. 14). SEM images as shown in (Fig. 14c) depicts bulk sheet into smaller layered sheets resulting in inhibition of crystal growth of polymeric $g-\mathrm{C}_{3} \mathrm{~N}_{4}$. Conventional water treatment are unaffected for the degradation of eosin $\mathrm{B}$ dye, photocatalytic results showed $75 \%$ of eosin B dye degradation within 60 min [70]. A single step pyrolysis assisted approach was used for the fabrication of zirconium $(\mathrm{Zr})$ doped $\mathrm{g}-\mathrm{C}_{3} \mathrm{~N}_{4}$. In this experiment urea (precursor) and zirconium nitrate (source) have been used. A higher resolution morphological, compositional and crystallographic observation is obtained via transmission electron microscopy (TEM) as illustrated in (Fig. 16). A worm-like porous sheet-type structure is possessed by $\mathrm{Zr}$ doped $\mathrm{g}-\mathrm{C}_{3} \mathrm{~N}_{4}$ as shown in (Fig. 16a). Insertion of $\mathrm{Zr}$ as dopant narrowed band gap from 2.7 $\mathrm{eV}$ to $2.55 \mathrm{eV}$ and caused $100 \%$ degradation of $\mathrm{RhB}$ within $110 \mathrm{~min}[71]$.

Calcination method usually occurs at $550{ }^{\circ} \mathrm{C}$ either using nitrogen flow or under ambient conditions for the synthesis of $\mathrm{g}-\mathrm{C}_{3} \mathrm{~N}_{4}$. Bichalo et al. carried a facile synthesis of iron $\mathrm{Fe}(\mathrm{III})$ doped g- $\mathrm{C}_{3} \mathrm{~N}_{4}$ by heating at high temperature in a closed alumina crucible using melamine and ferric chloride hexahydrate. TEM image as shown in (Fig. 16 b) reveals layered platelet-like morphology of Fe $10 \%$ doped $\mathrm{g}-\mathrm{C}_{3} \mathrm{~N}_{4}$. The results claimed $100 \%$ discoloration of $\mathrm{MB}$ dye and indigo-carmine (IC) as well as $80 \%$ and $60 \%$ degradation of $\mathrm{RhB}$ and phenol dye, respectively was observed within 90 min of reaction [72]. Liu et al. fabricated a binary composite via coupling of carbon quantum dots (CQDs) with Fe doped $\mathrm{g}-\mathrm{C}_{3} \mathrm{~N}_{4}$ that possessed high photodegradation activity. The grafted 
nanocomposite is prepared in a muffle furnace using precursors, DCDA and ferric chloride hexahydrate heated to $823 \mathrm{~K}$ that lead to formation of $\mathrm{Fe}(\mathrm{II})$ doped $\mathrm{g}-\mathrm{C}_{3} \mathrm{~N}_{4}$. The EPR/DMPO spin trap spectra in (Fig. 17) CQDs/Fe doped $\mathrm{g}-\mathrm{C}_{3} \mathrm{~N}_{4}$ displayed reduction in photoexcited EHP and decreased transportation distance via interfacial charge transfer effect (IFCT) which involved formation of $\mathrm{OH}^{\cdot}$ active species. An increased photocatalytic activity extended to near infrared region (760-1200nm) for eradication of 93\% MO dye and 71\% phenol, was observed [73]. Duo et al. synthesized copper $(\mathrm{Cu})$ doped $\mathrm{g}-\mathrm{C}_{3} \mathrm{~N}_{4}$ by a simple process of calcining $\mathrm{DCDA}, \mathrm{NH}_{4} \mathrm{Cl}$ and copper chloride $\left(\mathrm{CuCl}_{2}\right)$. The photocatalytic performance was indicated by degradation of $92 \% \mathrm{MB}$ dye [74]. Huang et al. prepared porous network of $\mathrm{O}$ doped $\mathrm{g}-\mathrm{C}_{3} \mathrm{~N}_{4}$ calcining melamine with hydrogen peroxide $\left(\mathrm{H}_{2} \mathrm{O}_{2}\right)$ at $550^{\circ} \mathrm{C}$. The irradiation area is increased by $20 \mathrm{~cm}^{2}$ for effective photodegradation of RhB, MO and phenol pollutants [75]. Diogo et al. synthesized Mo doped g$\mathrm{C}_{3} \mathrm{~N}_{4}$ using melamine and molybdenum dioxide as precursors and resulted in $99 \%$ non-selective oxidation of MB dye [76].

\subsection{Thermal polymerization method}

Thermal polymerization method is the most commonly employed technique for the synthesis of metal and non-metal doped $\mathrm{g}-\mathrm{C}_{3} \mathrm{~N}_{4}$. This method proceeds via conversion of monomeric precursors into polymers in the presence of high temperature. Xiong et al. prepared bridged potassium, K-dopedg- $\mathrm{C}_{3} \mathrm{~N}_{4}$ using DCDA precursor and $\mathrm{KBr}$ ( $\mathrm{K}$ source) that possess highly effective visible light photocatalytic ability for NO removal. From the literature it was concluded that incorporation of different concentrations of $\mathrm{K}$ into $\mathrm{g}-\mathrm{C}_{3} \mathrm{~N}_{4}$ reduced band gap e.g. observed band gap for $\mathrm{CN}, \mathrm{CN}-\mathrm{K} 1$, $\mathrm{CN}-\mathrm{K} 2, \mathrm{CN}-\mathrm{K} 3, \mathrm{CNK} 5$ and $\mathrm{CN}-\mathrm{K} 10$ were $2.45,2.34,2.19,2.15$ and $2.15 \mathrm{eV}$, respectively. Besides these results it was also observed that there was lowering in BET surface area from $27 \mathrm{~m}^{2} / \mathrm{g}$ to $8 \mathrm{~m}^{2} / \mathrm{g}$ on increasing concentration of dopant K [77]. Similarly, Zhang and co-workers formulated K-doped-g$\mathrm{C}_{3} \mathrm{~N}_{4}$ through thermal polymerization of DCDA and potassium iodide (KI) in atmosphere. 
The prepared nanohybrid formulation lowers the band gap from $2.67 \mathrm{eV}$ to $2.64 \mathrm{eV} \mathrm{VB}$ position of $\mathrm{g}-\mathrm{C}_{3} \mathrm{~N}_{4}$ which results in enhanced separation of photogenerated charge carriers under visible light. Doping with $\mathrm{K}$ also increases the degradation efficiency of phenol and MB up to 3.3 and 5.8 times higher than bulk g- $\mathrm{C}_{3} \mathrm{~N}_{4}[78]$. Zhang et al. designed a convenient method to prepare band gap-tunable novel sodium doped $\mathrm{g}-\mathrm{C}_{3} \mathrm{~N}_{4}$ photocatalyst using DCDA as monomer and sodium hydrate as precursor. The structural analysis of $\mathrm{Na}$ doped $\mathrm{g}_{-} \mathrm{C}_{3} \mathrm{~N}_{4}$ is evaluated via X-ray photoelectron spectroscopy (XPS) spectra using shift in binding energies values, which is probably due to higher electronegativity of $\mathrm{N}$ atom in Na-N bond. Evaluations of XPS data from (Fig. 10a) it is elucidated the $\mathrm{sp}^{2}$ hybridized $\mathrm{N}$ atom in $\mathrm{g}-\mathrm{C}_{3} \mathrm{~N}_{4}$ lattice with binding energy peak at $398.5 \mathrm{eV}$. Two sharp peaks at $284.6 \mathrm{eV}$ and 287.8 $\mathrm{eV}$ (Fig. 10b) indicates pure $\mathrm{CN}$ in $\mathrm{g}-\mathrm{C}_{3} \mathrm{~N}_{4}, \mathrm{sp}^{2} \mathrm{C}$ anchored to $\mathrm{NH}_{2}$ in aromatic group, respectively. In (Fig. 10c) it is shown, incorporation of $\mathrm{Na}$ ions into the big $\mathrm{C}-\mathrm{N}$ rings formed by the N-bridge strong electrostatic linking of triazine units in the plane of $\mathrm{g}-\mathrm{C}_{3} \mathrm{~N}_{4}$ due to loss of $3 \mathrm{~s}$ electrons. Also in (Fig. $10 \mathrm{c}$ inset) the probable doping site for $\mathrm{Na}$ is found to be on interstitial site ascribed to maximum inplanar distance of nitride pores $0.71 \mathrm{~nm}$, which is adequate to accommodate $\mathrm{Na}^{+}$. A shift of $0.65 \mathrm{eV}$ as displayed in (Fig. 10d) which further confirms that $\mathrm{Na}$ exhibits interstitial doping in $\mathrm{g}-\mathrm{C}_{3} \mathrm{~N}_{4}$. The band gap potential values are vital influential factors to ascertain the potential of semiconductor to generate ROS. The VB and CB potentials of doped $\mathrm{g}_{-} \mathrm{C}_{3} \mathrm{~N}_{4}$ photocatalysts are calculated and shown in (Fig. 11). Alteration in $\mathrm{CB}$ potential from $-1.18 \mathrm{eV}$ to $-0.26 \mathrm{eV}$ and $\mathrm{VB}$ potential from $+1.47 \mathrm{eV}$ to $2.27 \mathrm{eV}$ are obtained at optimized Na-CN-0.05M as shown in (Fig. 11a) for effective generation of ROS and eradication of $\mathrm{RhB}$ dye [79]. Hu et al. compared interstitial and substitutional phosphorus(P) doping of g- $\mathrm{C}_{3} \mathrm{~N}_{4}$ using diammonium hydrogen phosphate ( $\mathrm{P}$ source) and DCDA (monomer). The BrunauerEmmett-Teller (BET) characterization technique serves as an important basis to analyze the specific surface area after the incorporation of dopant as shown in (Fig. 12).

The results in (Fig. 12a) depicted higher BET specific surface area on increasing concentrations of $\mathrm{P}(2 \%, 4 \%, 6 \%, 8 \%$ and $10 \%)$ are calculated to be $\left(10.9 \mathrm{~m}^{2} / \mathrm{g}, 12.4 \mathrm{~m}^{2} / \mathrm{g}, 14.8 \mathrm{~m}^{2} / \mathrm{g}, 16.5 \mathrm{~m}^{2} / \mathrm{g}\right.$ and 
$17.7 \mathrm{~m}^{2} / \mathrm{g}$ ) respectively. The observed trend is probably due to inhibited crystal growth of $\mathrm{g}-\mathrm{C}_{3} \mathrm{~N}_{4}$ by dopant. They found that interstitial $\mathrm{P}$ doping is more effective in $100 \% \mathrm{RhB}$ dye degradation which is attributed to the phosphorus source [80].Sulfur (S) doped $g-\mathrm{C}_{3} \mathrm{~N}_{4}$, was prepared by heating common precursor DCDA and hydrogen sulfide $\left(\mathrm{H}_{2} \mathrm{~S}\right)$ at high temperature of $550^{\circ} \mathrm{C}$. Results of the experiment displayed complete oxidation process of phenol under visible light ( $\lambda>400 \mathrm{~nm})[81]$.

\subsection{Hydrothermal method}

Up to now, high temperature synthesis methods are mostly preferred. Hydrothermal method though seldom used has proven to be an effective low temperature synthesis technique. The use of water as solvent makes this method economical for large scale synthesis. Rong et al. prepared tungsten (W) doped $\mathrm{g}-\mathrm{C}_{3} \mathrm{~N}_{4}$ photocatalyst by one step hydrothermal method using common precursors DCDA, urea and sodium tungstate dihydrate. They found that introduction of $\mathrm{W}$ species increased BET surface area from $6.3 \mathrm{~m}^{2} / \mathrm{g}$ to $34.5 \mathrm{~m}^{2} / \mathrm{g}$ for bare $\mathrm{g}-\mathrm{C}_{3} \mathrm{~N}_{4}$ and $50 \% \mathrm{~W}$ doped $\mathrm{g}-\mathrm{C}_{3} \mathrm{~N}_{4}$, respectively as shown in (Fig. 12b). The photocatalytic degradation performance is determined under visible light irradiation as shown in (Fig. 13). A considerably higher degradation efficiency of MO dye was found to be $99.6 \%$ within optimum time of 60 min as depicted in (Fig. 13a) [82]. Zhang et al. followed similar synthesis approach at low temperature for preparation of $\mathrm{C}$ doped $\mathrm{g}-\mathrm{C}_{3} \mathrm{~N}_{4}$ with melamine and glucose precursors. The obtained superstructure possessed a lowered band gap of $2.0 \mathrm{eV}$ and a significantly improved photocatalytic degradation of 95\% 4-nitrophenol organic pollutant as compared to traditional g- $\mathrm{C}_{3} \mathrm{~N}_{4}$ [83]. Li et al. for the first time fabricated $\mathrm{O}$ doped $\mathrm{g}-\mathrm{C}_{3} \mathrm{~N}_{4}$ by a facile $\mathrm{H}_{2} \mathrm{O}_{2}$ hydrothermal approach using DCDA precursor. The $\mathrm{O}$ dopant in $\mathrm{g}-\mathrm{C}_{3} \mathrm{~N}_{4}$ induced tunability of $\mathrm{CB}$ and $\mathrm{VB}$ potentials to $-0.67 \mathrm{eV}$ and $1.82 \mathrm{eV}$, respectively. The results depicted photodegradation of $\mathrm{MB}$ dye to be 4 times higher than that of original $\mathrm{g}-\mathrm{C}_{3} \mathrm{~N}_{4}$ under same conditions [84]. Fan et al. constructed doped sulfur (S) g- $\mathrm{C}_{3} \mathrm{~N}_{4}$ nanostructures using tri-thiocyanuric acid (TTCA) as S source and melamine as precursor.. The prepared $\mathrm{S}$ doped $\mathrm{g}-\mathrm{C}_{3} \mathrm{~N}_{4}$ exhibit uniform size crystalline rod shaped structure as illustrated in 
(Fig. 14a). The obtained nanostructures possessed large BET surface area of $52 \mathrm{~m}^{2} / \mathrm{g}$ and modulated band gap of $2.56 \mathrm{eV}$ which offers more surface active sites and improved adsorption capacity.

Results exhibited successful degradation of $90 \% \mathrm{RhB}$ dye under visible light [85]. Liu et al. synthesized $\mathrm{O}$ doped $\mathrm{g}-\mathrm{C}_{3} \mathrm{~N}_{4}$ (GCNO) via hydrothermal treatment of melamine precursor with hydrogen peroxide. The exfoliated GCNO structure possessed exfoliated layers with larger porosity as shown in SEM image (Fig. 14b). Dye sensitization was carried out using four organic dyes i.e. eosin$\mathrm{Y}$, perylene, nile-red and coumarin on doped photocatalyst. Higher BET surface area $\left(19 \mathrm{~m}^{2} / \mathrm{g}\right)$ is obtained by GCNO whereas, only $\left(9 \mathrm{~m}^{2} / \mathrm{g}\right)$ by GCN. The PL spectra in (Fig. 8b) showed emission peaks at 449.8, 449.6, 449.5, 449.3 and $449.2 \mathrm{~nm}$ for GCNO-C, GCNO-P, bare $\mathrm{g}_{-} \mathrm{C}_{3} \mathrm{~N}_{4}$, GCNO-E and GCNO-N, respectively. The highest intensity peak of GCNO-N exhibited largest absorption, whereas GCNO-E and GCNO-P acts as photo-electron acceptor from the LUMO and leads to delayed recombination of photoinduced EHP. From the PL spectra it is notable that there is $6-8 \mathrm{~nm}$ red shift away from their main PL peaks. The band gap energies demonstrated in (Fig. 11b) clearly depicted a decrease in band gap from $2.7 \mathrm{eV}$ of $\mathrm{g}_{-} \mathrm{C}_{3} \mathrm{~N}_{4}$ to $2.6,2.05,1.9,1.7 \mathrm{eV}$ for GCNO, GCNO-E, GCNO-N, GCNO-P, respectively. An extended absorption of up to $650 \mathrm{~nm}$ is observed for GCNO-E, whereas GCNO-C can only absorb UV light with band gap energy $4.6 \mathrm{eV}$. The fabricated dye sensitized nanocomposites displayed phenol and MB dye degradation from water after $3 \mathrm{~h}$. of visible light irradiation. The following trend of MB photodegradation was followed as illustrated in (Fig. 13b) with various dye sensitized nanocomposites are GCNO-N(5\%) $<\mathrm{g}_{-} \mathrm{C}_{3} \mathrm{~N}_{4}(20 \%)<\mathrm{GCNO}(50 \%)<\mathrm{GCNO}-$ $\mathrm{C}(60 \%)<\mathrm{GCNO}-\mathrm{E}(80 \%)<\mathrm{GCNO}-\mathrm{P}(80 \%)$. Best photodegradation results were depicted by $80 \%$ of MB removal from water by $\mathrm{O}$ doped $\mathrm{g}_{-} \mathrm{C}_{3} \mathrm{~N}_{4}$-sensitized nile red (GCNO-N). Similarly, phenol degradation was evaluated, as shown in (Fig. 13c) bare $\mathrm{g}-\mathrm{C}_{3} \mathrm{~N}_{4}$ has no ability to remove phenol from water, other dye sensitized $\mathrm{O}$ doped $\mathrm{g}-\mathrm{C}_{3} \mathrm{~N}_{4}$ exhibited maximum phenol elimination in GCNO-E (65\%) followed by GCNO-C (60\%), GCNO-N (45\%), GCNO-P (30\%) and GCNO (25\%). 
From the above results it was concluded that GCNO-N promotes absorption of light, efficient degradation of $\mathrm{MB}$ and GCNO-E prevents EHP recombination, hence giving excellent phenol elimination. Therefore, a synergistic relationship exists between GCNO-E and GCNO-N for improved photocatalysis [86].

\subsection{Polycondensation method}

Polycondensation method is a step growth polymerization synthesis reaction. It is considered as one of the suitable method due to easy synthesis route and microwave assisted polycondensation mechanism [87].Various photocatalytic studies have been reported on non-metal doped-g- $\mathrm{C}_{3} \mathrm{~N}_{4}$ using this technique. Chai et al. prepared phosphorus (P) doped $\mathrm{g}-\mathrm{C}_{3} \mathrm{~N}_{4}$ using ammonium thiocyanate $\left(\mathrm{NH}_{4} \mathrm{SCN}\right)$ as $\mathrm{g}-\mathrm{C}_{3} \mathrm{~N}_{4}$ precursor and ammonium hexafluorophosphate $\left(\mathrm{NH}_{4} \mathrm{PF}_{6}\right)$ as $\mathrm{P}$ source, through a co-polycondensation procedure. The obtained nanocomposite exhibited enhanced photocatalytic degradation activity for $\mathrm{P}_{(0.5 \%)}$ doped g- $\mathrm{C}_{3} \mathrm{~N}_{4}, \mathrm{P}_{(1 \%)}$ doped $\mathrm{g}-\mathrm{C}_{3} \mathrm{~N}_{4}, \mathrm{P}_{(1.5 \%)}$ doped g- $\mathrm{C}_{3} \mathrm{~N}_{4}, \mathrm{P}_{(2.5 \%)}$ doped g$\mathrm{C}_{3} \mathrm{~N}_{4}$ are $92 \%, 95 \%, 86 \%$ and $75 \%$, respectively after 30 min visible light driven irradiation. The superior photodegradation ability of P-doped-g- $\mathrm{C}_{3} \mathrm{~N}_{4}$ in comparison to bulk $g-\mathrm{C}_{3} \mathrm{~N}_{4}$ is attributed to low charge carrier recombination and favorable optical properties [88]. Zhang et al. also studied photocatalytic mechanism of $\mathrm{P}$ doped $\mathrm{g}-\mathrm{C}_{3} \mathrm{~N}_{4}$ photocatalyst for mineralization of organic pollutants. They used DCDA monomer and 1-Butyl-3-methylimidazolium hexafluorophosphate (BMIM-PF $)$ as precursor molecules. The results demonstrated 98\% degradation of $\mathrm{RhB}$ and $\mathrm{MO}$ dye for $\mathrm{P}$ doped g$\mathrm{C}_{3} \mathrm{~N}_{4}$ whereas only $58 \%$ degradation in undoped $g-\mathrm{C}_{3} \mathrm{~N}_{4}$ [89]. A homogenous substitution of $\mathrm{C}$ with $\mathrm{N}$ in $\mathrm{g}-\mathrm{C}_{3} \mathrm{~N}_{4}$ structure using melamine as precursor to investigate induced intrinsic electronic and band structure changes, was demonstrated experimentally as well as theoretically by Dong and co-workers. They investigated density functional theory (DFT) calculations to explore self-doping of C atom into g- $\mathrm{C}_{3} \mathrm{~N}_{4}$ structure. From (Fig. 15) it was depicted that plane wave pseudopotential approach was used to explore band structure and density of state (DOS) calculation of bare $\mathrm{g}-\mathrm{C}_{3} \mathrm{~N}_{4}$ and $\mathrm{C}$ doped $\mathrm{g}-\mathrm{C}_{3} \mathrm{~N}_{4}$ in accordance to DFT calculations. The homogenous substitution of bridging $\mathrm{N}$ atom with $\mathrm{C}$ atom 
enhanced electrical conductivity and visible light absorbance due to generation of delocalized big $\pi$ bonds that facilitated electron transportation. The experimental results confirmed rapid degradation of $\mathrm{RhB}$ dye and narrowed band gap from 2.72 to $2.65 \mathrm{eV}$. From Mott-Schottky plots VB and CB of photocatalysts were calculated to be $1.70 \mathrm{eV}$ and $-0.95 \mathrm{eV}$ for $\mathrm{C}$ dopedg- $\mathrm{C}_{3} \mathrm{~N}_{4}$ and $1.33 \mathrm{eV}$ and -1.39 $\mathrm{eV}$ for pristine $\mathrm{g}-\mathrm{C}_{3} \mathrm{~N}_{4}[90]$. A novel one pot polycondensation strategy was studied by Zhao et al. in this work; they illustrated fabrication of $\mathrm{C}$ self-doped $\mathrm{g}-\mathrm{C}_{3} \mathrm{~N}_{4}$ via $\mathrm{C}$ foam and common precursor melamine. The optimized C-g- $\mathrm{C}_{3} \mathrm{~N}_{4}$ photocatalyst exhibited larger BET surface area $65 \mathrm{~m}^{2} / \mathrm{g}$. The results claimed $50 \%$ NO removal by doped nanohybrid and only $14.3 \% \mathrm{NO}$ removal by bulk $\mathrm{g}-\mathrm{C}_{3} \mathrm{~N}_{4}$ in near infrared region[91]. Feng et al. designed $\mathrm{S}$ doped nano-porous $\mathrm{g}-\mathrm{C}_{3} \mathrm{~N}_{4}$ rods by one dimensional thermal condensation of TTCA and melamine under $\mathrm{N}_{2}$ atmosphere at $550^{\circ} \mathrm{C}$. The obtained doped microrods exhibited 9.3 times increment in photocatalytic activity than bare $g-\mathrm{C}_{3} \mathrm{~N}_{4}$ [92].

\subsection{Solvothermal method}

In this synthesis approach, the use of heat and solvent are typical requirements. Various commonly available solvents are employed such as methanol and ethanol. Gao et al. synthesized $\mathrm{Cu}$ doped g$\mathrm{C}_{3} \mathrm{~N}_{4}$ nanosheets by using a two dimensional $\mathrm{CuCl}_{2}$-melamine supramolecular network as both sacrificial template and precursor in methanol. The prepared doped $\mathrm{g}-\mathrm{C}_{3} \mathrm{~N}_{4}$ possessed larger surface area of $40.86 \mathrm{~m}^{2} / \mathrm{g}$ in comparison to pure $\mathrm{g}-\mathrm{C}_{3} \mathrm{~N}_{4}$ having $5.26 \mathrm{~m}^{2} / \mathrm{g}$. The high degradation capability of $\mathrm{Cu}-\mathrm{g}-\mathrm{C}_{3} \mathrm{~N}_{4}$ obtained was $100 \%$ for $\mathrm{MB}$ dye as compared to pure $\mathrm{g}-\mathrm{C}_{3} \mathrm{~N}_{4}$ resulting in only $42 \% \mathrm{MB}$ degradation [93]. Similarly, Le et al. prepared $\mathrm{Cu}$ doped mesoporous (mp)g- $\mathrm{C}_{3} \mathrm{~N}_{4}$ using $\mathrm{CuCl}_{2}$ and melamine as precursors dissolved in ethanol solvent. A quenched photoluminescence (PL) emission with peak in the region of 500-580 $\mathrm{nm}$ was observed which has significantly caused increased separation rate of charge carriers. XRD patterns of bare $\mathrm{g}-\mathrm{C}_{3} \mathrm{~N}_{4}, m p g-\mathrm{C}_{3} \mathrm{~N}_{4}$ and $\mathrm{Cu}$ mp-g- $\mathrm{C}_{3} \mathrm{~N}_{4}$ revealed crystalline edge defects on incorporation of $\mathrm{Cu}$ dopant in pure mpg- $\mathrm{C}_{3} \mathrm{~N}_{4}$ lattice as there is a shift in interplanar stacking 2 theta peak $=27.3^{\circ}$ indexed at (002) planes as compared to no shift of peak in bare $\mathrm{g}-\mathrm{C}_{3} \mathrm{~N}_{4}$. SEM images as depicted in (Fig. 14d and e) shows platelet-like morphology and 
stacked micron sized sheets confirming porous sized structure of $\mathrm{Cu}$ doped $\mathrm{mpg}-\mathrm{C}_{3} \mathrm{~N}_{4}$. Furthermore, investigation from TEM image (Fig. 16c) illustrates floc-worm like porous morphology. The adsorption-desorption equilibrium depicted BET surface area to be $80.5 \mathrm{~m}^{2} / \mathrm{g}$ for $\mathrm{Cu}$ doped $\mathrm{mpg}-\mathrm{C}_{3} \mathrm{~N}_{4}$ composite whereas for bulk $\mathrm{g}-\mathrm{C}_{3} \mathrm{~N}_{4}$ it was only $10.9 \mathrm{~m}^{2} / \mathrm{g}$. They found that with increase in $\mathrm{Cu}$ concentration, degradation of $\mathrm{MO}$ increased, at optimum concentration $5 \mathrm{Cu} / \mathrm{mpg}-\mathrm{C}_{3} \mathrm{~N}_{4}$ the photocatalytic results displayed $90.2 \%$ removal of $\mathrm{MO}$ dye as compared to $19.7 \%$ in bulk g- $\mathrm{C}_{3} \mathrm{~N}_{4}$. The adsorption capacity for bare $\mathrm{g}-\mathrm{C}_{3} \mathrm{~N}_{4}, \mathrm{mpg}-\mathrm{C}_{3} \mathrm{~N}_{4}$ and $\mathrm{Cu}$ doped $\mathrm{g}-\mathrm{C}_{3} \mathrm{~N}_{4}$ is $12.5 \%, 30.4 \%$ and 43.5\%, respectively [94].Wang et al. synthesized Ti doped $\mathrm{g}-\mathrm{C}_{3} \mathrm{~N}_{4}$ by a facile one-pot solvothermal method using DCDA and tetrabutyl titanate as precursors dissolved in methanol solvent. Photocatalytic $\mathrm{RhB}$ dye degradation results for bare $\mathrm{g}-\mathrm{C}_{3} \mathrm{~N}_{4}$ and $\mathrm{Ti}$ doped $\mathrm{g}-\mathrm{C}_{3} \mathrm{~N}_{4}$ were $81.3 \%$ and $95.2 \%$, respectively within 60 min of visible light rays. The above synthesized Ti doped $g-C_{3} \mathrm{~N}_{4}$ nanocomposite revealed an increased BET specific surface area of $1548.3 \mathrm{~m}^{2} / \mathrm{g}$ whereas only $6.2 \mathrm{~m}^{2} / \mathrm{g}$ of pristine $\mathrm{g}-\mathrm{C}_{3} \mathrm{~N}_{4}$ [95]. Zhang et al. studied effect of hybridized metal porphyrins on $\mathrm{g}-\mathrm{C}_{3} \mathrm{~N}_{4}$ photocatalyst fabricated via solvothermal strategy. The reagents employed are 5,10,15,20tetraphenylporhinatoM(II) $(\mathrm{M}(\mathrm{II})=\mathrm{Cu}, \mathrm{Co}, \mathrm{Ni}) \quad(\mathrm{MTPP})$ and urea as $\mathrm{g}-\mathrm{C}_{3} \mathrm{~N}_{4}$ precursor. The photocatalytic performance of pure $\mathrm{g}-\mathrm{C}_{3} \mathrm{~N}_{4}$ and three MTPP was demonstrated by photodegradation of RhB dye in aqueous solution after adsorption-desorption equilibrium. The photo activity results of RhB dye degradation indicated following trend: CoTPP/g- $\mathrm{C}_{3} \mathrm{~N}_{4}(99.79 \%)>\mathrm{NiTPP} / \mathrm{g}-\mathrm{C}_{3} \mathrm{~N}_{4}(93.15 \%)$ $>\mathrm{CuTPP} / \mathrm{g}-\mathrm{C}_{3} \mathrm{~N}_{4}(69.16 \%)>$ pure $\mathrm{g}-\mathrm{C}_{3} \mathrm{~N}_{4}(60.36 \%)$ [96]. The aforementioned discussions on the synthetic routes have emphasized on the incorporation of dopant in matrix of $\mathrm{g}_{-} \mathrm{C}_{3} \mathrm{~N}_{4}$ while still maintaining the nano architecture. From the review of literature on multifarious synthetic routes it is evident that the fabrication techniques are cost effective, facile, economical implying easily available chemicals and equipment's. The myriads of solvothermal and hydrothermal approach includes utilization of non-toxic solvents as precursors. 
Apart, from high temperature assisted processes, synthesis at low temperature have simplified the development of bio-friendly noble metal free doped $\mathrm{g}-\mathrm{C}_{3} \mathrm{~N}_{4}$.

\section{Noble metal free doped $g-\mathrm{C}_{3} \mathrm{~N}_{4}$ as photocatalyst for water purification}

In contrast, addition of noble metals ( $\mathrm{Pt}, \mathrm{Au}, \mathrm{Ag}, \mathrm{Pd}, \mathrm{Ru}, \mathrm{Os}$ and $\mathrm{Ir}$ ) as dopants is a high cost process, corrosive nature and rarity of these noble metals has inhibited their large scale application. The recovery of $\mathrm{Au}$ and other precious noble metals from secondary resources is practically performed by dissolving aqua regia which is not a novel technology to treat water pollution [97]. Therefore, it is a significant urgent surge to design non-precious metal doped $\mathrm{g}-\mathrm{C}_{3} \mathrm{~N}_{4}$ based photocatalyst to form genuine earth-abundant photocatalytic systems for water and wastewater treatment. In recent years, the application of $\mathrm{g}-\mathrm{C}_{3} \mathrm{~N}_{4}$ in water purification and environmental remediation has reached its nascent stage. The incorporation of metals as dopants enhances photocatalytic properties of $\mathrm{g}-\mathrm{C}_{3} \mathrm{~N}_{4}$ by lowering the band gap, increasing surface area as well as visible light absorption performance and better separation of charge carriers. The most commonly employed synthesis technique is thermal condensation in which corresponding soluble metal salt is mixed with $\mathrm{g}-\mathrm{C}_{3} \mathrm{~N}_{4}$ precursor in deionized water with constant supply of heat to attain modulated band gap [24]. Several research groups have fabricated metal doped $\mathrm{g}-\mathrm{C}_{3} \mathrm{~N}_{4}$ to make more competent and recyclable photocatalyst for waste water disinfection.

\section{1. $\mathrm{Na}$ and $\mathrm{K}$ doped $\mathrm{g}-\mathrm{C}_{3} \mathrm{~N}_{4}$ photocatalyst}

Metallic impurities $\left(\mathrm{Na}^{+}\right.$and $\left.\mathrm{K}^{+}\right)$were introduced into the $\mathrm{N}$ sites of $\mathrm{g}-\mathrm{C}_{3} \mathrm{~N}_{4}$ framework, for extended visible-light photocatalysis, benefiting from the increased larger surface area, tunable band gaps and improved electronic structures for appropriate charge transfer. Maciej et al. demonstrated adsorption performance of $\mathrm{Na}$ doped $\mathrm{g}-\mathrm{C}_{3} \mathrm{~N}_{4}$ synthesized using cyanamide and $\mathrm{NaCl}$ as precursors. From $\mathrm{N}_{2}-$ adsorption/desorption isotherms textural properties of $\mathrm{Na}$ doped $\mathrm{g}-\mathrm{C}_{3} \mathrm{~N}_{4}$ were evaluated. The results depicted a change from $8 \mathrm{~mm}$ pore size to $1 \mathrm{~mm}$ pore size microporous nature of synthesized nanohybrid on increasing concentration of $\mathrm{Na}$. Therefore, the obtained doped nanohybrids possessed 
excellent adsorption capacity of $367 \mathrm{mg}^{-1}$ with equilibrium time $1 \mathrm{~min}$ in relation to removal of $\mathrm{MB}$ anionic dye. The adsorption of $\mathrm{MB}$ dye onto surface of $\mathrm{Na}$ doped $\mathrm{g}-\mathrm{C}_{3} \mathrm{~N}_{4}$ was attributed to electrostatic interactions [98]. Guo et al. found that deprotonation of $\mathrm{g}_{-} \mathrm{C}_{3} \mathrm{~N}_{4}$ with $\mathrm{Na}^{+}$significantly enhanced photocatalytic activity and visible light absorption. The Mott Schottky plots and XRD peaks revealed that $\mathrm{Na}$ ions are embedded into network of carbon nitride by substituting terminal protons of amino groups from melamine precursor and bonding with $\mathrm{N}$ atoms during thermal polymerization process. Furthermore, it was found that deprotonation causes limited changes in VB potential but declines the CB potential from $-1.31 \mathrm{eV}$ to $-1.19 \mathrm{eV}[99]$.

Similarly, $\mathrm{Hu}$ et al. synthesized band gap tailored potassium $(\mathrm{K})$ doped $\mathrm{g}-\mathrm{C}_{3} \mathrm{~N}_{4}$ using DCDA monomer and potassium hydrate as precursors for removal of $\mathrm{RhB}$ dye under visible light irradiation. The doped nanohybrid exhibited larger BET surface area $30.8 \mathrm{~m}^{2} / \mathrm{g}$ and modulated $\mathrm{CB}$ and VB potentials from $-1.09 \mathrm{eV}$ to $+1.56 \mathrm{eV}$ and $-0.31 \mathrm{eV}$ to $+2.21 \mathrm{eV}$, respectively for effective separation rate of photoinduced EHP. XPS measurements are performed to explore the dopant $\mathrm{K}$ attachment in g$\mathrm{C}_{3} \mathrm{~N}_{4}$ structure. The maximum in-planar distance was $0.71 \mathrm{~nm}$, which makes interstitial sites the most probable positions for $\mathrm{K}$ ions. Further analysis revealed ion-dipole interactions between $\mathrm{K}^{+}$and negatively charged $\mathrm{O}$ atoms of $\mathrm{C}-\mathrm{O}$ polyether ring [100]. Zhang et al. as previously reported effect of precursor concentration on $\mathrm{K}^{+}$photodecomposition activity of phenol and MB dye. BET surface measurements is decreased from $10.5 \mathrm{~m}^{2} / \mathrm{g}$ to $3.5 \mathrm{~m}^{2} / \mathrm{g}$ with increased mass fraction of KI. The electronic structure is evaluated by calculating flat band potentials $\left(\mathrm{V}_{\mathrm{fb}}\right)$ i.e. $-1.15 \mathrm{~V}$ and $-0.99 \mathrm{~V}$ for $\mathrm{g}$ $\mathrm{C}_{3} \mathrm{~N}_{4}$ and for $22 \% \mathrm{~K}$ doped $\mathrm{g}-\mathrm{C}_{3} \mathrm{~N}_{4}$, respectively similar to results obtained from DFT. The higher intensity of photodegraded phenol intermediates like maleic anhydride, dihydroxy benzene and 4,4 dihydroxy biphenyl results in increased degradation ability of pollutants [78]. Jiang et al. gave a systematic comparative study of doping effect of alkali metal ion $\left(\mathrm{Na}^{+}\right.$or $\left.\mathrm{K}^{+}\right)$doped $\mathrm{g}-\mathrm{C}_{3} \mathrm{~N}_{4}$ for visible light active photocatalysis. A conventional calcination method is opted for synthesis of $\mathrm{Na}$ and $\mathrm{K}$ doped $\mathrm{g}-\mathrm{C}_{3} \mathrm{~N}_{4}$ using melamine and metal hydroxides $(\mathrm{MOH}) \mathrm{M}=\mathrm{Na}, \mathrm{K}$ as precursors. According, to 
BET surface analysis $\mathrm{Na}$ doped $\mathrm{g}-\mathrm{C}_{3} \mathrm{~N}_{4}$ possesses surface area, $28 \mathrm{~m}^{2} / \mathrm{g}$ larger than $\mathrm{K}$ doped $\mathrm{g}-\mathrm{C}_{3} \mathrm{~N}_{4}$, $21 \mathrm{~m}^{2} / \mathrm{g}$ which provides more reaction sites for photocatalytic performance. Binding energies indicated a positive shift, by $0.2 \mathrm{eV}-0.4 \mathrm{eV}$ for $\mathrm{C} 1 \mathrm{~s}$ and $\mathrm{N} 1 \mathrm{~s}$ which resulted in formation of coordination bond between dopants and g- $_{3} \mathrm{~N}_{4}$ aromatic rings. They reported through DFT calculations, that band gap of g- $\mathrm{C}_{3} \mathrm{~N}_{4}$ could be decreased by incorporation of dopants ( $\mathrm{Na}$ and $\mathrm{K}$ ) to an extent of $2.42 \mathrm{eV}$ and 2.39 $\mathrm{eV}$, respectively. The obtained results clearly depicted, $\mathrm{Na}$ doped $\mathrm{g}_{-} \mathrm{C}_{3} \mathrm{~N}_{4}$ displayed more photocatalytic ability due to tailored electronic structure and redox potentials for efficient consumption of photogenerated electrons. In fact, metal cations are easily incorporated into $g-\mathrm{C}_{3} \mathrm{~N}_{4}$ framework due to strong interactions between metal dopants and lone pair electrons on nitrogen pots of $\mathrm{g}-\mathrm{C}_{3} \mathrm{~N}_{4}$. It is thus, rationale to conclude that alkali metal addition exhibits stable chemical activity in spite of its highly reactive nature, thus enhancing photodegradation of organic pollutants [101].

\subsection{Transition metal doped $g-C_{3} N_{4}$ photocatalyst}

Apart from metal based photocatalysis reactions, transition element doping is an essential technique to overcome water pollution related issues. As discussed above, narrowed band gap and prolonged life time of photogenerated charge carriers are necessary for enhanced photocatalytic processes. Transition metal, such as $\mathrm{Ti}, \mathrm{V}, \mathrm{Fe}, \mathrm{Co}, \mathrm{Ni}, \mathrm{Cu}, \mathrm{Zn}$, Mo and $\mathrm{Zr}$ were used to functionalize g$\mathrm{C}_{3} \mathrm{~N}_{4}$ with better carrier mobility, reduced band gap and improved absorption in visible region of spectrum. Wang et al. studied synergistic intervalence $\mathrm{e}^{-}$transfer effect of $\mathrm{Ti}^{+4}$ to $\mathrm{Ti}^{+3}$ doped $g-\mathrm{C}_{3} \mathrm{~N}_{4}$ for the application of RhB dye removal. Radical and hole trapping experiments were carried out to identify main ROS involved in RhB dye degradation using three scavengers-: EDTA-2Na $\left(\mathrm{h}^{+}\right)$, $\mathrm{p}-$ benzoquinone $\left(\mathrm{O}_{2}^{-}\right)$and isopropyl alcohol $\left(\mathrm{OH}^{\cdot}\right)$. The obtained results showed that photodegradation mechanism is largely dependent upon $\mathrm{h}^{+}$and ${ }^{\circ} \mathrm{O}_{2}{ }^{-}$compared with $\mathrm{OH}$. XPS measurements were performed to acquire information on surface chemical composition of Ti doped $\mathrm{g}-\mathrm{C}_{3} \mathrm{~N}_{4}$ from binding energies values of $\mathrm{Ti} 2 \mathrm{p}_{3 / 2}(458.8 \mathrm{eV})$ and $\mathrm{Ti} 2 \mathrm{p}_{1 / 2}(464.5 \mathrm{eV})$ which indicated that in $\mathrm{Ti}^{+3}$ gets bounded to $\mathrm{O}^{+4}$ in titanium-oxo cluster [95]. 
Another similar work has been reported for removal of $\mathrm{RhB}$ dye by Ti doped $\mathrm{g}_{-} \mathrm{C}_{3} \mathrm{~N}_{4}$. Prominent red shift was observed from the spectra of UV-visible diffuse reflectance spectra (DRS) which indicated extended absorption response from UV to visible region. Furthermore, a significant increase in Ti concentration led to decrease in optical band gap energy from $2.71 \mathrm{eV}$ to $2.55 \mathrm{eV}$ for bare $\mathrm{g}-\mathrm{C}_{3} \mathrm{~N}_{4}$ and $0.75 \mathrm{Ti} / \mathrm{g}-\mathrm{C}_{3} \mathrm{~N}_{4}$, respectively [69].

Ding et al. designed vanadium (V) doped $\mathrm{g}-\mathrm{C}_{3} \mathrm{~N}_{4}$ photocatalyst with common precursor urea and ammonium metavanadate $\left(\mathrm{NH}_{4} \mathrm{VO}_{3}\right)$ for effective hydroxylation of benzene to phenol. The structural stability of doped nanohybrid provides surface area for benzene adsorption and its hydroxylation to phenol over vanadium species which is supported by $\mathrm{NH}$ and $\mathrm{NH}_{2}$ groups of $\mathrm{g}-\mathrm{C}_{3} \mathrm{~N}_{4}$. The $100 \%$ yield of phenol is obtained at $0.4 \mathrm{~g}$ vanadium, optimized concentration of solvent (acetonitrile: acetic acid ) in 4:1and at temperature $323 \mathrm{~K}$ [102]. Tonda et al. demonstrated fabrication of Fe doped $\mathrm{g}_{-} \mathrm{C}_{3} \mathrm{~N}_{4}$ nanosheets using melamine and ferric chloride $\left(\mathrm{FeCl}_{3}\right)$ as precursors for $\mathrm{RhB}$ dye photocatalytic degradation under sunlight irradiation. The obtained binding energy value lies within the range of 710.3-711.8 eV which confirms +3 oxidation state of $\mathrm{Fe} . \mathrm{Fe}^{+3}$ acts as temporary photoinduced EHP trapping site. An increased absorption and red shift is exhibited by Fe doped nanocomposite thus, favoring the formation of more EHP. The photocatalytic mechanism involves reduction of $\mathrm{O}_{2}{ }^{-}$to $\mathrm{O}_{2}$ and oxidation of $\mathrm{OH}^{\cdot}$ or $\mathrm{H}_{2} \mathrm{O}$ molecules to $\mathrm{OH}^{\cdot}$ by trapped $\mathrm{e}^{-}$and valence $\mathrm{h}^{+}[103]$. Chen et al. designed Fe doped $\mathrm{g}-\mathrm{C}_{3} \mathrm{~N}_{4}$ photocatalyst by copolymerization of DCDA and $\mathrm{FeCl}_{3}$ at $600^{\circ} \mathrm{C}$ for photocatalytic oxidation of benzene to phenol. From the results it was concluded that Fe doped $\mathrm{g}_{-} \mathrm{C}_{3} \mathrm{~N}_{4}(10 \mathrm{wt} \%)$ nanocomposite exhibited $4.8 \%$ phenol degradation in visible light and only $1.8 \%$ in dark. An increase in photodegradation efficiency was observed on addition of SBA-15 i.e. mesoporous catalyst support that effectively increases surface area and $11.8 \%$ benzene conversion [104]. It was also found that Fe doped $\mathrm{g}_{-} \mathrm{C}_{3} \mathrm{~N}_{4}$ prepared by soft chemical methods was capable to oxidize phenol and $\mathrm{RhB}$ dye efficiently [105]. Mu et al. for the first time demonstrated enhanced peroxidase $\left(\mathrm{H}_{2} \mathrm{O}_{2}\right)$ like activity of Co doped $\mathrm{g}-\mathrm{C}_{3} \mathrm{~N}_{4}$ photocatalyst for wastewater treatment. The method opted was one pot thermal 
condensation using urea and cobalt chloride hexahydrate $\left(\mathrm{CoCl}_{2} \cdot 6 \mathrm{H}_{2} \mathrm{O}\right)$. The obtained peak at $572 \mathrm{~nm}$ by UV-vis DRS in the visible region of spectra displayed interaction between Co and $g-\mathrm{C}_{3} \mathrm{~N}_{4}$. The optimized content of Co (2.5\%) displayed higher affinity for organic substrate 3,3',5,5'tetramethylbenzidine (TMB) facilitating electron transfer from TMB to $\mathrm{H}_{2} \mathrm{O}_{2}$. The synthesized Co doped $\mathrm{g}-\mathrm{C}_{3} \mathrm{~N}_{4}$ successfully degraded $97 \% \mathrm{RhB}$ dye in comparison to pristine $\mathrm{g}-\mathrm{C}_{3} \mathrm{~N}_{4}$ with $34 \%$ degradation activity [106]. As previously stated, Das and co-workers fabricated Co doped $\mathrm{g}-\mathrm{C}_{3} \mathrm{~N}_{4}$ for the photodegradation of eosin B dye. Results revealed increased surface area from $50.9 \mathrm{~m}^{2} / \mathrm{g}$ to 68.3 $\mathrm{m}^{2} / \mathrm{g}$ and lowered band gap from $2.80 \mathrm{eV}$ to $2.76 \mathrm{eV}$. The dopant $\mathrm{Co}^{+2}$ in $\mathrm{g}_{-} \mathrm{C}_{3} \mathrm{~N}_{4}$ possesses property to temporarily act as trapping site for photoinduced charge carriers and reduction of EHP recombination, thus enhancing photocatalytic activity [70].

They also prepared nickel $(\mathrm{Ni})$ doped $\mathrm{g}-\mathrm{C}_{3} \mathrm{~N}_{4}$ nanosheets by thermal treatment of precursors urea and nickel nitrate hexahydrate for its application in degradation of MO dye. The XRD pattern in (Fig. 9c), peak at (100) planes confirms the bare $\mathrm{g}-\mathrm{C}_{3} \mathrm{~N}_{4}$ structure, on increasing the $\mathrm{Ni}$ dopant concentration to 2-3g Ni doped $\mathrm{g}-\mathrm{C}_{3} \mathrm{~N}_{4}$ peaks at (110), (002), (111), (112), (300) and (113) planes is attributed to $\beta$ phase of Ni nitride. The face centered structure (fcc) shows characteristic peaks at (111), (200) and (202) planes. The favorable incorporation position of dopant into the host lattice is either interstitial or substitutional as demonstrated in (Fig. 18). The interstitial site is the most probable attachment site for $\mathrm{Ni}$, as in-planar distance of $0.675 \mathrm{~mm}$ can easily accommodate $\mathrm{Ni}$ atom in the $\mathrm{g}-\mathrm{C}_{3} \mathrm{~N}_{4}$ framework without replacement of $\mathrm{N}$ or $\mathrm{C}$ atom (Fig. 18a). Substitutional doping is not possible due to larger ionic radii of $\mathrm{Ni}^{+2} 0.083 \mathrm{~mm}$ and $0.07 \mathrm{~mm}$ of $\mathrm{Ni}^{+3}$ than both $\mathrm{N}$ and $\mathrm{C}$ atom. Further structure confirmation is obtained from DFT calculations of bare and doped $\mathrm{g}_{-} \mathrm{C}_{3} \mathrm{~N}_{4}$ as clearly illustrated in (Fig. 19) project density of states plot (PDOS). The PDOS plots of bare $g-\mathrm{C}_{3} \mathrm{~N}_{4}$ (Fig. 19a) shows VB composed of $2 \mathrm{p} \mathrm{N}$ orbital with partial involvement from $2 \mathrm{~s} \mathrm{~N}$ and $\mathrm{C} 2 \mathrm{p}$ orbital. The PDOS plots of Ni modified $g-\mathrm{C}_{3} \mathrm{~N}_{4}$ (Fig. 19b and c) displayed ionic interactions between $3 \mathrm{~d}$ orbital of $\mathrm{Ni}$ with lone pairs of N2p $\mathrm{p}_{\mathrm{z}}$ In (Fig. 19d) the TDOS plot confirms formation of states in band gap region upon incorporation of Ni dopant 
[107]. $\mathrm{Cu}$ doped $\mathrm{g}-\mathrm{C}_{3} \mathrm{~N}_{4}$ nanosheets showed red shift of absorption extended to near infrared region (NIR), $600 \mathrm{~nm}$. XPS results illustrated that $\mathrm{Cu}$ was doped into network structure and then formed N-C$\mathrm{N}$ coordination bonds, which confirmed that $\mathrm{Cu}$ atoms are directly bonded to $\mathrm{sp}^{2}$ hybridized carbon [93]. Another similar approach involved formation of $\mathrm{CuO}-\mathrm{g}-\mathrm{C}_{3} \mathrm{~N}_{4}$ using melamine as precursor for effective 94\% RhB dye degradation [108]. Researchers introduced zinc oxide ( $\mathrm{ZnO}$ ) into Mo doped g$\mathrm{C}_{3} \mathrm{~N}_{4}$ to enhance photodegradation activity of $\mathrm{MB}$ and $\mathrm{RhB}$ dyes. Incorporation of $\mathrm{Mo}^{+6}$ takes place via substitution of $\mathrm{Zn}^{+2}$ into the $\mathrm{ZnO}$ lattice, as ionic radii of $\mathrm{Mo}^{+6}(0.0062 \mathrm{~nm})$ is less than that of $\mathrm{Zn}^{+2}$ $(0.074 \mathrm{~nm})$. The obtained binding energies of $\mathrm{Mo}_{5 / 2}$ at $232.20 \mathrm{eV}$ and $\mathrm{Mo}_{5 / 2}$ at $235.34 \mathrm{eV}$ confirmed the existence of Mo +6 oxidation state. The recorded transmission spectra of bare and doped photocatalyst exhibited $95 \%$ transmittance in visible and near IR region. The following trend in band gap is observed on addition of $\mathrm{Mo}$ dopant: $\mathrm{ZnO}(3.20 \mathrm{eV}), \mathrm{ZnO} / \mathrm{g}-\mathrm{C}_{3} \mathrm{~N}_{4}(3.01 \mathrm{eV}), \mathrm{ZnO}: \mathrm{Mo}_{(1 \%)}$ g$\mathrm{C}_{3} \mathrm{~N}_{4}(2.79 \mathrm{eV}), \mathrm{ZnO}: \mathrm{Mo}_{(2 \%)} \mathrm{g}-\mathrm{C}_{3} \mathrm{~N}_{4}(2.88 \mathrm{eV}), \mathrm{ZnO}: \mathrm{Mo}_{(3 \%)} \mathrm{g}_{-} \mathrm{C}_{3} \mathrm{~N}_{4}(2.93 \mathrm{eV})$ [68]. In another study, nonselective oxidation potential of Mo doped $\mathrm{g}-\mathrm{C}_{3} \mathrm{~N}_{4}$ for MB dye is explored when compared with pristine g- $\mathrm{C}_{3} \mathrm{~N}_{4}$ or $\mathrm{MoO}_{3}$. In addition, synthesized photocatalyst exhibited selective oxidation of diphenyl, methyl phenyl sulfides to sulfoxides and N-compounds (pyridine, quinoline) oxidation to corresponding N-oxides at room temperature $\left(25^{\circ} \mathrm{C}\right)$. Recyclability of Mo doped $\mathrm{g}_{-} \mathrm{C}_{3} \mathrm{~N}_{4}$ was reported to be $90-94 \%$ for five cycle test reactions with no appreciable loss of photoactivity, as determined via atomic absorption spectroscopy (AAS) [76]. As discussed above, $\mathrm{Zr}$ doped $\mathrm{g}_{-} \mathrm{C}_{3} \mathrm{~N}_{4}$ displayed high photodegradation performance for RhB dye. From the XPS and thermal analysis it was concluded that $\mathrm{Zr}$ exists in the oxidation state +4 in superstructure of $\mathrm{g}-\mathrm{C}_{3} \mathrm{~N}_{4}$. In accordance with EDX results, $\mathrm{Zr}$ dopant is embedded into in-planes of $\mathrm{g}_{-} \mathrm{C}_{3} \mathrm{~N}_{4}$, through $\mathrm{N}$-bridging [71]. From the review of literature, on metal and transition metal doping it is evident that incorporation of metal ions significantly reduces band gap, lowers the recombination rate of photoexcited EHP and broadened absorption in visible region. Nevertheless, alkali metal or transition metal doped $\mathrm{g}-\mathrm{C}_{3} \mathrm{~N}_{4}$ is allied with certain limitations of 
high reactivity, poor thermal stability and less availability of metals. In spite of these pitfalls, metallic dopants have been successfully used for the purpose of removal of toxic dyes and water purification.

\subsection{Rare earth metal doped g- $C_{3} N_{4}$ photocatalyst}

Rare earth metal cerium $(\mathrm{Ce})$ was incorporated in pristine $\mathrm{g}-\mathrm{C}_{3} \mathrm{~N}_{4}$ via thermal condensation of urea and cerium sulfate precursors which resulted in $90 \% \mathrm{RhB}$ degradation in 120 min of visible light irradiation. XPS spectrum analysis revealed interstitial occupancy by $\mathrm{Ce}^{+3}$ coordinated to lone pair of $\mathrm{N}$ atoms also ionic radii of $\mathrm{Ce}^{+3}$ was found to be $0.103 \mathrm{~nm}$, which is much larger than that of $\mathrm{N}$ and $\mathrm{C}$. Hence an increased electron density and interstitial attachment is promoted for Ce dopant. An increased BET surface area was observed to be $21.4 \mathrm{~m}^{2} / \mathrm{g}$ for Ce-doped $\mathrm{g}-\mathrm{C}_{3} \mathrm{~N}_{4}$ and only 11.1 $\mathrm{m}^{2} / \mathrm{g}$ for pristine $\mathrm{g}-\mathrm{C}_{3} \mathrm{~N}_{4}$. The calculated band gap energies were $2.7 \mathrm{eV}$ and $2.57 \mathrm{eV}$ for pristine $\mathrm{g}$ $\mathrm{C}_{3} \mathrm{~N}_{4}$ and $\mathrm{Ce}$ doped $\mathrm{g}-\mathrm{C}_{3} \mathrm{~N}_{4}$ [109]. Xu et al. systematically investigated the photocatalytic oxidation mechanism and effect of impurity concentration in europium(Eu) doped $g-C_{3} \mathrm{~N}_{4}$. In this experiment concentration of $\mathrm{Eu}$ dopant was varied in the range of 0.08 wt.\%-0.76 wt.\%. Among them, the optimized $\mathrm{CN}-\mathrm{Eu}-0.38 \%$ displayed a high $\mathrm{MB}$ dye degradation rate of $81.57 \%$ in comparison to degradation efficiency of only $53 \%$ by bulk g- $\mathrm{C}_{3} \mathrm{~N}_{4}$. Dopant Eu wt $\% \mathrm{CN}-0.38$ has effects on BET surface area which showed an increase from $12 \mathrm{~m}^{2} / \mathrm{g}$ to $23 \mathrm{~m}^{2} / \mathrm{g}$. An excess of $\mathrm{Eu}^{+3}$ may act as potential recombination sites for photoinduced excitons thus decreasing the photocatalytic rate of reaction [110]. Ruthenium $(\mathrm{Ru})$ has been employed in complex formation with $\mathrm{g}-\mathrm{C}_{3} \mathrm{~N}_{4}$ for the development of a heterogeneous photocatalyst. The synthesized $\mathrm{Ru}$ doped $\mathrm{g}-\mathrm{C}_{3} \mathrm{~N}_{4}$ improved $\mathrm{CO}_{2}$ reduction efficiency to formic acid and upgraded apparent quantum yield to $5.7 \%$ [111]. For the purpose of similar application, in-situ thermal polymerization of cyanuric acid, DCDA and $\mathrm{SeO}_{2}$ at $560^{\circ} \mathrm{C}$ lead to synthesis of selenium (Se) doped $\mathrm{g}-\mathrm{C}_{3} \mathrm{~N}_{4}$ nanosheets. In the UV-vis DRS, a red shift in absorption band is depicted which is due to formation of mid gap electronic state located at $-0.35 \mathrm{eV}$ at a lowered position than LUMO. Therefore a reduction in band gap energy from 2.83 to $2.78 \mathrm{eV}$ is observed after incorporation of Se dopant [112]. Wang et al. prepared yttrium (Y) doped g- $\mathrm{C}_{3} \mathrm{~N}_{4}$ 
photocatalyst via a facile pyrolysis technique with urea and yttrium nitrate as precursors. The XRD peaks in (Fig. 8d) indexed at (100) and (002) planes are weakened on increasing concentration of yttrium due to crystalline defects accompanied by incomplete polymerization. XPS measurements were demonstrated to explicate the chemical existence of yttrium in $\mathrm{Y}(+3)$ oxidation state as confirmed by binding energy values at 159.7 and $154.6 \mathrm{eV}$ ascribed to $\mathrm{Y}_{3 / 2}$ and $\mathrm{Y} 3 \mathrm{~d}_{5 / 2}$. TEM image as shown in (Fig. 16d) reveals sheet-worm like appearance with disordered aggregated arrangement of $0.25 \mathrm{Y}$ doped $\mathrm{g}-\mathrm{C}_{3} \mathrm{~N}_{4}$. Significantly, improved BET surface area from 68 to $103 \mathrm{~m}^{2} / \mathrm{g}$, decreased band gap from 2.50 to $2.70 \mathrm{eV}$ consequently, extended absorption in visible region. The $100 \%$ photocatalytic degradation efficiency of RhB dye was obtained by incorporation of optimized CN-Y-0.25g into g- $\mathrm{C}_{3} \mathrm{~N}_{4}$ lattice [113]. Recently, synthesized samarium $\left(\mathrm{Sm}^{+3}\right)$ doped $\mathrm{g}-\mathrm{C}_{3} \mathrm{~N}_{4}$ photocatalyst has successfully been used in removal of RhB, MB and eosin yellow dyes. In (Fig. 8c) PL emission peak at $572 \mathrm{~nm}$ for $0.02 \mathrm{wt} \% \mathrm{Sm}^{+3}$ is observed which is due to transitions from ${ }^{4} \mathrm{G}_{5 / 2}$ to ${ }^{6} \mathrm{H}_{7 / 2}$ which is absent in bare $\mathrm{g}-\mathrm{C}_{3} \mathrm{~N}_{4}$. RhB dye degradation as shown in (Fig. 13d) under various scavengers, results elucidate IPA, TEOA and AA which reduces the dye degradation efficiency. The main ROS participating in photocatalytic degradation mechanism are $\mathrm{OH}$ and $\mathrm{h}^{+}$. The red shift observed in FTIR confirmed interaction between $\mathrm{Sm}^{+3}$ with $\mathrm{g}-\mathrm{C}_{3} \mathrm{~N}_{4}$. Furthermore, it was determined that unfilled $4 \mathrm{f}$ orbital of $\mathrm{Sm}^{+3}$ captured photogenerated $\mathrm{e}^{-}$hence reduced recombination rate and improves photocatalytic activity [114].

\section{Nonmetal doping of $\mathrm{g}-\mathrm{C}_{3} \mathbf{N}_{4}$ photocatalyst for water purification}

The scarcity in nature and high cost of metal based photocatalysts pose as significant barriers with respect to large scale practical applications. Moreover, thermal instability of these metal doped semiconductor photocatalyst causes chemical corrosion and self-degradation. Thus, non-metal modified $\mathrm{g}-\mathrm{C}_{3} \mathrm{~N}_{4}$ has gained attention in the field of research. The inherent properties of non-metals such as high ionization energies and high electronegativity enables them to gain electrons and form strong covalent bonds in the parent lattice structure. As compared to metallic impurities non-metal 
dopants possess less thermal variation in chemical nature. Phosphorus, sulfur, carbon, nitrogen, oxygen, boron and halogens are the non-metal dopants which have been incorporated in $\mathrm{g}_{-} \mathrm{C}_{3} \mathrm{~N}_{4}$ to improve its photodegradation activity.

\subsection{Phosphorus doped g- $C_{3} N_{4}$ photocatalyst}

The addition of Phosphorus $(\mathrm{P})$ atom tailors the electronic property of $g-\mathrm{C}_{3} \mathrm{~N}_{4}$, enlarges specific area, promotes separation of photoinduced EHP, thus improving the photodegradation performance [115]. Keeping in consideration the advantages obtained by introduction of $\mathrm{P}$ as dopant, there is significant work in this area. Zhou et al. prepared $\mathrm{P}$ doped $\mathrm{g}-\mathrm{C}_{3} \mathrm{~N}_{4}$ by a low cost copolymerization method using hexa-choloro-cyclo triphosphazene and guanidinium hydrochloride as $\mathrm{P}$ and $\mathrm{g}-\mathrm{C}_{3} \mathrm{~N}_{4}$ precursors, respectively. A rapid $100 \% \mathrm{RhB}$ dye degradation is observed by $\mathrm{P}$ doped $\mathrm{g}-\mathrm{C}_{3} \mathrm{~N}_{4}$ in $10 \mathrm{~min}$ whereas in pure $\mathrm{g}-\mathrm{C}_{3} \mathrm{~N}_{4}$ photodegradation occurred in $30 \mathrm{~min}$. An increase in BET specific surface after P doping is attributed to release of gaseous products during the reaction between two precursors. The structural and surface chemical composition of synthesized P doped $g-\mathrm{C}_{3} \mathrm{~N}_{4}$ is confirmed by XPS and solid state phosphor-nuclear magnetic resonance $\left(\mathrm{P}^{31}-\mathrm{NMR}\right)$ results. They found that insertion of $\mathrm{P}$ species occurs by replacement of $\mathrm{sp}^{2}$ - hybridized carbon atom and by formation of covalent bonds with neighboring $\mathrm{N}$ atoms, leaving a lone pair of electrons on the $\pi$-conjugated triazine ring of $g-\mathrm{C}_{3} \mathrm{~N}_{4}$.

TEM and STEM gives more evidence of the morphology and uniform distribution of $\mathrm{P}$ atoms in layered platelet-like $\mathrm{g}-\mathrm{C}_{3} \mathrm{~N}_{4}$ lattice. In the network structure of $\mathrm{g}-\mathrm{C}_{3} \mathrm{~N}_{4}$ as shown in (Fig. 18b) the $\mathrm{P}$ atoms are located at the bay and corner-carbon positions. It is further revealed that the doped structure possesses two sites i.e. lewis acid $\left(\mathrm{P}^{+}\right)$and lewis base (amine or imine groups) which reduces recombination rate of photoexcited EHP, thus enhancing RhB dye degradation [116].Thermal exfoliation strategy has been successfully used to prepare metal-free P-doped porous ultrathin $g-\mathrm{C}_{3} \mathrm{~N}_{4}$ nanosheets by 2-aminoethylphosphonic acid (AEP) and melamine as precursors. A synergistic behavior was observed during degradation of $75 \% \mathrm{Cr}^{+6}$ and $90 \%$ 2,4- dichlorophenol (2,4-DCP) by ultrathin $\mathrm{P}$ doped $\mathrm{g}_{-} \mathrm{C}_{3} \mathrm{~N}_{4}$ nanosheets. The photogenerated electrons and $\mathrm{O}_{2}{ }^{-}$can effectively cause 
reduction of $\mathrm{Cr}^{+6}$ to $\mathrm{Cr}^{+3}$ whereas, photogenerated holes participate in degradation of 2,4-DCP. The optimized concentration of 2,4-DCP is $80 \mathrm{mg} / \mathrm{L}$ beyond which there is a decrease in photocatalytic activity due to saturation of reactant sites. Researchers reported that simultaneous degradation of these two toxic mutagens is possible due to electron donor nature of 2,4-DCP causing reduction of $\mathrm{Cr}^{+6}$ over doped nanosheets within 80 min of reaction. Furthermore, $70.3 \%$ of total organic carbon (TOC) was removed under $2 \mathrm{~h}$ of visible light irradiation confirming high mineralization and photodegradation efficiency. The ultrathin crystal nature of synthesized nanosheets is demonstrated via an increased BET surface area from $4.4 \mathrm{~m}^{2} / \mathrm{g}$ to $13.7 \mathrm{~m}^{2} / \mathrm{g}$ for bulk g- $\mathrm{C}_{3} \mathrm{~N}_{4}$ and $\mathrm{P}$ doped $\mathrm{g}-\mathrm{C}_{3} \mathrm{~N}_{4}$, respectively [117]. Similar exfoliation strategy was adopted for synthesis of black-P anchored $\mathrm{g}-\mathrm{C}_{3} \mathrm{~N}_{4}$ for molecular $\mathrm{O}_{2}$ evolution and $\mathrm{RhB}$ degradation [118]. The anchoring of square flake $\mathrm{TiO}_{2}$ onto $\mathrm{P}$ doped $\mathrm{g}-\mathrm{C}_{3} \mathrm{~N}_{4}$ has been investigated for improved photocatalytic activity and degradation of MB dye. The nanocomposite was prepared via solvent-thermal method using two precursors; melamine and phosphonitrilic chloride trimer $\left(\mathrm{Cl}_{6} \mathrm{~N}_{3} \mathrm{P}_{3}\right)$. The XPS binding energy peak at $132.2 \mathrm{eV}$ is of $\mathrm{P}_{(2 \mathrm{p})}-\mathrm{C}_{(1 \mathrm{~s})}$ bonds, that confirmed the incorporation of $\mathrm{P}$ atom by replacement of $\mathrm{N}$ atoms into $\mathrm{g}-\mathrm{C}_{3} \mathrm{~N}_{4}$ complex. SEM image in (Fig. 14f) confirms P doping as surface appears wrinkled and loose also the stacked lamellar structure is rough than pristine $\mathrm{g}_{-} \mathrm{C}_{3} \mathrm{~N}_{4}$. The sequence of photodegradation rate of $\mathrm{MB}$ dye with $\mathrm{P}_{(0.1 \%)}$ doped $\mathrm{g}_{-} \mathrm{C}_{3} \mathrm{~N}_{4} / \mathrm{TiO}_{2}$, $\mathrm{P}_{(0.3 \%)}$ doped $\mathrm{g}-\mathrm{C}_{3} \mathrm{~N}_{4} / \mathrm{TiO}_{2}, \mathrm{P}_{(0.5 \%)}$ doped $\mathrm{g}-\mathrm{C}_{3} \mathrm{~N}_{4} / \mathrm{TiO}_{2}$ are $96.5 \%, 95 \%, 77 \%$, whereas for pristine g$\mathrm{C}_{3} \mathrm{~N}_{4}$ and $\mathrm{g}-\mathrm{C}_{3} \mathrm{~N}_{4} / \mathrm{TiO}_{2}$ are $19 \%$ and $92 \%$, respectively after $135 \mathrm{~min}$ of visible light irradiation. The highest degradation was achieved at minimum concentration of $\mathrm{P}_{(0.1 \%)}$ which is due to the fact that excess dopant may act as recombination sites, hence increasing the recombination of charge carriers [119]. In another study $\mathrm{CeO}_{2}$ was coupled to $\mathrm{P}$ doped $\mathrm{g}-\mathrm{C}_{3} \mathrm{~N}_{4}$ through simply heating mixture of melamine and diammonium hydrogen phosphate followed by addition of $\mathrm{CeO}_{2}$ via calcination. The fabricated $\mathrm{CeO}_{2}-\mathrm{P}$ doped $\mathrm{g}-\mathrm{C}_{3} \mathrm{~N}_{4}$ lowered band gap from $2.71 \mathrm{eV}$ of bare $\mathrm{g}-\mathrm{C}_{3} \mathrm{~N}_{4}$ to $2.32 \mathrm{eV}$ at optimized concentration of $13.8 \% \mathrm{CeO}_{2}$. Furthermore, photocatalytic degradation of $\mathrm{MO}$ dye was evaluated to be 7.4, 4.9 times higher than bulk $\mathrm{CeO}_{2}$ and $\mathrm{g}-\mathrm{C}_{3} \mathrm{~N}_{4}$, respectively this behavior is ascribed 
to synergistic interactions between $\mathrm{CeO}_{2}$ and $\mathrm{P}$ doped $\mathrm{g}-\mathrm{C}_{3} \mathrm{~N}_{4}$ [120]. As previously discussed, Zhang et al. observed that photocatalytic efficiency of prepared photocatalysts are also influenced by doping site which is further dependent upon reactant molecules employed. The incorporation of $\mathrm{P}$ atoms at bay carbon corners by forming P-N bonding in the $\mathrm{g}-\mathrm{C}_{3} \mathrm{~N}_{4}$ lattice is attributed to leaching of ionic liquid $\mathrm{BMIM}^{-\mathrm{PF}_{6}}$ (P source), as confirmed by XPS results. From DFT calculations it was inferred that broadened visible light response is due to electron transfer from HOMO of $\mathrm{N}_{2 p}$ orbital to LUMO formed by $\mathrm{C}_{2 \mathrm{p}}$ orbital. A red shift is observed in the UV-vis spectra indicating small decrease in band gap due to lowering in the bottom of conduction band [89]. In another work similar reactants, ionic liquid BMIM-PF 6 and DCDA undergo co-condensation reaction forming $\mathrm{P}$ doped $\mathrm{g}-\mathrm{C}_{3} \mathrm{~N}_{4}$. The release of $\mathrm{PF}_{6}^{-}$from the precursor is responsible for reaction with amine group and bond length of P-N (150$170 \mathrm{pm})$ which is longer than that of $\mathrm{C}-\mathrm{N}(135 \mathrm{pm}) \mathrm{g}-\mathrm{C}_{3} \mathrm{~N}_{4}$ thus $\mathrm{P}$ atom leads to planar configuration of g- $\mathrm{C}_{3} \mathrm{~N}_{4}$ [121]. The influence of dopant content embedded into $\mathrm{g}-\mathrm{C}_{3} \mathrm{~N}_{4}$ lattice on photocatalytic activity has been studied considering band gap and degradation efficiency. The lowering in band gap energies is observed with increase in $\mathrm{P}$ concentration from $2.90 \mathrm{eV}$ in pure $\mathrm{g}-\mathrm{C}_{3} \mathrm{~N}_{4}$ to $2.86,2.80,2.71 \mathrm{eV}$ for $\mathrm{P}_{(1 \%)}$ doped g- $\mathrm{C}_{3} \mathrm{~N}_{4}, \mathrm{P}_{(1.5 \%)}$ doped $\mathrm{g}-\mathrm{C}_{3} \mathrm{~N}_{4}, \mathrm{P}_{(2.5 \%)}$ doped $\mathrm{g}-\mathrm{C}_{3} \mathrm{~N}_{4}$, respectively. Furthermore, excess doping of P resulted in lattice defects which are recombination centers for photoinduced EHP [88]. Ran et al. proposed and designed a novel porous $\mathrm{P}$ doped $\mathrm{g}-\mathrm{C}_{3} \mathrm{~N}_{4}$ via thermal exfoliation of bulk g$\mathrm{C}_{3} \mathrm{~N}_{4}$ to scheelite $\mathrm{g}-\mathrm{C}_{3} \mathrm{~N}_{4}$. The spectrum analysis obtained from EDX and XPS confirms that favorable $\mathrm{P}$ doping site is $\mathrm{C} 2$ in the $\mathrm{g}-\mathrm{C}_{3} \mathrm{~N}_{4}$ heptazine ring. The XRD diffraction peak (002) decreases the interlayer distance from $3.26 \mathrm{~A}^{\circ}$ to $3.22 \mathrm{~A}^{\circ}$ thereby resulting in formation of densely packed layers of $\mathrm{P}$ doped indicating successful exfoliation. In accordance to DFT calculations intrinsic band gap reduction is observed from $2.98 \mathrm{eV}$ to $2.66 \mathrm{eV}$, also empty hybridized orbital $\mathrm{C}_{2 \mathrm{~s}, 2 \mathrm{p}}, \mathrm{N}_{2 \mathrm{~s}, 2 \mathrm{p}}$ and $\mathrm{P}_{3 \mathrm{~s}, 3 \mathrm{p}}$ present below the $\mathrm{CB}$, act as separation centers and prevents charge recombination [122]. In another study, it was explored that incorporation of $\mathrm{P}$ atoms takes place at bay position as well as at edge terminal sites, as depicted by the results of XPS and $\mathrm{P}^{31} \mathrm{NMR}$. The method opted for synthesis is by 
direct thermolysis of melamine and hexachloro cyclo triphosphazene precursors. A significant change in optical and electronic structure occurs with extended absorption in the visible region (470 to 600 nm) [123]. Deng et al. synthesized Z-scheme photocatalyst comprised of $\mathrm{P}$ doped ultrathin $\mathrm{g}-\mathrm{C}_{3} \mathrm{~N}_{4}$ nanosheets coated with bismuth vanadate $\left(\mathrm{BiVO}_{4}\right)$ via one-pot precipitation method. SEM image as shown in (Fig. $14 \mathrm{~g}, \mathrm{~h}$ ) is in agreement to stacked layered structure of $\mathrm{P}$ doped $\mathrm{g}-\mathrm{C}_{3} \mathrm{~N}_{4}$. The prepared photocatalyst efficiently degraded $96.95 \%$ tetracycline as compared to bare $\mathrm{BiVO}_{4}(41.45 \%)$ and pristine $\mathrm{P}$ doped ultrathin $\mathrm{g}-\mathrm{C}_{3} \mathrm{~N}_{4}(71.78 \%)$ under 60 min of visible light irradiation. A synergistic relationship between $\mathrm{P}$ doped $\mathrm{g}-\mathrm{C}_{3} \mathrm{~N}_{4}$ and $\mathrm{BiVO}_{4}$ causes enhanced charge separation efficiency and increased carrier half-life (1.65 ns).The photocatalytic Z-scheme mechanism involved photogenerated electron transfer from $\mathrm{CB}$ of $\mathrm{BiVO}_{4}(0.32 \mathrm{eV})$ to $\mathrm{VB}$ of $\mathrm{P}$ doped $\mathrm{g}-\mathrm{C}_{3} \mathrm{~N}_{4}(1.89 \mathrm{eV})$ and recombination with free holes. The holes further react with $\mathrm{H}_{2} \mathrm{O}_{2}$ forming $\mathrm{OH}$ that are responsible for the tetracycline degradation [124]. A two-step hydrothermal synthesis route was followed in fabrication of P doped hexagonal tubular structure of $\mathrm{g}-\mathrm{C}_{3} \mathrm{~N}_{4}(\mathrm{P}-\mathrm{TCN})$ with a layered stacking arrangement. The synthesis process involved: (i) in-situ hydrolysis of melamine with cyanuric acid; (ii) release of $\mathrm{P}$ from phosphoric acid on heat treatment and formation of hexagonal tubular micro nanostructures as shown in SEM image (Fig. 14i, j).The P-TCN structure displayed surface area of $22.95 \mathrm{~m}^{2} / \mathrm{g}$ more than 3.73 $\mathrm{m}^{2} / \mathrm{g}$ of $\mathrm{g}-\mathrm{C}_{3} \mathrm{~N}_{4}$ with pore size of $40-60 \mathrm{~nm}$ embedded in the tube wall which provides more active catalytic sites. The incorporation of $\mathrm{P}$ leads to decrease in band gap from $2.67 \mathrm{eV}$ to $2.55 \mathrm{eV}$ and lowering in $\mathrm{CB}$ edge from-1.0 eV to $-1.11 \mathrm{eV}$ of $\mathrm{g}-\mathrm{C}_{3} \mathrm{~N}_{4}$ and $\mathrm{P}-\mathrm{TCN}$, respectively. This $\mathrm{CB}$ negative shift of P-TCN is due to quantum confinement effect (QCE) induced by micro nanostructures [125]. Zhu et al. designed mesoporous $\mathrm{P}$ doped $\mathrm{g}-\mathrm{C}_{3} \mathrm{~N}_{4}$ nanostructure flowers via condensation and thermolysis of melamine and organo-phosphonic acid at $550^{\circ} \mathrm{C}$. The morphology of synthesized $\mathrm{P}$ doped $\mathrm{g}-\mathrm{C}_{3} \mathrm{~N}_{4}$ has interconnected nanoflower structure as depicted in (Fig. 16e) The obtained XPS results displayed in-planar coordination of $\mathrm{P}$ into $\mathrm{g}-\mathrm{C}_{3} \mathrm{~N}_{4}$ structure and delocalization of lone pair of electrons to the $\pi$-conjugated tri-s-triazine ring. A modification in optical properties is observed which 
is reflected by color change from pale yellow for bare $\mathrm{g}-\mathrm{C}_{3} \mathrm{~N}_{4}$ to dark brown for $\mathrm{P}$ doped $\mathrm{g}-\mathrm{C}_{3} \mathrm{~N}_{4}$ nanostructure and further quantification is performed by UV-vis spectroscopy. They found lowering in band gap energies and favored light absorption in visible region [126]. Additionally, Hu et al. reported interstitially $\mathrm{P}$ doped $\mathrm{g}-\mathrm{C}_{3} \mathrm{~N}_{4}$ in comparison to preferential substitutional addition at bay carbon sites. This is attributed to the type of precursor utilized which strongly determines the doping site [80]. The above research work on $\mathrm{P}$ doping has been utilized to design efficiently band gap engineered $g-\mathrm{C}_{3} \mathrm{~N}_{4}$ photocatalyst.

\subsection{Sulfur doped g- $C_{3} N_{4}$ photocatalyst}

The potency of sulfur (S) as a dopant has been widely used in the enhancement of photocatalytic activity of $\mathrm{g}-\mathrm{C}_{3} \mathrm{~N}_{4}$. On the basis of first principle studies, thermodynamic and kinetic analysis a preferred explanation on induced effects by $\mathrm{S}$ doping has been given by Sergey and Sebastian. They found that $\mathrm{S}$ atom attaches onto reactive $\mathrm{N}$-sites at the edges of tri-s-triazine $g-\mathrm{C}_{3} \mathrm{~N}_{4}$ lattice. The nature of chemical bonding between $\mathrm{N}$ and $\mathrm{S}$ has been analyzed via valence charge densities of $\mathrm{S}$ doped $\mathrm{g}-\mathrm{C}_{3} \mathrm{~N}_{4}$ and pristine $\mathrm{g}-\mathrm{C}_{3} \mathrm{~N}_{4}$. It was observed that $\mathrm{S}$ partially donates electrons from $\mathrm{p}_{\mathrm{x}}{ }^{-}$and $\mathrm{p}_{\mathrm{y}}{ }^{-}$to $\mathrm{g}-\mathrm{C}_{3} \mathrm{~N}_{4}$ and back donation of electronic charge from $\mathrm{p}_{\mathrm{z}}$ states. From the obtained configuration it was concluded that $\mathrm{S}$ atom is non-uniformly distributed and leads to shift in fermi level to $\mathrm{CB}$ causing narrowing in band gap. As a result, efficient charge separation is achieved and photocatalytic activity of synthesized doped photocatalyst is enhanced [127]. As discussed above, it was theoretically and experimentally reported that homogenous substitution of $\mathrm{N}_{(2 \mathrm{p})}$ with $\mathrm{S}_{(3 \mathrm{p})}$ results in an upward $\mathrm{VB}_{(\max )}$ shift by $0.33 \mathrm{eV}$ and simultaneous elevation in $\mathrm{CB}_{(\min )}$ by $0.45 \mathrm{eV}$, explored by ultraviolet photoelectron spectra. This unusual up-shiftment and widening of VB is accompanied with an increment in band gap from $2.73 \mathrm{eV}$ to $2.85 \mathrm{eV}$ for $\mathrm{g}-\mathrm{C}_{3} \mathrm{~N}_{4}$ and $\mathrm{S}$ doped $\mathrm{g}-\mathrm{C}_{3} \mathrm{~N}_{4}$, respectively which is endorsed to quantum confinement effect. The reduction in average particle size from $1 \mu \mathrm{m}$ to 120 $\mathrm{nm}$, is determined to be a possible factor in enlargement of band gap. Also, there is an increased surface area from $12 \mathrm{~m}^{2} / \mathrm{g}$ of $\mathrm{g}-\mathrm{C}_{3} \mathrm{~N}_{4}$ to $63 \mathrm{~m}^{2} / \mathrm{g}$ for $\mathrm{S}$ doped $\mathrm{g}-\mathrm{C}_{3} \mathrm{~N}_{4}$ contributing to photocatalytic 
oxidation of phenol under $\lambda>400 \mathrm{~nm}$ [81]. Wang et al. utilized thiourea and melamine precursors calcined at $520^{\circ} \mathrm{C}$ for the synthesis of $\mathrm{S}$ doped $\mathrm{g}-\mathrm{C}_{3} \mathrm{~N}_{4}$ photocatalyst. XPS spectral peak at $164 \mathrm{eV}$ was assigned to $\mathrm{C}-\mathrm{S}$ bond which was formed by substitution of $\mathrm{N}$ by $\mathrm{S}$ atom in $\mathrm{g}-\mathrm{C}_{3} \mathrm{~N}_{4}$ framework and a sharp peak centered at $169.3 \mathrm{eV}$ is significant for presence of $\mathrm{SO}_{4}^{-2}$. In (Fig. 11c) it is clearly shown that there is formation of impurity state below $\mathrm{CB}$ which involves rapid migration of photoinduced electrons from the impurity state to $\mathrm{CB}$ or from VB to the impurity state. Photocatalytic reduction of $\mathrm{CO}_{2}$ results showed $\mathrm{CH}_{3} \mathrm{OH}$ yield with pristine g- $\mathrm{C}_{3} \mathrm{~N}_{4}$ was $0.81 \mathrm{molg}^{-1}$ whereas for $\mathrm{S}$ dopedg- $\mathrm{C}_{3} \mathrm{~N}_{4}$ it was 1.12 molg $^{-1}$ [128]. Lu et al. designed and developed metal free $\mathrm{S}$ doped $\mathrm{g}-\mathrm{C}_{3} \mathrm{~N}_{4}$ for photocatalytic removal of radioactive pollutant $\mathrm{UO}_{2}^{+2}$ under visible light irradiation. On varying the concentrations of precursors urea and thiourea different BET surface areas are obtained i.e. $8.2,5.3,15.5,12.7 \mathrm{~m}^{2} / \mathrm{g}$ corresponding to bare $\mathrm{g}-\mathrm{C}_{3} \mathrm{~N}_{4}, \mathrm{~S}_{(0.08 \%)} / \mathrm{g}-\mathrm{C}_{3} \mathrm{~N}_{4}, \mathrm{~S}_{(0.34 \%)} / \mathrm{g}-\mathrm{C}_{3} \mathrm{~N}_{4}$ and $\mathrm{S}_{(0.49 \%)} / \mathrm{g}-\mathrm{C}_{3} \mathrm{~N}_{4}$. The photocatalytic rate of reaction and reduction of $\mathrm{UO}_{2}^{+2}$ is increased as follows; $\mathrm{S}_{(0.49 \%)} / \mathrm{g}-\mathrm{C}_{3} \mathrm{~N}_{4}\left(0.13 \mathrm{~min}^{-1}, 95 \%\right)>$ $\mathrm{S}_{(0.34 \%)} / \mathrm{g}-\mathrm{C}_{3} \mathrm{~N}_{4}\left(0.10 \mathrm{~min}^{-1}, 84 \%\right)>\mathrm{S}_{(0.08 \%)} / \mathrm{g}-\mathrm{C}_{3} \mathrm{~N}_{4}\left(0.09 \mathrm{~min}^{-1}, 80 \%\right)>\mathrm{g}-\mathrm{C}_{3} \mathrm{~N}_{4}\left(0.07 \mathrm{~min}^{-1}, 71 \%\right)$ under 20 min of visible light irradiation. From (Fig. 20) it is exemplified that band gap difference between HOMO and LUMO is lowered from $1.51 \mathrm{eV}$ to $0.81 \mathrm{eV}$ (substitution of $\mathrm{N}_{2 p}$ with $\mathrm{S}$ ) and to $0.84 \mathrm{eV}$ (substitution of $\mathrm{N}_{3 p}$ with $\mathrm{S}$ ). Furthermore expansion in $\mathrm{g}-\mathrm{C}_{3} \mathrm{~N}_{4}$ lattice is obtained due to longer $\mathrm{S}-\mathrm{C}$ (1.62-1.84 $\mathrm{A})$ bond lengths than $\mathrm{N}-\mathrm{C}$ bonds $\left(1.35 \sim 1.46^{\circ} \mathrm{A}\right)$. According to DFT calculations the formation of coordination complex is confirmed by decrease in binding energy from $-120.13 \mathrm{eV}$ for bare $\mathrm{g}-\mathrm{C}_{3} \mathrm{~N}_{4}$ to -121.00 and $121.47 \mathrm{eV}$ for $\mathrm{S}_{(0.49 \%)} / \mathrm{g}-\mathrm{C}_{3} \mathrm{~N}_{4}$ and $\mathrm{S}_{(0.08 \%)} / \mathrm{g}-\mathrm{C}_{3} \mathrm{~N}_{4}$ photocatalysts [129]. In another study, effect of temperature has been investigated in S mediated polycondensation reaction utilizing precursors melamine and TTCA. In the synthesis process-SH (thiol) group acts as the leaving group and similar electronegativity between $\mathrm{S}$ and $\mathrm{N}$ leads to structural substitution of $\mathrm{N}$ with $\mathrm{S}$. The $\mathrm{UV}$ vis spectra displays reduction in band gap to be $2.70 \mathrm{eV}, 2.72 \mathrm{eV}$ and $2.67 \mathrm{eV}$ for bulk $\mathrm{g}-\mathrm{C}_{3} \mathrm{~N}_{4}, \mathrm{~S}$ doped g- $\mathrm{C}_{3} \mathrm{~N}_{4}$ at $600^{\circ} \mathrm{C}$ and $650^{\circ} \mathrm{C}$, respectively [130]. Liang et al. synthesized a series of $\mathrm{S}$ doped g$\mathrm{C}_{3} \mathrm{~N}_{4}$ grafted with zinc phthalocyanines (ZnTNPc) using common precursor melamine and thiourea via 
thermal condensation process. A synergistic relation between $\mathrm{S}$ doped $\mathrm{g}-\mathrm{C}_{3} \mathrm{~N}_{4}$ and $\mathrm{ZnTNPc}$ was exhibited for photocatalytic removal of MB dye which was 4.4 times higher than that of ZnTNPc. From Mott-Schottky results it is revealed that incorporation of S atoms reduces the band gap and also decreases the $\mathrm{CB}$ from $-1.03 \mathrm{~V}$ to $-0.84 \mathrm{~V}$, thus promoting $\mathrm{MB}$ photocatalytic degradation [131]. Hong and co-authors prepared mpg- $\mathrm{C}_{3} \mathrm{~N}_{4}$ with in-situ addition of $\mathrm{S}$ dopant possessing higher surface area of $128 \mathrm{~m}^{2} / \mathrm{g}$ and enhanced photocatalytic activity. The synthesis process involved single precursor, thiourea which undergoes thermal decomposition and leads to formation of several intermediate compounds such as cyanamide which forms source for $\mathrm{g}_{-} \mathrm{C}_{3} \mathrm{~N}_{4}$. The proposed mechanism depicts reaction between $-\mathrm{SH}$ group with $-\mathrm{NH}_{2}$ (amine) group of cyanamide and results in formation of S-N bonds [132]. As explored by DFT calculations narrowing of band gap is attributed to formation of new electron occupied energy level bands slightly above the VB on interaction between $S_{(3 p)}$ and $N_{(2 p)}$ states. The excitation of electrons takes place from the new VB level to the $\mathrm{CB}$ of $\mathrm{g}-\mathrm{C}_{3} \mathrm{~N}_{4}$, this reduced band gap subsequently extends absorption in visible light range and increased photocatalytic activity [133]. A simple and cost effective method for fabrication of S-self dopedg- $\mathrm{C}_{3} \mathrm{~N}_{4}$ is by heating thiourea in air in temperature range of $470^{\circ} \mathrm{C}-575^{\circ} \mathrm{C}$. The TEM image (Fig. 16f) represents a crumpled lamellar morphology of $\mathrm{S}$ doped $\mathrm{g}_{-} \mathrm{C}_{3} \mathrm{~N}_{4}$. The prepared photocatalyst showed photodegradation of $\mathrm{MB}$ dye under visible light irradiation [134]. A photocatalytic temperature assisted control strategy for the photodegradation of $\mathrm{RhB}$ dye and reduction of $\mathrm{Cr}^{+6}$ was exhibited by $\mathrm{S}$ doped $\mathrm{g}-\mathrm{C}_{3} \mathrm{~N}_{4}$ [135].

\subsection{Oxygen doped g- $C_{3} N_{4}$ photocatalyst}

Oxygen $(\mathrm{O})$ doped $\mathrm{g}-\mathrm{C}_{3} \mathrm{~N}_{4}$ was successfully obtained by ultrasonic-assisted method by thermal condensation of urea in dispersion aqueous medium nitric acid $\left(\mathrm{HNO}_{3}\right)$. XPS spectra indicated peak shift from (531.8 to $532.2 \mathrm{eV}$ ) for $\mathrm{O}_{(1 \mathrm{~s})}$ and peak at $289.2 \mathrm{eV}$ which confirmed the $\mathrm{sp}^{2} \mathrm{C}$ atom bonding with $\mathrm{O}_{(1 \mathrm{~s})}$. Furthermore, absorbance intensity peaks were obtained from the FTIR spectrum at 1705, 1300 and $980 \mathrm{~cm}^{-1}$ for $\mathrm{C}=\mathrm{O}$ bonds, $\mathrm{C}-\mathrm{O}$ bonds and $\mathrm{C}-\mathrm{O}-\mathrm{C}$ bonds, respectively. An increased BET surface area from $48.48 \mathrm{~m}^{2} / \mathrm{g}$ to $107.93 \mathrm{~m}^{2} / \mathrm{g}$ significantly enhances $\mathrm{RhB}$ dye photodegradation in near 
infrared light [136]. Also, RhB dye degradation dye under anoxic conditions is studied which resulted in increment in BET surface area from $9.2 \mathrm{~m}^{2} / \mathrm{g}$ to $12.8 \mathrm{~m}^{2} / \mathrm{g}$ of $\mathrm{g}-\mathrm{C}_{3} \mathrm{~N}_{4}$ and $\mathrm{O}$ doped $\mathrm{g}-\mathrm{C}_{3} \mathrm{~N}_{4}$, respectively after 20 min of plasma treatment. A red shift in absorption and decrease in band gap energy is observed from 2.66 to $2.55 \mathrm{eV}$ after incorporation of $\mathrm{O}$ atom which contributed to increment in absorption ability for dye abatement [63]. As previously discussed above, dye sensitization was carried out using four organic dyes i.e.; eosin-Y $(\mathrm{E})$, perylene $(\mathrm{P})$, nile-red $(\mathrm{N})$ and coumarin $(\mathrm{C})$ on $\mathrm{O}$ doped $\mathrm{g}-\mathrm{C}_{3} \mathrm{~N}_{4}$ (GCNO) photocatalyst [86]. First principle calculations, based on DFT computation identified two-coordinated $\mathrm{N}$ position as the most suitable substitutional site for $\mathrm{O}$ atoms as only -0.74 $\mathrm{eV}$ formation energy is required. The integration of $\mathrm{O}$ atom narrowed band gap from 1.09 to $0.68 \mathrm{eV}$ which promoted charge separation [75]. Qui et al. synthesized porous $\mathrm{O}$ doped $\mathrm{g}_{-} \mathrm{C}_{3} \mathrm{~N}_{4}$ by condensation of urea and oxalic acid under high temperature of $550^{\circ} \mathrm{C}$. The incorporation of $\mathrm{O}$ atom into $\mathrm{g}-\mathrm{C}_{3} \mathrm{~N}_{4}$ lattice was performed of $\mathrm{sp}^{2} \mathrm{~N}$ atom and thereby lowered the band gap from $2.91 \mathrm{eV}$ to $2.07 \mathrm{eV}$. Also, there is a shift in the $\mathrm{VB}$ edge from $1.95 \mathrm{eV}$ to $2.46 \mathrm{eV}$ thus making $\mathrm{O}_{2}{ }^{-}$and $\mathrm{OH}^{\cdot}$ radicals as the major reactive species in photocatalytic removal of bisphenol A (BSA). It is observed that with increased oxalic acid concentration from 0 to $40 \%$ the BET surface area is also enlarged from 35.3 to $105.2 \mathrm{~m}^{2} / \mathrm{g}$. They claimed $56 \%$ mineralization of BSA which is ascribed to unique electronic structure and promoted light absorption up to $700 \mathrm{~nm}$ that improved charge separation and generation [137]. Guo et al. reported photo-Fenton reaction for the introduction of $\mathrm{O}$ atom into thin sheets of $\mathrm{g}-\mathrm{C}_{3} \mathrm{~N}_{4}$. The successfully synthesized holey structured $\mathrm{O}$ doped $\mathrm{g}-\mathrm{C}_{3} \mathrm{~N}_{4}$ possessed high surface area of $348 \mathrm{~m}^{2} / \mathrm{g}$ and reduced bang gap of $2.43 \mathrm{eV}$, which promoted photocatalytic degradation of RhB dye [138].

\subsection{Nitrogen, carbon, boron and halogen doped g- $C_{3} N_{4}$ photocatalyst}

A facile solid state transformation route comprised of sol-gel and thermal exfoliation techniques followed for the synthesis of $\mathrm{N}$ doped g- $\mathrm{C}_{3} \mathrm{~N}_{4}$ complexed with $\mathrm{LaTiO}_{3}(\mathrm{CLT})$. The results of photocatalytic activity by hybrid nanocomposites indicated RhB dye degradation to be $90 \%, 85 \%$ and 
$80 \%$ in case of CLT- $\left(60,40\right.$ and $20 \mathrm{wt} \%$ of $\left.\mathrm{N}-\mathrm{LaTiO}_{3}\right)$ whereas only $52 \%$ and $35 \%$ decomposition is found for $\mathrm{NLaTiO}_{3}$ and $\mathrm{g}-\mathrm{C}_{3} \mathrm{~N}_{4}$, respectively. Also, photocatalytic performance of CLT-60 is noticed in $84 \%$ eradication of 2,4-DCP in $50 \mathrm{~min}$ of visible light irradiation. The BET surface analysis and pore volume was found to be $43.0 \mathrm{~m}^{2} / \mathrm{g}$ and $0.135 \mathrm{~cm}^{3} / \mathrm{g}$ of CLT- 6 that is higher than $16.0 \mathrm{~m}^{2} / \mathrm{g}$ and $0.105 \mathrm{~cm}^{3} / \mathrm{g}$ of pristine $\mathrm{g}-\mathrm{C}_{3} \mathrm{~N}_{4}$ [139]. Fang et al. successfully prepared self $\mathrm{N}$ doped $\mathrm{g}-\mathrm{C}_{3} \mathrm{~N}_{4}$ by thermal condensation of melamine with hydrazine hydrate. The XPS data analysis revealed lowering in peak ratio from 2.87 to 1.18 consequently for $\mathrm{C} \mathrm{sp}^{2}$ and $\mathrm{C} \mathrm{sp}$ that confirmed $\mathrm{sp}^{2} \mathrm{C}$ has been substituted by $\mathrm{N}$ atom. Integration of $\mathrm{N}$ dopant induces band gap reduction from 2.72 to $2.65 \mathrm{eV}$ for bare $\mathrm{g}-\mathrm{C}_{3} \mathrm{~N}_{4}$ and $\mathrm{N}$ doped $\mathrm{g}-\mathrm{C}_{3} \mathrm{~N}_{4}[140]$.

Ran et al. designed $\mathrm{C}$ self-doped $\mathrm{g}_{-} \mathrm{C}_{3} \mathrm{~N}_{4}$ by co-pyrolysis of urea and saccharine for $\mathrm{NO}$ pollutant elimination from water. Photocatalytic mechanism has been investigated by DFT calculations and in situ DRIFTS technology to study adsorption of NO on the surface of doped photocatalyst. The localization of free electrons on substituted $\mathrm{C}$ atom and electron deficient nature of $\mathrm{N}$ atom, leads to acceptance of free electrons from $\mathrm{NO}$ and its conversion into an intermediate product nitrosyl $\left(\mathrm{NO}^{+}\right)$ which accelerates oxidation process. Furthermore, they found improved BET surface area from 81 $\mathrm{m}^{2} / \mathrm{g}$ to $118 \mathrm{~m}^{2} / \mathrm{g}$ of bulk g- $\mathrm{C}_{3} \mathrm{~N}_{4}$ and $\mathrm{C}$ self-doped $\mathrm{g}-\mathrm{C}_{3} \mathrm{~N}_{4}$, respectively also there is an increased NO removal efficiency to $56.77 \%$ after $30 \mathrm{~min}$ of visible light irradiation [141]. A synergistic effect has been observed between carbon dopant and $\mathrm{g}-\mathrm{C}_{3} \mathrm{~N}_{4}$ for photocatalytic degradation of $\mathrm{MB}$ dye. The doped nanocomposite is prepared by hydrothermal treatment on DCDA and glucose solution under thermal heating at $550^{\circ} \mathrm{C}$. The XRD peaks (Fig. 8e) at (100) and (002) planes corresponds to interplanar structural stacking. Furthermore, TEM image (Fig. 16g) indicates irregular shaped microporous structure. An experiment was performed to explicate the adsorption ability of doped g$\mathrm{C}_{3} \mathrm{~N}_{4}$ compared to bare $\mathrm{g}-\mathrm{C}_{3} \mathrm{~N}_{4}$. The maximum $97 \% \mathrm{MB}$ degradation is observed on increasing the glucose concentration from $0.0025 \mathrm{~g}$ to $0.005 \mathrm{~g}$ however, a decrease in photocatalytic activity is prevalent after an optimum increase in weight of glucose. This behavior is attributed to shading effect 
by $\mathrm{C}$ which acts as a barrier in the absorption of incident light by $\mathrm{g}-\mathrm{C}_{3} \mathrm{~N}_{4}$ [142]. Similar synthesis technique and precursors has been used at low temperature for fabrication of carbon doped $\mathrm{g}-\mathrm{C}_{3} \mathrm{~N}_{4}$ ultrathin nanosheets. Photocatalytic experiments were carried out for degradation of 4-nitrophenol (4NP) considerably displayed increased photocatalytic efficacy due to the formation of thin nanosheets, that improved separation between photogenerated EHP and sufficient visible light absorption [143]. As discussed above, $\mathrm{C}$ self-doped $\mathrm{g}-\mathrm{C}_{3} \mathrm{~N}_{4}$ has emerged as a promising photocatalyst in eradication of harmful dyes released into water bodies $[90,91]$.

A possible mechanism for boron to act as dopant states that boron atom acts as lewis acid site and forms a lewis pair on combining with lewis base sites in carbon nitride polymers. They are known to facilitate the formation of EHP and enhance the surface reactivity of photocatalyst [144].The incorporation of electron deficient $\mathrm{B}$ atom into $\mathrm{g}-\mathrm{C}_{3} \mathrm{~N}_{4}$ lattice, exhibited highly efficient reduction of radioactive uranium $\mathrm{U}(\mathrm{VI})$ to $\mathrm{U}(\mathrm{IV})$. XPS peak located at $398.2 \mathrm{eV}$ endows to N-B bonding. The obtained B doped $\mathrm{g}-\mathrm{C}_{3} \mathrm{~N}_{4}$ lowered the band gap values from 2.57 to $2.49 \mathrm{eV}$ corresponding to bare g$\mathrm{C}_{3} \mathrm{~N}_{4}$ and 0.91 wt.\% B doped $\mathrm{g}-\mathrm{C}_{3} \mathrm{~N}_{4}$ which promoted eradication of $\mathrm{UO}_{2}^{+2}$ [145]. Yan et al. designed and developed porous $\mathrm{B}$ doped $\mathrm{g}-\mathrm{C}_{3} \mathrm{~N}_{4}$ nanosheets from a robust, simple one pot facile thermal polymerization method using urea and $\mathrm{H}_{3} \mathrm{BO}_{3}$ precursor. The broadened XRD peak and increased interplanar stacking distance from 0.323 to $0.327 \mathrm{~nm}$ confirmed integration of $\mathrm{B}$ atom into $\mathrm{g}-\mathrm{C}_{3} \mathrm{~N}_{4}$ framework. A favorable synergistic association between B dopant and $g-\mathrm{C}_{3} \mathrm{~N}_{4}$ predominantly improved adsorption capacity of $\mathrm{MB}$ dye to $89 \%$ in comparison to $14 \% \mathrm{MB}$ removal by pristine $\mathrm{g}_{-} \mathrm{C}_{3} \mathrm{~N}_{4}$ with 17 times rapid reaction rate of $0.02 \mathrm{~h}^{-1}$ [146]. A successful sustainable alternative approach for photo conversion of $\mathrm{CO}_{2}$ to fuels has been achieved by B doped $\mathrm{g}_{-} \mathrm{C}_{3} \mathrm{~N}_{4}$ prepared via thermal condensation of common precursors melamine and DCDA. A reduction in band gap from 2.75 to $2.66 \mathrm{eV}$ was observed with absorption in visible light irradiation [147]. B doped $g-\mathrm{C}_{3} \mathrm{~N}_{4}$ was also prepared via borane $\left(\mathrm{BH}_{3} \mathrm{NH}_{3}\right)$ source and substitution of $\mathrm{C}$ atoms with $\mathrm{B}$ dopant for desirable $\pi$-bonded electronic 
configuration and tunable band gap [148]. In a similar work calcination process was carried with precursors sodium tetraphenyl boron and urea for the photodegradation of phenol and MO dye [149].

Fluorinated $\mathrm{g}-\mathrm{C}_{3} \mathrm{~N}_{4}$ heterogeneous photocatalyst was designed and developed for the purpose of oxidation of benzene to phenol and further non-toxic compounds under visible light irradiation. The preparation has been initiated by incorporation of $\mathrm{NH}_{4} \mathrm{~F}$ into $\mathrm{g}-\mathrm{C}_{3} \mathrm{~N}_{4}$ lattice via thermal condensation process. The XRD peak patterns revealed partial conversion of $\mathrm{sp}^{2} \mathrm{C}$ to $\mathrm{sp}^{3} \mathrm{C}$ due to bond formation between highly electronegative F species with C. Moreover, XPS peak at $686.2 \mathrm{eV}$ was attributed to the F-C bond. Furthermore, DFT calculations indicated shift in both HOMO and LUMO to higher energy levels on incorporation of $\mathrm{F}$ at bay carbon. However, it was observed that introduction of $\mathrm{F}$ dopant at corner C site up-shifted LUMO to higher energy levels and HOMO to lower energy levels, thus promoted photocatalysis. A reduction in band gap from $2.69 \mathrm{eV}$ to $2.63 \mathrm{eV}$ of bare $\mathrm{g}-\mathrm{C}_{3} \mathrm{~N}_{4}$ and $\mathrm{F}$ doped $\mathrm{g}-\mathrm{C}_{3} \mathrm{~N}_{4}$ was obtained with an extension of spectrum in visible region [150]. Bromine (Br) modified $\mathrm{g}-\mathrm{C}_{3} \mathrm{~N}_{4}$ based photocatalyst was fabricated through one-pot co-condensation of urea with $\mathrm{NH}_{4} \mathrm{Br}$. The optimized concentration of $\mathrm{NH}_{4} \mathrm{Br}(0.1 \mathrm{~g})$ improved BET surface area to $55 \mathrm{~m}^{2} / \mathrm{g}$ but an increase in wt. to $0.3-0.5 \mathrm{~g}$ of $\mathrm{NH}_{4} \mathrm{Br}$ led to texture and surface morphology defects with surface area $24 \mathrm{~m}^{2} / \mathrm{g}$ (Fig. 12c) [151]. Zhang et al. for the first time synthesized halogen doped $\mathrm{g}-\mathrm{C}_{3} \mathrm{~N}_{4}$ using hydrothermal post-treatment on melamine and $\mathrm{NH}_{4} \mathrm{Br} / \mathrm{NH}_{4} \mathrm{Cl}$ to enhance photocatalytic efficiency. They gave a comparative study of as-prepared photocatalysts and found $\mathrm{Br}$ doped $\mathrm{g}-\mathrm{C}_{3} \mathrm{~N}_{4}$ displayed a higher surface area, maximum decrease in band gap of $24.2 \mathrm{~m}^{2} / \mathrm{g}, 2.53 \mathrm{eV}$ than $11.6 \mathrm{~m}^{2} / \mathrm{g}, 2.62 \mathrm{eV}$ and $8.5 \mathrm{~m}^{2} / \mathrm{g}, 2.68 \mathrm{eV}$ of $\mathrm{Cl}$ doped $\mathrm{g}-\mathrm{C}_{3} \mathrm{~N}_{4}$ and bare $\mathrm{g}-\mathrm{C}_{3} \mathrm{~N}_{4}$, respectively. From the above observations it was concluded, $\mathrm{Br}$ atom is a better dopant that $\mathrm{Cl}$ due to more delocalization of valence electrons over the $\pi$ electron cloud of $\mathrm{g}_{-} \mathrm{C}_{3} \mathrm{~N}_{4}$ ascribed to lower electronegativity of $\mathrm{Br}$ [152]. Han et al. reported a cost effective approach, ball-milling method for mass production of I doped $g-\mathrm{C}_{3} \mathrm{~N}_{4}$ nanosheets. They found substitution of $\mathrm{Nsp}^{2}$ by I dopant due to lower formation energy and negligible steric hindrance as compared to $\mathrm{Nsp}^{3}$. BET analysis showed an increase in surface area to eight fold $\left(80.2 \mathrm{~m}^{2} / \mathrm{g}\right)$ than 
bulk g- $\mathrm{C}_{3} \mathrm{~N}_{4}$ [153]. Similarly, iodine (I) introduction in $\mathrm{g}-\mathrm{C}_{3} \mathrm{~N}_{4}$ framework has successfully enlarged surface area from 12 to $23 \mathrm{~m}^{2} / \mathrm{g}$ also reduced band gap from $2.75 \mathrm{eV}$ to $2.69 \mathrm{eV}$ for $\mathrm{g}_{-} \mathrm{C}_{3} \mathrm{~N}_{4}$ and I doped $\mathrm{g}_{-} \mathrm{C}_{3} \mathrm{~N}_{4}$, respectively, thus inhibited charge recombination [154]. Li et al. designed and synthesized dysprosium orthovanadate $\left(\mathrm{DyVO}_{4}\right)$ heterojunction with I doped $\mathrm{g}-\mathrm{C}_{3} \mathrm{~N}_{4}$ by calcining the mixture of DCDA, ammonium iodine and $\mathrm{DyVO}_{4}$ at $550^{\circ} \mathrm{C}$. The prepared composite at optimized weight percentage of $6.3 \%$ possessed BET surface area of $50 \mathrm{~m}^{2} / \mathrm{g}$ higher than that of pristine $\mathrm{g}-\mathrm{C}_{3} \mathrm{~N}_{4}$, DyVO $_{4}$, I doped $\mathrm{g}_{-} \mathrm{C}_{3} \mathrm{~N}_{4}$ at $7,20,22 \mathrm{~m}^{2} / \mathrm{g}$, respectively. Furthermore, a narrowed optical band gap is achieved i.e. from $2.70 \mathrm{eV}$ of $\mathrm{g}-\mathrm{C}_{3} \mathrm{~N}_{4}$ and $2.68 \mathrm{eV}$ of I doped $\mathrm{g}-\mathrm{C}_{3} \mathrm{~N}_{4}$ to $2.32 \mathrm{eV}$ of $\mathrm{DyVO}_{4} / \mathrm{I}$ doped g$\mathrm{C}_{3} \mathrm{~N}_{4}$ which extended absorption to $700 \mathrm{~nm}$ in visible region. These improved properties contributed to $65 \%$ removal of $\mathrm{MB}$ dye by $6.3 \% \mathrm{DyVO}_{4} / \mathrm{I}$ doped $\mathrm{g}-\mathrm{C}_{3} \mathrm{~N}_{4}$, whereas only $21 \%, 35 \%$ and $8 \%$ of $\mathrm{MB}$ eradication was obtained consequently by bulk g- $\mathrm{C}_{3} \mathrm{~N}_{4}$, I doped $\mathrm{g}-\mathrm{C}_{3} \mathrm{~N}_{4}$ and $\mathrm{DyVO}$ after $4 \mathrm{hr}$ of visible light irradiation [155]. Zhu et al. explored monolayer $\mathrm{g}-\mathrm{C}_{3} \mathrm{~N}_{4}$ potency to incorporate halogen dopant on interstitial sites. They concluded on the basis of DFT calculations and formation energy values that F and $\mathrm{Cl}$ species has moderate atomic radii and requires only $1.15 \mathrm{eV}$ and $3.52 \mathrm{eV}$ for interstitial addition into g- $\mathrm{C}_{3} \mathrm{~N}_{4}$ lattice. However, $\mathrm{Br}$ and I species have larger atomic radii of $(1.03 \AA$ and $1.39 \AA)$ much greater than those of $\mathrm{C}$ and $\mathrm{N}$ atoms $(0.65 \AA$ and $0.54 \AA)$ also formation energies are higher i.e. $3.67 \mathrm{eV}$ and $3.36 \mathrm{eV}$, hence cannot undergo substitution. Therefore, halogen atoms preferentially dope into the interstitial site of $\mathrm{g}-\mathrm{C}_{3} \mathrm{~N}_{4}$ lattice. Further studies revealed involvement of $\mathrm{F}$ dopant in lowering of $\mathrm{VB}$ and hence located in $\mathrm{HOMO}$, whereas other halogen impurities constitute $\mathrm{CB}$ and are dominated in LUMO this exceptional nature of F is ascribed to its high electronegativity (4.0 eV) [57].

\section{Co-doping of $g-\mathrm{C}_{3} \mathrm{~N}_{4}$ as photocatalyst for water purification}

The purpose of increased photocatalytic efficiency can also be achieved by co-doping and tridoping of metals and non-metals into $\mathrm{g}_{-} \mathrm{C}_{3} \mathrm{~N}_{4}$ lattice. From the study of literature it is evident that doping of two or more elements significantly overcomes the limitations prevailing in hierarchical structure of bulk $g-\mathrm{C}_{3} \mathrm{~N}_{4}$. Duo et al. designed and synthesized $\mathrm{Fe}^{+2}$ and $\mathrm{S}$ co-doped $\mathrm{g}-\mathrm{C}_{3} \mathrm{~N}_{4}$ by 
calcifying melamine, $\mathrm{FeCl}_{3}$ and TTCA at $550{ }^{\circ} \mathrm{C}$. The XRD peak at (100) and (002) planes confirms the interlayer stacking structure of $g-\mathrm{C}_{3} \mathrm{~N}_{4}$ as shown in (Fig. 9f). SEM image (Fig. 14k) shows irregular porous structure of co-doped $\mathrm{g}-\mathrm{C}_{3} \mathrm{~N}_{4}$. An increased pore area are obtained for Fe-S co-doped g- $\mathrm{C}_{3} \mathrm{~N}_{4}$ i.e. $75.84 \mathrm{~m}^{2} / \mathrm{g}$, as compared to $15.48 \mathrm{~m}^{2} / \mathrm{g}$ of pure $\mathrm{g}-\mathrm{C}_{3} \mathrm{~N}_{4}$ and $53.53 \mathrm{~m}^{2} / \mathrm{g}$ of $\mathrm{Fe}^{+2}$ doped $\mathrm{g}-\mathrm{C}_{3} \mathrm{~N}_{4}$. A synergistic effect of both co-dopants was observed for $91 \% \mathrm{RhB}$ dye photocatalytic eradication under 60 min visible light irradiation [156]. Ball milling and annealing of precursors DCDA, ferric nitrate and diammonium hydrogen phosphate resulted in synthesis of $\mathrm{Fe}$ and $\mathrm{P}$ co-doped $\mathrm{g}-\mathrm{C}_{3} \mathrm{~N}_{4}$ for application of RhB dye degradation. From XPS spectra and (Fig. 18c) it was deduced that Fe and P atoms form coordination bond with $\mathrm{N}$ at interstitial site in two different lattices as maximum in-planar distance of nitride pores $0.71 \mathrm{~nm}$ was not sufficient to accommodate both elements. Due to the higher electronegativity of $\mathrm{N}$ atom only two $\mathrm{N}$ atoms coordinates with $\mathrm{P} 2 \mathrm{p}$ atom as confirmed by higher binding energy of $132.5 \mathrm{eV}$. The prepared Fe and $\mathrm{P}$ co-doped $\mathrm{g}-\mathrm{C}_{3} \mathrm{~N}_{4}$ possessed a higher BET surface area of $17.5 \mathrm{~m}^{2} / \mathrm{g}$ than $10.9 \mathrm{~m}^{2} / \mathrm{g}$ of bare $\mathrm{g}-\mathrm{C}_{3} \mathrm{~N}_{4}$ and reduced band gap from 2.62 to $1.95 \mathrm{eV}$ [157]. Hu et al. designed and synthesized $\mathrm{O}$ functionalized S-P co-doped $\mathrm{g}-\mathrm{C}_{3} \mathrm{~N}_{4}$ anoxic photocatalyst, through hydrothermal treatment of thiourea and ammonium hydrogen phosphate. They found photocatalytic degradation of $\mathrm{RhB}$ dye to be $92 \%$ in 120 min under anoxic environment, inhibited crystal growth of g- $\mathrm{C}_{3} \mathrm{~N}_{4}$, reduced band gap and enhanced adsorption ability of co-doped $\mathrm{g}_{-} \mathrm{C}_{3} \mathrm{~N}_{4}$ to capture photogenerated electrons [158]. Similarly, degradation of various dyes like MB, MO, RhB and phenol are evaluated under anoxic conditions through P-O co-doped $\mathrm{g}-\mathrm{C}_{3} \mathrm{~N}_{4}$ photocatalyst synthesized via hydrothermal assisted dissolution-precipitation process. The PL spectra in (Fig. 8d) has a broad peak at $465 \mathrm{~nm}$ and results in increased ROS separation. The BET surface calculations revealed an increased surface area from $4.9 \mathrm{~m}^{2} / \mathrm{g}$ to $92.5 \mathrm{~m}^{2} / \mathrm{g}$ as shown in (Fig. 12d) [159]. In another study the successful incorporation of heteroatom's $\mathrm{K}$ and $\mathrm{P}$ into $\mathrm{g}-\mathrm{C}_{3} \mathrm{~N}_{4}$ framework and surface composition was unveiled via results of XPS spectra. The binding energy peaks at 292.6 and $295.2 \mathrm{eV}$ are ascribed to $\mathrm{K} 2 \mathrm{p}_{3 / 2}$ and $2 \mathrm{p}_{1 / 2}$ involved in K-N bond. The TEM image (Fig. 16h) shows layered nonporous nanosheet structure 
of K-P co-doped $\mathrm{g}-\mathrm{C}_{3} \mathrm{~N}_{4}$. The substitution of the $\mathrm{C}$ species by $\mathrm{P}$ in $\mathrm{g}-\mathrm{C}_{3} \mathrm{~N}_{4}$ network is attributed to significant peaks at 133.0 and $134.1 \mathrm{eV}$ is due to P-N bond [160]. Zhao et al. designed band gap modulated $\mathrm{K}$ and $\mathrm{Na}$ co-doped $\mathrm{g}-\mathrm{C}_{3} \mathrm{~N}_{4}$ annealing mixture of eutectic salts $(\mathrm{KCl}-\mathrm{NaCl})$ with melamine precursor. Elemental analysis results depicted interstitial doping of $\mathrm{Na}^{+}$and $\mathrm{K}^{+}$as the maximum inplanar distance of nitride pores, $0.71 \mathrm{~nm}$ is sufficient to intake both dopants. It was further observed that with a controllable increase in weight ratio of eutectic salts to melamine there is modulation in $\mathrm{CB}$ from -1.09 to $-0.29 \mathrm{eV}$ and $\mathrm{VB}$ from +1.55 to $+2.25 \mathrm{eV}$. The tuned band gap and increased BET surface area from 8.9 to $59.2 \mathrm{~m}^{2} / \mathrm{g}$ of pristine $\mathrm{g}-\mathrm{C}_{3} \mathrm{~N}_{4}$ and co-doped $\mathrm{g}-\mathrm{C}_{3} \mathrm{~N}_{4}$ photocatalyst increased $\mathrm{RhB}$ dye photocatalytic degradation to $90 \%$ and also inhibited crystal growth of $\mathrm{g}-\mathrm{C}_{3} \mathrm{~N}_{4}$ [161]. Another studies involved $\mathrm{K}$ and $\mathrm{Cl}$ introduction in $\mathrm{g}-\mathrm{C}_{3} \mathrm{~N}_{4}$ matrix for photocatalytic $\mathrm{NO}$ removal [162]. Experimental and theoretical studies have proved that incorporation of co-dopants more efficiently advances the photocatalytic properties of $\mathrm{g}-\mathrm{C}_{3} \mathrm{~N}_{4}$ photocatalyst. A comparative SEM images (Fig. 141) reveals a huge lamellar-like microstructure morphology of Fe doped g- $\mathrm{C}_{3} \mathrm{~N}_{4}$ whereas in (Figure $14 \mathrm{~m}$ ) C-Fe doped $\mathrm{g}-\mathrm{C}_{3} \mathrm{~N}_{4}$ has a transformed morphology to curved stacked sheets. The synergistic outcome is prevalent in case of $\mathrm{C}$ and $\mathrm{Fe}$ co-doped $\mathrm{g}-\mathrm{C}_{3} \mathrm{~N}_{4}$ ascribed to following obtained results: i) tailored band gap from 2.77 to $2.62,2.54,2.31 \mathrm{eV}$ for bulk g- $\mathrm{C}_{3} \mathrm{~N}_{4}$, Fe doped $\mathrm{g}-\mathrm{C}_{3} \mathrm{~N}_{4}, \mathrm{C}$ doped $\mathrm{g}-\mathrm{C}_{3} \mathrm{~N}_{4}$ and $\mathrm{C}$ Fe co-doped $\mathrm{g}_{-} \mathrm{C}_{3} \mathrm{~N}_{4}$, respectively extended light absorption to $537 \mathrm{~nm}$ in visible region; ii) increased BET surface area from 22 to $66 \mathrm{~m}^{2} / \mathrm{g}$ and smaller particle size from 14.935 to $10.162 \mathrm{~nm}$ for pristine g$\mathrm{C}_{3} \mathrm{~N}_{4}$ and co-doped $\mathrm{g}-\mathrm{C}_{3} \mathrm{~N}_{4}$ inhibited the photo excitons recombination; iii) a remarkable positive VB $+1.50 \mathrm{eV}$ favored oxidation ability of co-doped $\mathrm{g}-\mathrm{C}_{3} \mathrm{~N}_{4}$. These improved photocatalytic properties exhibited $100 \%$ RhB dye eradication within 180 min under visible-light irradiation, whereas only $17 \%$ of $\mathrm{RhB}$ was removed by bare $\mathrm{g}-\mathrm{C}_{3} \mathrm{~N}_{4}$ under same conditions [163]. Reactive rare alkali metals cesium (Cs) and rubidium $(\mathrm{Rb})$ were effectively intercalated as co-dopants in interlayers of $\mathrm{g}_{-} \mathrm{C}_{3} \mathrm{~N}_{4}$ via copyrolysis to maximize NO removal [164]. Further investigations have emerged new insights into design and fabrication of tri-doped S-Co-O g- $\mathrm{C}_{3} \mathrm{~N}_{4}$ photocatalyst. A decreased surface area is obtained 
due to irregular nanorods and nano-plates formation as shown in (Fig. 14n, o). A two-step synthesis process was carried, firstly mixture of thiourea and $\mathrm{Co}\left(\mathrm{NO}_{3}\right)_{2} \cdot 6 \mathrm{H}_{2} \mathrm{O}$ precursors were annealed followed by hydrothermal post-treatment in absence of hydrogen peroxide. From the prepared tri-doped S-Co-O g- $\mathrm{C}_{3} \mathrm{~N}_{4}$ photocatalyst characterization results it was observed that $95 \% \mathrm{RhB}$ dye was degraded within $120 \mathrm{~min}$ in anoxic environment [165].

\section{Other potential applications of modulated $g-C_{3} N_{4}$}

Apart from aforementioned photocatalytic water purification, doped $\mathrm{g}-\mathrm{C}_{3} \mathrm{~N}_{4}$ nanohybrids have potential application in water splitting, hydrogen production, photocatalytic air purification, $\mathrm{CO}_{2}$ reduction and photo electrochemical devices for solar energy storage.166].Water splitting via sunlight is an economic means to produce $\mathrm{H}_{2}$ as exemplified via copolymerization of phenyl urea with precursor urea leading to a notable improvement by a factor of 9 in an assay of $\mathrm{H}_{2}$ production extending into visible spectrum[167]. Li et al. found photocatalytic $\mathrm{H}_{2}$ evolution activity to be 5 times faster in the sample prepared via glycine as compared to pristine $\mathrm{g}-\mathrm{C}_{3} \mathrm{~N}_{4}$ synthesized via traditional precursors; urea, DCDA, melamine and thiourea [168]. Boron nitride quantum dots decorated on g$\mathrm{C}_{3} \mathrm{~N}_{4}$ exhibited oxytetracycline hydrochloride degradation and effective generation of $\mathrm{H}_{2}$ [169]. A metal free phosphorene/g- $\mathrm{C}_{3} \mathrm{~N}_{4}$ involving van der Walls interactions in heterostructure for improved photocatalytic $\mathrm{H}_{2}$ production activity as compared to Pt decorated $\mathrm{g}-\mathrm{C}_{3} \mathrm{~N}_{4}$ [170]. It is worth mentioning that poly triazine imide and poly heptazine imide which are visible-light-responsive exhibits captivating results in $\mathrm{H}_{2}$ generation [171-175]. In another work a sulfur mediated synthesis approach to modify $\mathrm{g}_{-} \mathrm{C}_{3} \mathrm{~N}_{4}$ properties resulted in optimized photocatalytic ability for water reduction [176]. Impregnation of $\mathrm{Co}^{+2}$ in $\mathrm{g}-\mathrm{C}_{3} \mathrm{~N}_{4}$ network enhanced light-induced water oxidation ability of bare g$\mathrm{C}_{3} \mathrm{~N}_{4}[177]$.

The practical large scale application of $\mathrm{g}-\mathrm{C}_{3} \mathrm{~N}_{4}$ as photoanode in PEC cells has envisaged the requirement to store solar energy into chemical fuels to meet energy demands [178]. Fang et al. 
observed that sulfur atom act as adhesive interface on polymeric carbon nitride (PCN) film and exhibit high PEC efficiency in photocatalytic water splitting [179]. Also, coating of PCN served as charge collectors onto yttrium doped $\mathrm{ZnO}$ photoanode to promote water splitting [180]. Furthermore, it has been explored by Ruan and co-workers that nanolayer doping by boron dopant enhances the PEC efficiency by lowering band gap from $2.7 \mathrm{eV}$ to $2.65 \mathrm{eV}$ [181].

The mitigating effect of toxic gases in the environment induced the advancements of photocatalytic technology for efficient air purification. Recently, Cui et al. anchored oxygen/barium dopants onto PCN fabricated via one-step in situ co-pyrolysis of urea with barium carbonate $\left(\mathrm{BaCO}_{3}\right)$. The obtained photocatalyst enhanced nitrous oxide (NO) removal and inhibited the release of toxic intermediates [182]. Similarly, co-pyrolysis of urea with strontium carbonate $\left(\mathrm{SrCO}_{3}\right)$ revealed photocatalytic oxidation of NO $[183,184]$. In another study it was observed that more side-products $\left(\mathrm{NO}_{2}{ }^{-}, \mathrm{NO}_{3}{ }^{-}\right)$are released over $\mathrm{O} / \mathrm{K}$ intercalated $\mathrm{g}-\mathrm{C}_{3} \mathrm{~N}_{4}$ as compared to bare $\mathrm{g}-\mathrm{C}_{3} \mathrm{~N}_{4}$ to impede the toxic $\mathrm{NO}_{2}$ accumulation [185]. In order to improve the $\mathrm{NO}$ removal efficiency, tailoring of rate determining step during photocatalysis process has been successfully performed in Ca intercalated g$\mathrm{C}_{3} \mathrm{~N}_{4}$ [186]. A suitable substitute for noble metal is bismuth (Bi) and manganese (Mn) atom, incorporated into $\mathrm{g}_{-} \mathrm{C}_{3} \mathrm{~N}_{4}$ framework for $\mathrm{NO}$ degradation under visible light illumination [187,188]. The above discussion exemplifies the overwhelmingly diversified applications of $\mathrm{g}_{-} \mathrm{C}_{3} \mathrm{~N}_{4}$ as photocatalyst and the various possibilities for rendering a large span of solar spectrum by virtue of its extraordinary properties. In light of this, we would like to highlight that modulated $g-\mathrm{C}_{3} \mathrm{~N}_{4}$ will lead to a rational and unprecedented breakthroughs in the journey of fetching practical benefits of photocatalysis.

\section{Conclusion and future aspects}

For the development of cleaner and sustainable environment, $\mathrm{g}-\mathrm{C}_{3} \mathrm{~N}_{4}$ has fascinated researchers for the protagonist role in applications of water treatment, air purification, organic pollutant degradation, water splitting, formation of photoelectrochemical cells for solar energy storage and reduction of $\mathrm{CO}_{2}$ 
to renewable hydrocarbon fuels. The cornucopia properties associated with $\mathrm{g}-\mathrm{C}_{3} \mathrm{~N}_{4}$ based nanomaterials have remarkably boosted its photocatalytic activity. From the review of literature, it is evident that bare $\mathrm{g}-\mathrm{C}_{3} \mathrm{~N}_{4}$ has inherent limitations such as low surface area, large band gap and high recombination rate of charge carriers which reduces its photocatalytic efficiency. To address these shortfalls there are certain recognized criteria's to be fulfilled, including (1) complete utilization of solar energy from UV to NIR region, (2) facilitated separation of photo-carriers, and (3) enhancement of photocatalytic surface area to strengthen the anchoring ability of $\mathrm{g}_{-} \mathrm{C}_{3} \mathrm{~N}_{4}$. Since there are many research articles in evidence of $\mathrm{g}-\mathrm{C}_{3} \mathrm{~N}_{4}$ as photoactive materials, we herein presented a comprehensive overview of photocatalytic degradation mechanism, various noble metal free doping synthesis strategies to enrich the electronic and optical properties of $g-\mathrm{C}_{3} \mathrm{~N}_{4}$.

\section{Current Scenario}

Until now, significant research is focused on utilizing noble metal free doping of $g-\mathrm{C}_{3} \mathrm{~N}_{4}$ due to abundance, cost effective and chemical stability of noble metal free dopants. Mainly, metal, non-metal, transition metal and rare earth metals have been explored as noble metal free dopants and they are known to significantly improve photocatalytic ability of bare $\mathrm{g}-\mathrm{C}_{3} \mathrm{~N}_{4}$. The properties such as enhanced visible light response, tailored band gap, prolonged photo carriers lifetime, facile synthesis techniques with high thermal and chemical stability which subsequently makes noble metal free doped $g-\mathrm{C}_{3} \mathrm{~N}_{4}$ an ideal candidate for environment remediation. Precisely, the vital characteristics for improved photocatalytic performance of doped $\mathrm{g}_{-} \mathrm{C}_{3} \mathrm{~N}_{4}$ are extended $\pi$-conjugated structure, larger BET surface area and porosity which provides more catalytic reaction sites. Furthermore, tuned electronic structure leads to orbital hybridization between impurity orbital and molecular orbital of $g-\mathrm{C}_{3} \mathrm{~N}_{4}$ and increases charge separation. The interstitial and substitutional addition is governed by the atomic radii of both dopant and host $\mathrm{g}-\mathrm{C}_{3} \mathrm{~N}_{4}$. With all these beneficial transformations in $\mathrm{g}-\mathrm{C}_{3} \mathrm{~N}_{4}$ structure there are chances that vacancies and newly formed energy bands may act as recombination sites, moreover thermal stability of element dopants are poor, thus leading to decreased quantum efficiency. These shortfalls 
need to be resolved to elucidate fundamental structural and mechanistic transformation to fetch a better understanding of photocatalytic activity. 


\section{Challenges for future research}

Although there has been diversified study on doping of $\mathrm{g}-\mathrm{C}_{3} \mathrm{~N}_{4}$, but for the large scale application of noble metal free doped $\mathrm{g}-\mathrm{C}_{3} \mathrm{~N}_{4}$ photocatalyst there remains several challenges such as; doping mechanism, site of attachment of dopant, assessment of integration and visible light absorption still remains to be unraveled. In accordance to the future aspects and requirements a novel paradigm for attainment of high quantum degradation efficiency. The emphasis is to ameliorate the oxidative and reductive nature of $\mathrm{g}-\mathrm{C}_{3} \mathrm{~N}_{4}$ responsible for photodegradation of pollutants and evolution of $\mathrm{H}_{2}$ and $\mathrm{O}_{2}$, respectively. Hence, for designing and fabrication of robust and efficient noble metal free doped g$\mathrm{C}_{3} \mathrm{~N}_{4}$ based photocatalytic systems, following key directions must be taken into consideration:

(1) The researchers should focus on extending light harvesting range from UV to NIR spectrum to avail extensive renewable solar energy to deteriorate environmental implications via bio-friendly photocatalytic system. For this, noble metal free $\mathrm{g}-\mathrm{C}_{3} \mathrm{~N}_{4}$ should be combined with plasamonic photocatalyst or metal/carbon quantum dots.

(2) The role of various morphologies such as nanofibers, nanotubes, nanosheets, nanorods and mesoporous structure of $\mathrm{g}-\mathrm{C}_{3} \mathrm{~N}_{4}$ must be explored for achieving higher surface area. Generally, it is accepted that two dimensional (2D) morphology is highly suited for catalytic application and must be preferred for designing of noble metal free doped $\mathrm{g}-\mathrm{C}_{3} \mathrm{~N}_{4}$ based photocatalysts. 2D photocatalysts have more catalytic reaction sites for anchoring of pollutants, thereby enhancing its photocatalytic ability.

(3) The isolation and quick recovery of noble metal free doped $g-\mathrm{C}_{3} \mathrm{~N}_{4}$ photocatalysts are highly needed for higher recyclability of photocatalysts. The researchers should dope $g-C_{3} \mathrm{~N}_{4}$ with magnetic dopants like iron oxide and ferrites having paramagnetic/superparamagnetic nature. 
4. The development of innovative, feasible, facile and cost-effective fabrication methods should be adopted for the synthesis. Non-metal doping of $\mathrm{g}-\mathrm{C}_{3} \mathrm{~N}_{4}$ is preferred due to less thermal variation, high cost and scarcity of metallic dopants. Moreover, researcher should try to find more innovative way to improve overall efficacy of synthesis method using microwave radiations assisted polycondensation methods.

Therefore, advancements and contributions in this field of research has aspired scientific community to pave way for commercial application of element doped $\mathrm{g}-\mathrm{C}_{3} \mathrm{~N}_{4}$ photocatalysts. The accompanied collaborations of experimental and theoretical investigations will without doubt be able to diminish environment related subject issues comprehensively discussed in this review article.

\section{Acknowledgement}

The corresponding author, Dr. Pankaj Raizada is grateful to Science and Engineering Research Board- DST (SERB), Department of Science and Technology (DST) New Delhi, India for financial support through Young Scientist Fast Track research project no. YSS/2015/000898. 


\section{References:}

[1]. S. Banerjee, S. C. Pillai, P. Falaras, K. E. O’shea, J. A. Byrne and D. D. Dionysiou, New insights into the mechanism of visible light photocatalysis, J. Phys. Chem. Lett. 5 (2014) 2543-2554, DOI: 10.1021/jz501030x.

[2]. B. Priya, P. Raizada, N. Singh, P. Thakur, P.J.J.O.C. Singh, Adsorptional photocatalytic mineralization of oxytetracycline and ampicillin antibiotics using $\mathrm{Bi}_{2} \mathrm{O}_{3} / \mathrm{BiOCl}$ supported on graphene sand composite and chitosan, J. Colloid Interface Sci. 479 (2016) 271-283, DOI: $10.1016 /$ j.jcis.2016.06.067.

[3]. S. Gautam, P. Shandilya, V.P. Singh, P. Raizada, P. Singh, Solar photocatalytic mineralization of antibiotics using magnetically separable $\mathrm{NiFe}_{2} \mathrm{O}_{4}$ supported onto graphene sand composite and bentonite, J. Water Process Eng. 14 (2016) 86-100, DOI: 10.1016/j.jwpe.2016.10.008.

[4]. V. K. Gupta, D. Pathania, P. Singh, Pectin-cerium (IV) tungstate nanocomposite and its adsorptional activity for removal of methylene blue dye, Int. J. Environ. Sci. Technol. 11 (2014) 2015-2024

[5]. P. Raizada, J. Kumari, P. Shandilya, P. Singh, Kinetics of photocatalytic mineralization of oxytetracycline and ampicillin using activated carbon supported $\mathrm{ZnO} / \mathrm{ZnWO}_{4}$, Desalin. Water Treat. 79 (2017) 204-213, DOI: 10.5004/dwt.2017.20831.

[6]. P. Singh, S. Gautam, P. Shandilya, B. Priya, V.P. Singh, P. Raizada, Graphene bentonite supported $\mathrm{ZnFe}_{2} \mathrm{O}_{4}$ as super-paramagnetic photocatalyst for antibiotic degradation, Adv. Mater. Lett. 8 (2017) 229-238, DOI: 10.5185/amlett.2017.1467.

[7]. P. Singh, Sonu, P. Raizada, A. Sudhaik, P. Shandilya, P. Thakur, S. Agarwal, V.K. Gupta, Enhanced photocatalytic activity and stability of $\mathrm{AgBr} / \mathrm{BiOBr} /$ graphene heterojunction for phenol degradation under visible light, J. Saudi Chem. Soc. (2018), DOI: 10.1016/j.jscs.2018.10.005. 
[8]. S. Gautam, P. Shandilya, B. Priya, V.P Singh, P. Raizada, R. Rai, M.A. Valente, P. Singh: Superparamagnetic $\mathrm{MnFe}_{2} \mathrm{O}_{4}$ dispersed over graphitic carbon sand composite and bentonite as magnetically recoverable photocatalyst for antibiotic mineralization. Sep. Purif. Technol. 172 (2016) 498-511, DOI: 10.1016/j.seppur.2016.09.006.

[9]. G. Mamba, A. Mishra, Graphitic carbon nitride $\left(\mathrm{g}-\mathrm{C}_{3} \mathrm{~N}_{4}\right)$ nanocomposites: a new and exciting generation of visible light driven photocatalysts for environmental pollution remediation, Appl. Catal., B, 198 (2016) 347-377, DOI: 10.1039/C2CP42484C.

[10]. P. Singh, P. Raizada, D. Pathania, G. Sharma, P. Sharma, Microwave induced KOH activation of guava peel carbon as an adsorbent for congo red dye removal from aqueous phase, Indian J. Chem. 20(5) (2013) 305-311.

[11]. P. Singh, P. Raizada, D. Pathania, A. Kumar, P. Thakur, Preparation of BSA-ZnWO nanocomposites with enhanced adsorptional photocatalytic activity for methylene blue degradation, Int. J. Photoenergy, 2013 (2013) 1-7, DOI: 10.1155/2013/726250.

[12]. B. Pare, S.B. Jonnalagadda, H. Tomar, P. Singh, V.W. Bhagwat, ZnO assisted photocatalytic degradation of acridine orange in aqueous solution using visible irradiation, Desalination, 232 (2008) 80-90, DOI: 10.1016/j.desal.2008.01.007.

[13]. Y. Shiraishi, S. Kanazawa, Y. Sugano, D. Tsukamoto, H. Sakamoto, S. Ichikawa, T. Hirai, Highly Selective Production of Hydrogen Peroxide on Graphitic Carbon Nitride $\left(\mathrm{g}-\mathrm{C}_{3} \mathrm{~N}_{4}\right)$ Photocatalyst Activated by Visible Light, ACS Catal. 4 (2014) 774-780, DOI: $\underline{10.1021 / \operatorname{cs} 401208 \mathrm{c} .}$

[14]. H. Yi, D. Huang, G. Zeng, C. Lai, L. Qin, M. Cheng, S. Ye, B. Song, X. Ren, X. Guo, Selective prepared carbon nanomaterials for advanced photocatalytic application in environmental pollutant treatment and hydrogen production, Appl. Catal., B, 239 (2018) 408-424, DOI: 10.1016/j.apcatb.2018.07.068. 
[15]. D.B. Miklos, C. Remy, M. Jekel, K.G. Linden, J.E. Drewes, U.J.W.R. Hübner, Evaluation of advanced oxidation processes for water and wastewater treatment-A critical review, Water Res. 139 (2018) 118-131, DOI: 10.1016/j.watres.2018.03.042.

[16]. B. Pare, P. Singh, S.B. Jonnalgadda, Degradation and mineralization of Victoria blue B dye in a slurry photoreactor using advanced oxidation process, J. Sci. Ind. Res. 68(8) (2009) 724-729.

[17]. A. Sudhaik, P. Raizada, P. Shandilya, D.Y. Jeong, J.H. Lim, P. Singh, Review on fabrication of graphitic carbon nitride based efficient nanocomposites for photodegradation of aqueous phase organic pollutants, J. Ind. Eng. Chem. 68 (2018) 2851, DOI: 10.1016/j.jiec.2018.07.007.

[18]. A. Di Mauro, M.E. Fragala, V. Privitera, G. Impellizzeri, ZnO for application in photocatalysis: from thin films to nano-structures, Mater. Sci. Semicond. Process, 69 (2017) 44-51, DOI: 10.1016/j.mssp.2017.03.029.

[19]. B. Pare, P. Singh, S.B. Jonnalgadda, Visible light induced heterogeneous advanced oxidation process to degrade pararosanilin dye in aqueous suspension of $\mathrm{ZnO}$, Indian $\mathrm{J}$. Chem. 47(6) (2008) 830-835.

[20]. H. Yi, M. Jiang, D. Huang, G. Zeng, C. Lai, L. Qin, C. Zhou, B. Li, X. Liu, Cheng, Advanced photocatalytic Fenton-like process over biomimetic hemin- $\mathrm{Bi}_{2} \mathrm{WO}_{6}$ with enhanced pH, J. Taiwan Inst. Chem. Eng.93 (2018) 184-192, DOI: 10.1016/j.jtice.2018.06.037.

[21]. P. Raizada, P. Singh, A. Kumar, B. Pare, S.B. Jonnalagadda, P. Technology, Zero valent iron-brick grain nanocomposite for enhanced solar-Fenton removal of malachite green, Sep. Purif. Technol. 133 (2014) 429-437. DOI: 10.1016/j.seppur.2014.07.012. 
[22]. P. Singh, P. Raizada, S. Kumari, A. Kumar, D. Pathania, P. Thakur, Solar-Fenton removal of malachite green with novel $\mathrm{Fe}^{0}$-activated carbon nanocomposite, Appl. Catal., A, 476 (2014) 9-18. DOI: 10.1016/j.apcata.2014.02.009.

[23]. A. Sudhaik, P. Raizada, P. Shandilya, P. Singh, magnetically recoverable graphitic carbon nitride and $\mathrm{NiFe}_{2} \mathrm{O}_{4}$ based magnetic photocatalyst for degradation of oxytetracycline antibiotic in simulated wastewater under solar light, J. Environ. Chem. Eng. 6(4) (2018) 3874-3883, DOI: 10.1016/j.jece.2018.05.039.

[24]. L. Jiang, X. Yuan, Y. Pan, J. Liang, G. Zeng, Z. Wu and H. Wang, Doping of graphitic carbon nitride for photocatalysis: a review, Appl. Catal., B, 217 (2017) 388-406, DOI: 10.1016/j.apcatb.2017.06.003.

[25]. S. Banerjee, D.D. Dionysiou, S.C. Pillai, Self-cleaning applications of $\mathrm{TiO}_{2}$ by photoinduced hydrophilicity and photocatalysis, Appl. Catal., B, 176-177 (2015) 396-428, DOI: 10.1016/j.apcatb.2015.03.058.

[26]. P. Raizada, B. Priya, P. Thakur, P. Singh, Solar light induced photodegradation of oxytetracycline using $\mathrm{Zr}$ doped $\mathrm{TiO}_{2} / \mathrm{CaO}$ based nanocomposite, Indian J. Chem. 55 (07) (2016) 803-809.

[27]. C. Lai, M.M. Wang, G.M. Zeng, Y.G. Liu, D.L. Huang, C. Zhang, R.Z. Wang, P. Xu, M. Cheng, C. Huang, Synthesis of surface molecular imprinted $\mathrm{TiO}_{2} /$ graphene photocatalyst and its highly efficient photocatalytic degradation of target pollutant under visible light irradiation, Appl. Surf. Sci. 390 (2016) 368-376, DOI: 10.1016/j.apsusc.2016.08.119

[28]. H. Yi, L. Qin, D. Huang, G. Zeng, C. Lai, X. Liu, B. Li, H. Wang, C. Zhou, F. Huang, Nano-structured bismuth tungstate with controlled morphology: fabrication, modification, environmental application and mechanism insight, Chem. Eng. J. 358 (2018) 480-496, DOI: 10.1016/j.cej.2018.10.036. 
[29]. P. Raizada, P. Singh, A. Kumar, G. Sharma, B. Pare, S.B. Jonnalagadda, P. Thakur, Solar photocatalytic activity of nano-ZnO supported on activated carbon or brick grain particles: role of adsorption in dye degradation, Appl. Catal., A, 486 (2014) 159-169, DOI: 10.1016/j.apcata.2014.08.043

[30]. P. Raizada, A. Sudhaik, P. Singh, P. Shandilya, V.K. Gupta, A. Hosseini, S. Aggarwal, $\mathrm{Ag}_{3} \mathrm{PO}_{4}$ modified phosphorus and sulphur co-doped graphitic carbon nitride as a direct Zscheme photocatalyst for 2, 4-dimethyl phenol degradation, J. Photochem. Photobiol. A, 374 (2019) 22-35, DOI: 10.1016/j.jphotochem.2019.01.015.

[31]. B. Priya, P. Shandilya, P. Raizada, P. Thakur, N. Singh, P. Singh, Photocatalytic mineralization and degradation kinetics of ampicillin and oxytetracycline antibiotics using graphene sand composite and chitosan supported BiOCl, J. Mol. Catal. 423 (2016) 400413, DOI: 10.1016/j.molcata.2016.07.043.

[32]. P. Raizada, J. Kumari, P. Shandilya, R. Dhiman, V.P. Singh, P. Singh, Magnetically retrievable $\mathrm{Bi}_{2} \mathrm{WO}_{6} / \mathrm{Fe}_{3} \mathrm{O}_{4}$ immobilized on graphene sand composite for investigation of photocatalytic mineralization of oxytetracycline and ampicillin, Process Saf. Environ. Prot. 106 (2017) 104-116, DOI: 10.1016/j.psep.2016.12.012.

[33]. S. Gautam, P. Shandilya, B. Priya, V.P. Singh, P. Raizada, R. Rai, M. Valente, P. Singh, Superparamagnetic $\mathrm{MnFe}_{2} \mathrm{O}_{4}$ dispersed over graphitic carbon sand composite and bentonite as magnetically recoverable photocatalyst for antibiotic mineralization, Sep. Purif. Technol. 172 (2017) 498-511, DOI: 10.1016/j.seppur.2016.09.006

[34]. P. Singh, B. Priya, P. Shandilya, P. Raizada, N. Singh, B. Pare, S.B. Jonnalagadda, Photocatalytic mineralization of antibiotics using $60 \% \mathrm{WO}_{3} / \mathrm{BiOCl}$ stacked to graphene sand composite and chitosan, Arab. J. Chem. (2016), DOI: 10.1016/j.arabjc.2016.08.005 
[35]. S. Hua, D. Qu, L. An, W. Jiang, Y. Wen, X. Wang, Z. Sun, Highly efficient p-type $\mathrm{Cu}_{3} \mathrm{P} / \mathrm{n}$-type $\mathrm{g}-\mathrm{C}_{3} \mathrm{~N}_{4}$ photocatalyst through Z-scheme charge transfer route, Appl. Catal., B, 240 (2019) 253-261. DOI: 10.1016/j.apcatb.2018.09.010.

[36]. P. Shandilya, D. Mittal, A. Sudhaik, M. Soni, P. Raizada, A.K. Saini, P. Singh, GdVO modified fluorine doped graphene nanosheets as dispersed photocatalyst for mitigation of phenolic compounds in aqueous environment and bacterial disinfection, Sep. Purif. Technol. 210 (2019) 804-816, DOI: 10.1016/j.seppur.2018.08.077.

[37]. P. Shandilya, D. Mittal, M. Soni, P. Raizada, A. Hosseini, A.K. Saini, P. Singh, Fabrication of fluorine doped graphene and $\mathrm{SmVO}_{4}$ based dispersed and adsorptive photocatalyst for abatement of phenolic compounds from water and bacterial disinfection, J. Clean. Prod. 203 (2018) 386-399, DOI: 10.1016/j.jclepro.2018.08.271.

[38]. P. Shandilya, D. Mittal, M. Soni, P. Raizada, J.H. Lim, D.Y. Jeong, R.P. Dewedi, A.K. Saini, P. Singh, Islanding of $\mathrm{EuVO}_{4}$ on high-dispersed fluorine doped few layered graphene sheets for efficient photocatalytic mineralization of phenolic compounds and bacterial disinfection. J. Taiwan Inst. Chem. Eng. (2018), DOI: 10.1016/j.jtice.2018.08.034

[39]. L.W. Zhang, Y.J. Wang, H.Y. Cheng, W.Q. Yao, Y. Zhu, Synthesis of porous $\mathrm{Bi}_{2} \mathrm{WO}_{6}$ thin films as efficient visible light active photocatalysts, 21 (2009) 1286-1290, Adv. Mater. DOI: 10.1002/adma.200801354.

[40]. D. Pathania, Sarita, P. Singh, D. Pathania, Preparation and characterization of nanoscale cadmium oxide using bovine serum albumin as green capping agent and its photocatalytic $\begin{array}{lllll}\text { activity, Desalin. Water } & \text { Treat. } 52 \quad \text { (2014) 3497-3503, DOI: }\end{array}$ $\underline{10.1080 / 19443994.2013 .803342}$ 
[41]. P. Singh, S. Gautam, P. Shandilya, B. Priya, V.P. Singh, P. Raizada: Graphene bentonite supported $\mathrm{ZnFe}_{2} \mathrm{O}_{4}$ as superparamagnetic photocatalyst for antibiotic degradation. Adv. Mater. Lett. 8(3) (2017) 229-238, DOI:10.5185/amlett.2017.1467.

[42]. S. Gautam, P. Shandilya, P. Singh, P. Raizada, P. Singh: Model Solar photocatalytic mineralization of antibiotics using magnetically separable $\mathrm{NiFe}_{2} \mathrm{O}_{4}$ supported onto graphene sand composite and bentonite. J. Water Process Eng. 14 (2016) 86-100, DOI: 10.1016/j.jwpe.2016.10.008.

[43]. Z. Zhou, Y. Zhang, Y. Shen, S. Liu, Y. Zhang, Molecular engineering of polymeric carbon nitride: advancing applications from photocatalysis to biosensing and more, Chem. Soc. Rev. 47 (2018) 2298-2321, DOI: 10.1039/C7CS00840F.

[44]. P. Singh, P. Shandilya, P. Raizada, A. Sudhaik, A. Rahmani-Sani, A. Hosseini, Review on various strategies for enhancing photocatalytic activity of graphene-based nanocomposites for water purification, Arab. J. Chem. (2018), DOI: 10.1016/j.arabjc.2018.12.001.

[45]. E. Kroke, M. Schwarz, E. Horath-Bordon, P. Kroll, B. Noll, A.D.J.N.J.O.C. Norman, Tris-triazine derivatives. Part I. From trichloro-tri-s-triazine to graphitic $\mathrm{C}_{3} \mathrm{~N}_{4}$ structures, New J. Chem. 26 (2002) 508-512. DOI: 10.1039/B111062B.

[46]. E. Wirnhier, M. Mesch, J. Senker, W. Schnick, Formation and characterization of melam, melam hydrate, and a melam-melem adduct, Chem. A Eu. J. 19 (2013) 2041-2049, DOI: 10.1002/chem.201203340.

[47]. J. Liebig, Ueber Mellon und Mellonverbindungen, Justus Liebigs Ann. Der Chemie, 50 (1844) 337-363, DOI: 10.1002/jlac.18440500302.

[48]. J. Zhu, P. Xiao, H. Li, S. Carabineiro, Graphitic carbon nitride: synthesis, properties, and applications in catalysis, Appl. Mater. Interfaces. 6 (2014) 6, DOI: 10.1021/am502925j. 
[49]. Kessler, F. K. Zheng, Y. Schwarz, D. Merschjann, C. Schnick, W. Wang, X. Bojdys, Functional carbon nitride materials-design strategies for electrochemical devices. Nat. Rev. Mater. 2(6) (2017) 17030, DOI: 10.1038/natrevmats.2017.30.

[50]. Z. Zhao, Y. Sun, F. Dong, Graphitic carbon nitride-based nanocomposites: a review, Nanoscale. 7 (2015) 15. DOI: 10.1039/C4NR03008G.

[51]. J. Zhang, X. Chen, K. Takanabe, K. Maeda, K. Domen, J. Epping, X. Fu, M. Antonietti, X. Wang, Synthesis of a carbon nitride structure for visible light catalysis by copolymerization, Angew. Chem. Int. Ed. 49 (2010) 441-444, DOI: 10.1002/anie.200903886.

[52]. S. Zuluaga, L. Liu, N. Shafiq, S.M. Rupich, J. Veyan, Y. Chabal, T. Thonhauser, Structural band-gap tuning in $\mathrm{g}-\mathrm{C}_{3} \mathrm{~N}_{4}$, Phys. Chem. Chem. Phys. 17 (2015) 957-962, DOI:10.1039/C4CP05164E.

[53]. M. Bojdys, J. Müller, M. Antonietti, A. Thomas, Ionothermal synthesis of crystalline, condensed, graphitic carbon nitride, Chem. Eur. J. 14 (2008) 8177-8182, DOI: 10.1002/chem.200800190.

[54]. G. Zhang, L. Lin, G. Li, Y. Zhang, A. Savateev, S. Zafeiratos, X. Wang, M. Antonietti, Ionothermal Synthesis of Triazine-Heptazine Based Copolymers with Apparent Quantum Yields of $60 \%$ at $420 \mathrm{~nm}$ for Solar Hydrogen Production from "Sea Water", Angew. Chem. Int. Ed. 57 (2018) 9372-9376, DOI: 10.1002/anie.201804702.

[55]. P. Raizada, A. Sudhaik, P. Singh, P. Shandilya, P. Thakur, H. Jung, Visible light assisted photodegradation of 2, 4-dinitrophenol using $\mathrm{Ag}_{2} \mathrm{CO}_{3}$ loaded phosphorus and sulphur codoped graphitic carbon nitride nanosheets in simulated wastewater, Arab. J. Chem. (2018), DOI: $10.1016 /$ j.arabjc.2018.10.004 
[56]. P. Singh, P. Raizada, D. Pathania, G. Sharma, P. Sharma, Microwave induced KOH activation of guava peel carbon as an adsorbent for congo red dye removal from aqueous phase, Indian J. Chem. 20 (5) (2013) 305-311.

[57]. B. Zhu, J. Zhang, C. Jiang, B. Cheng, J. Yu, First principle investigation of halogen-doped monolayer $\quad \mathrm{g}-\mathrm{C}_{3} \mathrm{~N}_{4}$ photocatalyst, Appl. Catal., $\quad$ B. 207 (2017) 27-34,_ DOI: 10.1016/j.apcatb.2017.02.020.

[58]. Y. Zhang, H. Gong, G. Li, H. Zeng, L. Zhong, K. Liu, H. Cao, H. Yan, Synthesis of graphitic carbon nitride by heating mixture of urea and thiourea for enhanced photocatalytic $\mathrm{H}_{2}$ production from water under visible light, Int. J. Hydrogen Energy, 42 (2017)143-151. DOI:10.1016/j.ijhydene.2016.11.040.

[59]. X. Song, H. Tao, L. Chen, Y. Sun, Synthesis of Fe/g- $\mathrm{C}_{3} \mathrm{~N}_{4}$ composites with improved visible light photocatalytic activity. Mater. Lett. 116 (2014) 265. DOI: 10.1016/j.matlet.2013.11.043.

[60]. P. Raizada, A. Sudhaik, P. Singh, P. Shandilya, A.K. Saini, V.K. Gupta, J. Lim, H. Jung, A. Hosseini, Fabrication of $\mathrm{Ag}_{3} \mathrm{VO}_{4}$ decorated phosphorus and sulphur co-doped graphitic carbon nitride as a high-dispersed photocatalyst for phenol mineralization and E. coli disinfection, Sep. Purif. Technol. $212 \quad$ (2019) 887-900, 10.1016/j.seppur.2018.12.007.

[61]. M. Jourshabani, Z. Shariatinia, A. Badiei, In situ fabrication of $\mathrm{SnO}_{2} / \mathrm{S}-\mathrm{doped} g-\mathrm{C}_{3} \mathrm{~N}_{4}$ nanocomposites and improved visible light driven photodegradation of methylene blue, J. Mol. Liq. 248 (2017) 688-702, DOI: 10.1016/j.molliq.2017.10.110.

[62]. M. Jourshabani, Z. Shariatinia, A. Badiei, Controllable synthesis of mesoporous sulfurdoped carbon nitride materials for enhanced visible light photocatalytic-degradation, Langmuir, 33(2017)7062-7078, DOI: 10.1021/acs.langmuir.7b01767. 
[63]. X. Qu, S. Hu, J. Bai, P. Li, G. Lu, X. Kang, A facile approach to synthesize oxygen-doped g- $\mathrm{C}_{3} \mathrm{~N}_{4}$ with enhanced visible light activity under anoxic conditions via oxygen-plasmatreatment, New J. Chem. 42 (2018) 4998-5004, DOI:10.1039/C7NJ04760F.

[64]. H. Wang, M. Li, H. Li, Q. Lu, Y. Zhang, S. Yao, Porous graphitic carbon nitride with controllable nitrogen vacancies: As promising catalyst for enhanced degradation of pollutant under visible light, Mater. Des. 162 (2019) 210-218, DOI: $\underline{10.1016 / \text { j.matdes.2018.11.049. }}$

[65]. S. Yan, Z. Li, Z. Zou, Photodegradation of rhodamine B and methyl orange over borondoped $\mathrm{g}_{-} \mathrm{C}_{3} \mathrm{~N}_{4}$ under visible light irradiation, Langmuir, 26 (2010) 3894-390, DOI: 10.1021/la904023j.

[66]. S. Thaweesak, S. Wang, M. Lyu, M. Xiao, P. Peerakiatkhajohn, L. Wang, Boron-doped graphitic carbon nitride nanosheets for enhanced visible light photocatalytic water splitting, Dalton Trans. 46 (2017) 10714-10720, DOI: 10.1039/C7DT00933J.

[67]. H. Sudrajat, A one-pot solid-state route for realizing highly visible light active Na-doped g- $\mathrm{C}_{3} \mathrm{~N}_{4}$ photocatalysts, J. Solid State Chem. $26 \quad$ (2018) 257, DOI:10.1016/j.jssc.2017.09.024.

[68]. E. Sindhuja, K. Ravichandran, Cost-effective fabrication of $\left(g-\mathrm{C}_{3} \mathrm{~N}_{4}+\mathrm{Mo}\right)$ added photostable $\mathrm{ZnO}$ thin films for enhanced visible light responsive photocatalytic dye degradation, Mater. Res. Bull. $103 \quad$ (2018) 299-308, DOI:

\subsection{6/j.materresbull.2018.03.007.}

[69]. Y. Wang, Y. Wang, Y. Chen, C. Yin, Y. Zuo, L. Cui, Synthesis of Ti-doped graphitic carbon nitride with improved photocatalytic activity under visible light, Mater. Lett. 139 (2015) 70-72, DOI: 10.1016/i.matlet.2014.10.008. 
[70]. D. Das, D. Banerjee, B. Das, N. Das, K. Chattopadhyay, Effect of cobalt doping into graphitic carbon nitride on photo induced removal of dye from water, Mater. Res. Bull. 89 (2017) 170-179, DOI: 10.1016/j.materresbull.2017.01.034.

[71]. Y. Wang, Y. Wang, Y. Li, H. Shi, Y. Xu, H. Qin, X. Li, Y. Zuo, S. Kang, L. Cui, Simple synthesis of Zr-doped graphitic carbon nitride towards enhanced photocatalytic performance under simulated solar light irradiation, Catal. Commun. 72 (2015) 24-28, DOI: $10.1016 /$ j.catcom.2015.08.022.

[72]. H. Bicalho, J. Lopez, I. Binatti, P. Batista, J. Ardisson, R. Resende, E. Lorençon, Facile synthesis of highly dispersed Fe (II)-doped $\mathrm{g}-\mathrm{C}_{3} \mathrm{~N}_{4}$ and its application in Fenton-like catalysis, J. Mol. Catal. 435 (2017) 156-165, DOI: 10.1016/j.mcat.2017.04.003.

[73]. Q. Liu, T. Chen, Y. Guo, Z. Zhang, X. Fang, Grafting Fe (III) species on carbon nanodots/Fe-doped $\mathrm{g}-\mathrm{C}_{3} \mathrm{~N}_{4}$ via interfacial charge transfer effect for highly improved photocatalytic performance, Appl. Catal., B. 205 (2017) 173-181, DOI: 10.1016/j.apcatb.2016.12.028.

[74]. H. Dou, L. Chen, S. Zheng, Y. Zhang, G. Q. Xu, Band structure engineering of graphitic carbon nitride via $\mathrm{Cu}^{2+/} \mathrm{Cu}^{+}$doping for enhanced visible light photoactivity, Mater. Chem. Phys. 214 (2018) 482-488, DOI: 10.1016/j.matchemphys.2018.04.071.

[75]. Z. Huang, J. Song, L. Pan, Z. Wang, X. Zhang, J. Zou, W. Mi, X. Zhang L. Wang, Carbon nitride with simultaneous porous network and O-doping for efficient solar-energy-driven hydrogen evolution, Nano Energy, 12 (2015) 646-656, DOI: 10.1016/j.nanoen.2015.01.043.

[76]. D. Gonçalves, R. Alvim, H. Bicalho, A. Peres, I. Binatti, P. F. Batista, L. Teixeira, R. Resende, E. Lorençon, Highly dispersed Mo-doped graphite carbon nitride: potential application as oxidation catalyst with hydrogen peroxide, New J. Chem. 42 (2018) 57205727, DOI: 10.1039/C8NJ00316. 
[77]. T. Xiong, W. Cen, Y. Zhang, F. Dong, Bridging the $g-\mathrm{C}_{3} \mathrm{~N}_{4}$ interlayers for enhanced photocatalysis, ACS Catal. 6 (2014) 2462-2472, DOI:10.1021/acscatal.5b02922.

[78]. M. Zhang, X. Bai, D. Liu, J. Wang, Y. Zhu, Enhanced catalytic activity of potassiumdoped graphitic carbon nitride induced by lower valence position, Appl. Catal., B. 164 (2015) 77-81, DOI: 10.1016/j.apcatb.2014.09.020.

[79]. J. Zhang, S. Hu, Y. Wang, A convenient method to prepare a novel alkali metal sodium doped carbon nitride photocatalyst with a tunable band structure, RSC Adv. 4 (2014) 62912-62919, DOI: 10.1039/C4RA11377B.

[80]. S. Hu, L. Ma, J. You, F. Li, Z. Fan, F. Wang, D. Liu, J. Gui, A simple and efficient method to prepare a phosphorus modified $\mathrm{g}_{-} \mathrm{C}_{3} \mathrm{~N}_{4}$ visible light photocatalyst, RSC Adv. 4 (2014) 21657-21663, DOI: 10.1039/C4RA02284J.

[81]. G. Liu, P. Niu, C. Sun, S. Smith, Z. Chen, G. Lu, H. Cheng, Unique electronic structure induced high photo reactivity of sulfur-doped graphitic- $\mathrm{C}_{3} \mathrm{~N}_{4}$, J. Am. Chem. Soc. 132 (2010) 11642-11648, DOI: 10.1021/ja103798k.

[82]. X. Rong, F. Qiu, J. Rong, X. Zhu, J. Yan, D. Yang, Enhanced visible light photocatalytic activity of W-doped porous g- $\mathrm{C}_{3} \mathrm{~N}_{4}$ and effect of $\mathrm{H}_{2} \mathrm{O}_{2}$, Mater. Lett. 164 (2016) 12, DOI: $\underline{10.1016 / \text { i.matlet.2015.10.131. }}$.

[83]. Zhang, X. Li, C. Shao, Y. Liu, Hydrothermal synthesis of carbon-rich graphitic carbon nitride nanosheets for photo-redox catalysis, J. Mater. Chem. A, 3 (2015) 3281, DOI: 10.1039/C5TA00202H.

[84]. J. Li, B. Shen, Z. Hong, B. Lin, B. Gao, Y. Chen, A facile approach to synthesize novel oxygen-doped $\mathrm{g}_{-} \mathrm{C}_{3} \mathrm{~N}_{4}$ with superior visible-light photo reactivity, Chem. Commun. 48 (2012) 12017, DOI: 10.1039/C2CC35862J. 
[85]. Q. Fan, J. Liu, Y. Yu, S. Zuo, B. Li, A simple fabrication for sulfur doped graphitic carbon nitride porous rods with excellent photocatalytic activity degrading RhB dye, Appl. Surf. Sci. 391(2017) 360-368, DOI: 10.1016/j.apsusc.2016.04.055.

[86]. S. Liu, H. Sun, H. Ang, M. Tade, S. Wang, Integrated oxygen-doping and dye sensitization of graphitic carbon nitride for enhanced visible light photodegradation, $\mathrm{J}$. Colloid Interface Sci. 476 (2016) 193-199, DOI: 10.1016/j.jcis.2016.05.026.

[87]. M. Durka, G. Dimitrakis, D. Bogdał, A. Stankiewicz ,G. Stefanidis, A concise review on microwave-assisted polycondensation reactions and curing of polycondensation polymers with focus on the effect of process conditions, Chem. Eng. J. 264 (2015) 633-644, DOI: $\underline{10.1016 / j . c e j .2014 .11 .087}$

[88]. B. Chai, J. Yan, C. Wang, Z. Ren, Y. Zhu, Enhanced visible light photocatalytic degradation of Rhodamine B over phosphorus doped graphitic carbon nitride, Appl. Surf. Sci. 391 (2017) 376, DOI: 10.1016/j.apsusc.2016.06.180.

[89]. L. Zhang, X. Chen, J. Guan, Y. Jiang, T. Hou, X. Mu, Facile synthesis of phosphorus doped graphitic carbon nitride polymers with enhanced visible-light photocatalytic activity, Mater. Res. Bull. 48 (2013) 3485-349, DOI: 10.1016/j.materresbull.2013.05.040.

[90]. G. Dong, K. Zhao, L. Zhang, Carbon self-doping induced high electronic conductivity and photo-reactivity of $\mathrm{g}-\mathrm{C}_{3} \mathrm{~N}_{4}, \quad$ Chem. Commun. 48 (2012) 6178-6180, DOI: 10.1039/C2CC32181E.

[91]. Z. Zhao, Y. Sun, F. Dong, Y. Zhang, H. Zhao, Template synthesis of carbon self-doped g$\mathrm{C}_{3} \mathrm{~N}_{4}$ with enhanced visible to near-infrared absorption and photocatalytic performance, RSC Adv. 5 (2015) 39549-39556, DOI: 10.1039/C5RA03433G.

[92]. L. Feng, Y. Zou, C. Li, S. Gao, L. Zhou, Q. Sun, M. Fan, H. Wang, D. Wang, G. Li, Nanoporous sulfur-doped graphitic carbon nitride microrods: A durable catalyst for visible-light- 
driven $\mathrm{H}_{2}$ evolution, Int. J. Hydrogen Energy, 39 (2014) 15373-15379, DOI: $\underline{10.1016 / j . i j h y d e n e .2014 .07 .160 .}$

[93]. J. Gao, J. Wang, X. Qian, Y. Dong, H. Xu, R. Song, C. Yan, H. Zhu, Q. Zhong, G. Qian, One-pot synthesis of copper-doped graphitic carbon nitride nanosheet by heating $\mathrm{Cu}-$ melamine supramolecular network and its enhanced visible-light-driven photocatalysis, J. Solid State Chem. 228 (2015) 60, DOI: 10.1016/j.jssc.2015.04.027.

[94]. S. Le, T. Jiang, Q. Zhao, X. Liu, Y. Li, B. Fang, M. Gong, Cu-doped mesoporous graphitic carbon nitride for enhanced visible-light driven photocatalysis, RSC Adv. 6 (2016) 3881138819, DOI:10.1039/C6RA03982K.

[95]. H. Wang, X. Yuan, Y. Wu, G. Zeng, X. Chen, L. Leng, H. Li, Synthesis and applications of novel graphitic carbon nitride/metal-organic frameworks mesoporous photocatalyst for dyes removal, Appl. Catal., B. 174 (2015) 445, DOI: 10.1016/j.apcatb.2015.03.037.

[96]. J. Zhang, A. Wang, W. Zhao, C. Li, X. Chen, Y. Wang, W. Zhu, Q. Zhong, Influence of metal-porphyrins on the photocatalysis of graphitic carbon nitride, Dyes Pigm.153 (2018) 241-247, DOI:10.1016/j.dyepig.2018.02.028.

[97]. D. Masih, Y. Ma, S. Rohani, Graphitic $\mathrm{C}_{3} \mathrm{~N}_{4}$ based noble-metal-free photocatalyst systems, Appl. Catal., B, 206 (2017) 556-588, DOI: 10.1016/j.apcatb.2017.01.061.

[98]. M. Fronczak, M. Krajewska, K. Demby, M. Bystrzejewski, Extraordinary adsorption of methyl blue onto sodium-doped graphitic carbon nitride, J. Phys. Chem. C, 121 (2017) 15756-15766, DOI: 10.1021/acs.jpcc.7b03674.

[99]. F. Guo, J. Chen, M. Zhang, B. Gao, B. Lin, Y. Chen, Deprotonation of $\mathrm{g}_{-} \mathrm{C}_{3} \mathrm{~N}_{4}$ with Na ions for efficient non-sacrificial water splitting under visible light, J. Mater. Chem. A, 4 (2016) 10806-10809, DOI: 10.1039/C6TA03424A. 
[100]. S. Hu, F. Li, Z. Fan, F. Wang, Y. Zhao, Z. Lv, Band gap-tunable potassium doped graphitic carbon nitride with enhanced mineralization ability, Dalton Trans. 44 (2015) 1084, DOI:10.1039/C4DT02658F.

[101]. J. Jiang, S. Cao, C. Hu and C. Chen, A comparison study of alkali metal-doped g- $\mathrm{C}_{3} \mathrm{~N}_{4}$ for visible-light photocatalytic hydrogen evolution, Chin. J. Catal. 38 (2017) 1981-1989, DOI: $\underline{10.1016 / \mathrm{S} 1872-2067(17) 62936-\mathrm{X} .}$

[102]. G. Ding, W. Wang, T. Jiang, B. Han, H. Fan, G. Yang, Highly selective synthesis of phenol from benzene over a vanadium-doped graphitic carbon nitride catalyst, Chem. Cat. Chem. 5 (2013) 192-200, DOI: 10.1002/cctc.201200502.

[103]. S. Tonda, S. Kumar, S. Kandula, V. Shanker, Fe-doped and mediated graphitic carbon nitride nanosheets for enhanced photocatalytic performance under natural sunlight, J. Mater. Chem. A, 2 (2014) 6772, DOI: 10.1039/C3TA15358D.

[104]. X. Chen, J. Zhang, X. Fu, M. Antonietti, X. Wang, Fe-g- $\mathrm{C}_{3} \mathrm{~N}_{4}$-catalyzed oxidation of benzene to phenol using hydrogen peroxide and visible light, J. Am. Chem. Soc. 131 (2009) 11658-11659, DOI: 10.1021/ja903923s.

[105]. X. Wang, X. Chen, A. Thomas, X. Fu, M. Antonietti, Metal containing carbon nitride compounds: a new functional organic-metal hybrid material, Adv. Mater. 21 (2009) 16091612, DOI: 10.1002/adma.200802627.

[106]. J. Mu, J. Li, X. Zhao, E. Yang, Cobalt-doped graphitic carbon nitride with enhanced peroxidase-like activity for wastewater treatment, RSC Adv. 6 (2016) 35568, DOI: 10.1039/C6RA02911F.

[107]. D. Das, D. Banerjee, M. Mondal, A. Shett, B. Das, N. Das, U. Ghorai, K. Chattopadhyay, Nickel doped graphitic carbon nitride nanosheets and its application for dye degradation by chemical catalysis, Mater. Res. Bull. 101 (2018) 291-304, DOI: $\underline{10.1016 / j . m a t e r r e s b u l 1.2018 .02 .004 . ~}$ 
[108]. J. Wang, H. Xu, X. Qian, Y. Dong, J. Gao, G. Qian, J. Yao, Direct Synthesis of Porous Nanorod Type Graphitic Carbon Nitride/CuO Composite from $\mathrm{Cu}-\mathrm{Melamine}$ Supramolecular Framework towards Enhanced Photocatalytic Performance, Chem. Asian J.10 (2015) 1276-1280, DOI: 10.1002/asia.201500131.

[109]. R. Jin, S. Hu, J. Gui and D. Liu, A Convenient Method to Prepare Novel Rare Earth Metal Ce Doped Carbon Nitride with enhanced photocatalytic activity under visible light, Bull. Korean Chem. Soc. 36 (2015) 17-23, DOI: 10.1002/bkcs.10001.

[110]. X. Dong, L. Xiaoni, L. Juan, L. Huang, Synthesis and photocatalytic performance of europium-doped graphitic carbon nitride, J. Rare Earth, 31 (2013) 1085-1091, DOI: 10.1016/S1002-0721(12)60408-6.

[111]. R. Kuriki, K. Sekizawa, O. Ishitani, K. Maeda, Visible-light-driven $\mathrm{CO}_{2}$ reduction with carbon nitride: enhancing the activity of ruthenium catalysts, Angew. Chem. Int. Ed. 54 (2015) 2406-2409, DOI:10.1002/anie.201411170.

[112]. A. Kumar, R. Yadav, N. Park, J. Baeg, Facile one-pot two-step synthesis of novel in situ selenium-doped carbon nitride nanosheet photocatalysts for highly enhanced solar fuel production from $\mathrm{CO}_{2}$, ACS Appl. Nano Mater. 1 (2018) 47-54, DOI: $\underline{10.1021 / \text { acsanm. } 7 b 00024 .}$

[113]. Y. Wang, Y. Li, X. Bai, Q. Cai, C. Liu, Y. Zuo, S. Kang, L. Cui, Facile synthesis of Ydoped graphitic carbon nitride with enhanced photocatalytic performance, Catal. Commun. 84 (2016)179-182, DOI: 10.1016/j.catcom.2016.06.020.

[114]. J. Thomas, K. Ambili, S. Radhika, Synthesis of $\mathrm{Sm}^{3+-}$ doped graphitic carbon nitride nanosheets for the photocatalytic degradation of organic pollutants under sunlight, Catal. Today, 310 (2018) 11, DOI: 10.1016/j.cattod.2017.06.029.

[115]. P. Wang, C. Guo, S. Hou, X. Zhao, L. Wu, Y. Pei, Y. Zhang, J. Gao, J. Xu, Compounds, Template-free synthesis of bubble-like phosphorus-doped carbon nitride with enhanced 
visible-light photocatalytic activity, J. Alloys Compd. 769 (2018) 503-511, DOI: $\underline{10.1016 / j . j a l l c o m .2018 .08 .034 . ~}$

[116]. Y. Zhou, L. Zhang, J. Liu, X. Fan, B. Wang, M. Wang, W. Ren, J. Wang, M. Li, J. Shi, Brand new P-doped $\mathrm{g}-\mathrm{C}_{3} \mathrm{~N}_{4}$ : enhanced photocatalytic activity for $\mathrm{H}_{2}$ evolution and Rhodamine B degradation under visible light, J. Mater. Chem. 3 (2015) 3862-3867, DOI: $\underline{10.1039 / C 4 T A 05292 G .}$

[117]. Y. Deng, L. Tang, G. Zeng, Z. Zhu, M. Yan, Y. Zhou, J. Wang, Y. Liu, J. Wang, Insight into highly efficient simultaneous photocatalytic removal of $\mathrm{Cr}$ (VI) and 2,4-diclorophenol under visible light irradiation by phosphorus doped porous ultrathin $g-\mathrm{C}_{3} \mathrm{~N}_{4}$ nanosheets from aqueous media: performance and reaction mechanism, Appl. Catal., B, 203 (2017) 343-354, DOI: 10.1016/j.apcatb.2016.10.046.

[118]. Y. Zheng, Z. Yu, H. Ou, A.M. Asiri, Y. Chen, X. Wang, Black phosphorus and polymeric carbon nitride heterostructure for photoinduced molecular oxygen activation, Adv. Funct. Mater. 28 (2018) 1705407, DOI: 10.1002/adfm.201705407.

[119]. Z. Li, G. Jiang, Z. Zhang, Y. Wu, Y. Han, Phosphorus-doped g- $\mathrm{C}_{3} \mathrm{~N}_{4}$ nanosheets coated with square flake-like $\mathrm{TiO}_{2}$ : Synthesis, characterization and photocatalytic performance in visible light, J. Mol. Catal. A, 425 (2016) 340, DOI: 10.1016/i.molcata.2016.10.020.

[120]. J. Luo, X. Zhou, L. Ma, X. Xu, Enhancing visible-light photocatalytic activity of $g-\mathrm{C}_{3} \mathrm{~N}_{4}$ by doping phosphorus and coupling with $\mathrm{CeO}_{2}$ for the degradation of methyl orange under visible light irradiation, RSC Adv. 5 (2015) 68728-68735, DOI: 10.1039/C5RA10848A.

[121]. Y. Zhang, T. Mori, J. Ye, M. Antonietti, Phosphorus-doped carbon nitride solid: enhanced electrical conductivity and photocurrent generation, J. Amer. Chem. Soc.132 (2010) 6294, DOI: $10.1021 /$ ja101749y. 
[122]. Ran, T. Y. Ma, G. Gao, X.-W. Du, S. Qiao, Porous P-doped graphitic carbon nitride nanosheets for synergistically enhanced visible-light photocatalytic $\mathrm{H}_{2}$ production, Energy Environ. Sci. 8 (2015) 3708-3717, DOI: 10.1039/C5EE02650D.

[123]. H. Lan, H. Wang, L. Chen, C. Au, S. Yin, Phosphorous-modified bulk graphitic carbon nitride: Facile preparation and application as an acid-base bifunctional and efficient catalyst for $\mathrm{CO}_{2}$ cycloaddition with epoxides, Carbon, 100 (2016), DOI: $\underline{10.1016 / j . c a r b o n} .2015 .12 .098$.

[124]. Y. Deng, L. Tang, G. Zeng, J. Wang, Y. Zhou, J. Wang, J. Tang, L. Wang, C. Feng, Facile fabrication of mediator-free Z-scheme photocatalyst of phosphorous-doped ultrathin graphitic carbon nitride nanosheets and bismuth vandate composites with enhanced tetracycline degradation under visible light, J. Colloid Interface Sci. 509 (2018) 219-234, DOI: $\underline{10.1016 / j . j \text { jcis.2017.09.016. }}$

[125]. Guo, Z. Deng, M. Li, B. Jiang, C. Tian, Q. Pan, H. Fu, Phosphorus-doped carbon nitride tubes with a layered micro-nanostructure for enhanced visible-light photocatalytic hydrogen evolution, Angew. Chem. Int. Ed. 128 (2016) 1862, DOI: $\underline{10.1002 / \text { ange. } 201508505 .}$

[126]. Y. Zhu, T. Ren, Z. Yuan, Mesoporous phosphorus-doped g- $\mathrm{C}_{3} \mathrm{~N}_{4}$ nanostructured flowers with superior photocatalytic hydrogen evolution performance, ACS Appl. Mater. Interfaces, 7 (2015) 16850-16856, DOI: 10.1021/acsami.5b04947.

[127]. S. Stolbov, S. Zuluaga, Sulfur doping effects on the electronic and geometric structures of graphitic carbon nitride photocatalyst: insights from first principles. J. Phys. Condens. Matter, 25 (2013) 85507, DOI: 10.1088/0953-8984/25/8/085507.

[128]. K. Wang, Q. Li, B. Liu, B. Cheng, W. Ho, J. Yu, Sulfur-doped $\mathrm{g}_{-} \mathrm{C}_{3} \mathrm{~N}_{4}$ with enhanced photocatalytic $\mathrm{CO}_{2}-$ reduction performance, Appl. Catal., B, 176 (2015) 44-52, DOI:10.1016/j.apcatb.2015.03.045. 
[129]. Lu, P. Zhang, S. Jiang, X. Wu, S. Song, M. Zhu, Z. Lou, Z. Li, F. Liu, Y. Liu, Photocatalytic reduction elimination of $\mathrm{UO}_{2}{ }^{2+}$ pollutant under visible light with metal-free sulfur doped $g-\mathrm{C}_{3} \mathrm{~N}_{4}$ photocatalyst, Appl. Catal., B, 200 (2017) 378-385, DOI:10.1016/j.apcatb.2016.07.036.

[130]. J. Zhang, J. Sun, K. Maeda, K. Domen, P. Liu, M. Antonietti, X. Fu, X. Wang, Sulfurmediated synthesis of carbon nitride: band-gap engineering and improved functions for photocatalysis, Energy Environ. Sci. 4 (2011) 675-678, DOI: 10.1039/C0EE00418A.

[131]. Q. Liang, M. Zhang, C. Liu, S. Xu, Z. Li, Sulfur-doped graphitic carbon nitride decorated with zinc phthalocyanines towards highly stable and efficient photocatalysis. Appl. Catal., A, 519 (2016)107, DOI: 10.1016/j.apcata.2016.03.033.

[132]. J. Hong, X. Xia, Y. Wang, R. Xu, Mesoporous carbon nitride with in situ sulfur doping for enhanced photocatalytic hydrogen evolution from water under visible light, J. Mater. Chem. 22 (2012)15006-15012, DOI:10.1039/C2JM32053C.

[133]. L. Ge, C. Han, X. Xiao, L. Guo, Y. Li, Enhanced visible light photocatalytic hydrogen evolution of sulfur-doped polymeric $\mathrm{g}-\mathrm{C}_{3} \mathrm{~N}_{4}$ photocatalysts, Mater. Res. Bull. 48 (2013) 3919-3925, DOI: 10.1016/j.materresbull.2013.06.002.

[134]. L. Cao, R. Wang, D. Wang, Synthesis and characterization of sulfur self-doped g- $\mathrm{C}_{3} \mathrm{~N}_{4}$ with efficient visible-light photocatalytic activity, Mater. Lett. 149 (2015) 50-53, DOI: $\underline{10.1016 / \text { j.matlet.2015.02.119. }}$

[135]. Y. Zheng, Z. Yu, F. Lin, F. Guo, K. Alamry, L. Taib, A. Asiri, X. Wang, Sulfur-doped carbon nitride polymers for photocatalytic degradation of organic pollutant and reduction of Cr (VI), Molecules, 22 (2017) 572, DOI: 10.3390/molecules22040572.

[136]. X. Liu, X. Wu, J. Li, L. Liu, Y. Ma, Simple synthesis of oxygen functional layered carbon nitride with near-infrared light photocatalytic activity, Catal. Commun. 91 (2017) 21-24, DOI: 0.1016/j.catcom.2016.12.001. 
[137]. P. Qiu, C. Xu, H. Chen, F. Jiang, X. Wang, R. Lu, X. Zhang, One step synthesis of oxygen doped porous graphitic carbon nitride with remarkable improvement of photo-oxidation activity: Role of oxygen on visible light photocatalytic activity, Appl. Catal., B, 206 (2017) 319-327, DOI: 10.1016/j.apcatb.2017.01.058.

[138]. S. Guo, Y. Zhu, Y. Yan, Y. Min, J. Fan, Q. Xu, Holey structured graphitic carbon nitride thin sheets with edge oxygen doping via photo-Fenton reaction with enhanced photocatalytic activity, Appl. Catal., B, 185 (2016) 315-321, DOI: 10.1016/j.apcatb.2015.11.030.

[139]. M. Rakibuddin, H. Kim, M. Khan, Graphite-like carbon nitride modified N-doped $\mathrm{LaTiO}_{3}$ nanocomposite for higher visible light photocatalytic and photo-electrochemical performance, Appl. Surf. Sci. 452 (2018) 400-412, DOI: 10.1016/j.apsusc.2018.05.018.

[140]. J. Fang, H. Fan, M. Li, C. Long, Nitrogen self-doped graphitic carbon nitride as efficient visible light photocatalyst for hydrogen evolution, J. Mater. Chem. 3 (2015) 13819-13826, DOI: $10.1039 / \mathrm{C} 5 \mathrm{TA} 02257 \mathrm{~F}$.

[141]. M. Ran, J. Li, W. Cui, Y. Li, P. Li, F. Dong, Efficient and stable photocatalytic NO removal on $\mathrm{C}$ self-doped $\mathrm{g}-\mathrm{C}_{3} \mathrm{~N}_{4}$ : electronic structure and reaction mechanism, Catal. Sci. Technol. 8 (2018) 3387-3394, DOI: 10.1039/C8CY00887F.

[142]. Y. Li, S. Wu, L. Huang, J. Wang, H. Xu, H. Li, Synthesis of carbon-doped g-C ${ }_{3} \mathrm{~N}_{4}$ composites with enhanced visible-light photocatalytic activity, Mater. Lett. 137 (2014) 281-284, DOI: 10.1016/j.matlet.2014.08.142.

[143]. P. Zhang, X. Li, C. Shao, Y. Liu, Hydrothermal synthesis of carbon-rich graphitic carbon nitride nanosheets for photo-redox catalysis, J. Mater. Chem. A, 3 (2015) 3281-3284, DOI: 10.1039/C5TA00202H.

[144]. Z. Lin, X. Wang, Nanostructure engineering and doping of conjugated carbon nitride semiconductors for hydrogen photosynthesis, Angew. Chem. Int. Ed.125 (2013)17791782, DOI: 10.1002/ange.201209017. 
[145]. C. Lu, R. Chen, X. Wu, M. Fan, Y. Liu, Z. Le, S. Jiang, S. Song, Boron doped g-C $\mathrm{N}_{4}$ with enhanced photocatalytic $\mathrm{UO}_{2}{ }^{2+}$ reduction performance, Appl. Surf. Sci. 360 (2016)10161022, DOI:10.1016/j.apsusc.2015.11.112.

[146]. Q. Yan, G. Huang, D. Li, M. Zhang, A. Pan, W. Huang, Facile synthesis and superior photocatalytic and electrocatalytic performances of porous B-doped $\mathrm{g}-\mathrm{C}_{3} \mathrm{~N}_{4}$ nanosheets, $\mathrm{J}$. Mater. Sci. Technol. 34 (2018) 2515-2520, DOI: 10.1016/j.jmst.2017.06.018

[147]. N. Sagara, S. Kamimura, T. Tsubota, T. Ohno, Photoelectrochemical $\mathrm{CO}_{2}$ reduction by a ptype boron-doped $\mathrm{g}-\mathrm{C}_{3} \mathrm{~N}_{4}$ electrode under visible light, Appl. Catal., B, 192 (2016) 193198, DOI:10.1016/j.apcatb.2016.03.055.

[148]. Y. Wang, H. Li, J. Yao, X. Wang, M. Antonietti, Synthesis of boron doped polymeric carbon nitride solids and their use as metal-free catalysts for aliphatic $\mathrm{C}-\mathrm{H}$ bond oxidation, Chem. Sci.2 (2011) 446-450, DOI:10.1039/C0SC00475H.

[149]. H. Li, Y. Liu, X. Gao, C. Fu, X. Wang, Facile Synthesis and Enhanced Visible-Light Photocatalysis of Graphitic Carbon Nitride Composite Semiconductors, Chem. Sus. Chem. 8 (2015) 1189-1196, DOI: 10.1002/cssc.201500024.

[150]. Y. Wang, Y. Di, M. Antonietti, H. Li, X. Chen, X. Wang, Excellent visible-light photocatalysis of fluorinated polymeric carbon nitride solids, Chem. Mater. 22 (2010) 5119-5121, DOI: 10.1021/cm1019102.

[151]. Z. Lan, G. Zhang, X. Wang, A facile synthesis of Br-modified $g-\mathrm{C}_{3} \mathrm{~N}_{4}$ semiconductors for photo-redox water splitting, Appl. Catal., B, 192 (2016) 116-125, DOI: $\underline{10.1016 / j . a p c a t b .2016 .03 .062 .}$

[152]. C. Zhang, J. Bai, L. Ma, Y. Lv, F. Wang, X. Zhang, X. Yuan, S. Hu, Synthesis of halogen doped graphite carbon nitride nanorods with outstanding photocatalytic $\mathrm{H}_{2} \mathrm{O}_{2}$ production ability via saturated $\mathrm{NH}_{4} \mathrm{X}(\mathrm{X}=\mathrm{Cl}, \mathrm{Br})$ solution-hydrothermal post-treatment, Diamond Relat. Mater. 87 (2018) 215-222, DOI: 10.1016/j.diamond.2018.06.013. 
[153]. Q. Han, C. Hu, F. Zhao, Z. Zhang, N. Chen, L. Qu, One-step preparation of iodine-doped graphitic carbon nitride nanosheets as efficient photocatalysts for visible light water splitting, J. Mater. Chem. A, 3 (2015) 4612-4619, DOI: 10.1039/C4TA06093H.

[154]. G. Zhang, M. Zhang, X. Ye, X. Qiu, S. Lin, X. Wang, Iodine modified carbon nitride semiconductors as visible light photocatalysts for hydrogen evolution, Adv. Mater. 26 (2014) 805-809, DOI: 10.1002/adma.201303611.

[155]. H. Li, Y. Liu, Y. Cui, W. Zhang, C. Fu, X. Wang, Facile synthesis and enhanced visiblelight photoactivity of $\mathrm{DyVO}_{4} / \mathrm{g}-\mathrm{C}_{3} \mathrm{~N}_{4}$ I composite semiconductors, Appl. Catal., B, 183 (2016) 426-432, DOI: 10.1016/j.apcatb.2015.11.012.

[156]. H. Dou, S. Zheng, Y. Zhang, The effect of metallic Fe (II) and non-metallic S co-doping on the photocatalytic performance of graphitic carbon nitride, RSC Adv. 8 (2018) 7558-7568,

\section{DOI: $10.1039 / \mathrm{C} 8 \mathrm{RA} 00056 \mathrm{E}$.}

[157]. S. Hu, L. Ma, J. You, F. Li, Z. Fan, G. Lu, D. Liu, J. Gui, Enhanced visible light photocatalytic performance of $\mathrm{g}-\mathrm{C}_{3} \mathrm{~N}_{4}$ photocatalysts co-doped with iron and phosphorus, Appl. Surf. Sci. 311 (2014) 164-171, DOI: 10.1016/j.apsusc.2014.05.036.

[158]. Hu, L. Ma, Y. Xie, F. Li, Z. Fan, F. Wang, Q. Wang, Y. Wang, X. Kang, G. Wu, Hydrothermal synthesis of oxygen functionalized S-P co-doped $\mathrm{g}-\mathrm{C}_{3} \mathrm{~N}_{4}$ nanorods with outstanding visible light activity under anoxic conditions, Dalton Trans. 44 (2015) 2088920897, DOI: 10.1039/C5DT04035C.

[159]. H. Ma, Y. Li, S. Li and N. Liu, Novel P,O co-doped g- $\mathrm{C}_{3} \mathrm{~N}_{4}$ with large specific surface area: Hydrothermal synthesis assisted by dissolution-precipitation process and their visible light activity under anoxic conditions, Appl. Surf. Sci. 357 (2014) 131-138, DOI: 10.1016/j.apsusc.2015.09.009.

[160]. J. Tian, T. Wu, D. Wang, Y. Pei, M. Qiao, B. Zong, One-pot synthesis of potassium and phosphorus-doped carbon nitride catalyst derived from urea for highly efficient visible 
light-driven hydrogen peroxide production, Catal. Today, (2018), DOI: $\underline{10.1016 / j . c a t t o d .2018 .07 .039 .}$

[161]. J. Zhao, L. Ma, H. Wang, Y. Zhao, J. Zhang and S. Hu, Novel band gap-tunable K-Na codoped graphitic carbon nitride prepared by molten salt method, Appl. Surf. Sci. 332 (2015) 625-630, DOI: 10.1016/j.apsusc.2015.01.233.

[162]. T. Xiong, H. Wang, Y. Zhou, Y. Sun, W. Cen, H. Huang, Y. Zhang, F. Dong, KClmediated dual electronic channels in layered $\mathrm{g}-\mathrm{C}_{3} \mathrm{~N}_{4}$ for enhanced visible light photocatalytic NO removal, Nanoscale, $10 \quad$ (2018) 8066-8074, 10.1039/C8NR01433G.

[163]. Zhang, J. Li, M. Zeng, J. Li, J. Xu, X. Wang, Band gap engineering and mechanism study of non-metal and metal ion co-doped carbon nitride: $\mathrm{C}$ and $\mathrm{Fe}$ as an example, Chem. Eur. J. 20 (2014) 9805-9812, DOI: 10.1002/chem.201400060.

[164]. J. Li, W. Cui, Y. Sun, Y. Chu, W. Cen, F. Dong, Directional electron delivery via a vertical channel between $\mathrm{g}-\mathrm{C}_{3} \mathrm{~N}_{4}$ layers promotes photocatalytic efficiency, J. Mater. Chem. A. 5 (2017) 9358-9364, DOI: 10.1039/C7TA02183F.

[165]. H. Ma, S. Zhao, S. Li, N. Liu, A facile approach to synthesizing $\mathrm{S}-\mathrm{Co}-\mathrm{O}$ tri-doped g- $\mathrm{C}_{3} \mathrm{~N}_{4}$ with enhanced oxygen-free photocatalytic performance via a hydrothermal post-treatment, RSC Adv. 5 (2015) 79585-79592, DOI: 10.1039/C5RA14081A.

[166]. J. Xu, M. Shalom, Conjugated carbon nitride as an emerging luminescent material: quantum dots, thin films and their applications in imaging, sensing, optoelectronic-devices and photo-electrochemistry. Chem. Photo. Chem. DOI: 10.1002/cptc.201800256.

[167]. G. Zhang, X. Wang, A facile synthesis of covalent carbon nitride photocatalysts by Copolymerization of urea and phenyl-urea for hydrogen evolution, J. Catal. 307 (2013) 246253, DOI: 10.1016/j.jcat.2013.07.026. 
[168]. G. Li, J. Shi, G. Zhang, Y. Fang, M. Anpo, X. Wang, The facile synthesis of graphitic carbon nitride from amino acid and urea for photocatalytic $\mathrm{H}_{2}$ production, Res. Chem. Intermed. 43 (2017) 5137-5152, DOI: 10.1007/s11164-017-3041-1.

[169]. Y. Yang, C. Zhang, D. Huang, G. Zeng, J. Huang, C. Lai, C. Zhou, W. Wang, H. Guo, W. Xue, Boron nitride quantum dots decorated ultrathin porous $\mathrm{g}-\mathrm{C}_{3} \mathrm{~N}_{4}$ : Intensified exciton dissociation and charge transfer for promoting visible-light-driven molecular oxygen activation, Appl. Catal., B, 245 (2019) 87-99, DOI: 10.1016/j.apcatb.2018.12.049.

[170]. J. Ran, W. Guo, H. Wang, B. Zhu, J. Yu, S. Qiao, Metal-free 2D/2D phosphorene/g- $\mathrm{C}_{3} \mathrm{~N}_{4}$ Van der Waals heterojunction for highly enhanced visible-light photocatalytic $\mathrm{H}_{2}$ production, Adv. Mater. 30 (2018) 1800128, DOI: 10.1002/adma.201800128.

[171]. G. Zhang, G. Li, T. Heil, S. Zafeiratos, A. Savateev, X. Wang, M. Antonietti, Tailoring Grain Boundary Chemistry of Polymeric Carbon Nitride for Enhanced Solar $\mathrm{H}_{2}$ Production and $\mathrm{CO}_{2}$ Reduction, Angew. Chem. Int. Ed. (2019), DOI: 10.1002/ange.201811938.

[172]. A. Savateev, S. Pronkin, J. Epping, M. Willinger, C. Wolff, D. Neher, M. Antonietti, D. Dontsova, Potassium Poly (heptazine imides) from Aminotetrazoles: Shifting Band Gaps of Carbon Nitride-like Materials for More Efficient Solar Hydrogen and Oxygen Evolution, Chem. Cat. Chem. 9 (2017) 167-174, DOI: 10.1002/cctc.201601165.

[173]. M.K. Bhunia, K. Yamauchi, K. Takanabe, Harvesting solar light with crystalline carbon nitrides for efficient photocatalytic hydrogen evolution, Angew. Chem. Int. Ed. 53 (2014) 11001-11005, DOI: 10.1002/anie.201405161.

[174]. G. Zhang, G. Li, Z. Lan, L. Lin, A. Savateev, T. Heil, S. Zafeiratos, X. Wang, M. Antonietti, Optimizing optical absorption, exciton dissociation, and charge transfer of a polymeric carbon nitride with ultrahigh solar hydrogen production activity, Angew. Chem. Int. Ed. 56 (2017) 13445-13449, DOI: 10.1002/anie.201706870. 
[175]. K. Schwinghammer, B. Tuffy, M.B. Mesch, E. Wirnhier, C. Martineau, F. Taulelle, W. Schnick, J. Senker, B. Lotsch, Triazine-based carbon nitrides for visible-light-driven hydrogen evolution, Angew. Chem. Int. Ed. 52 (2013) 2435-2439, DOI:

\subsection{2/anie. 201206817.}

[176]. J. Zhang, M. Zhang, G. Zhang, X. Wang, Synthesis of carbon nitride semiconductors in sulfur flux for water photo-redox catalysis, ACS Catal. 2 (2012) 940-948, DOI: $10.1021 / \mathrm{cs} 300167 \mathrm{~b}$.

[177]. Zhang, C. Huang, X. Wang, Dispersing molecular cobalt in graphitic carbon nitride frameworks for photocatalytic water oxidation, Small, 11 (2015) 1215-1221, DOI: 10.1002/sml1.201402636.

[178]. M. Volokh, G. Peng, J. Barrio, M. Shalom, Carbon nitride materials for water splitting photoelectrochemical cells, Angew. Chem. Int. Ed. (2018), DOI: 10.1002/anie.201806514.

[179]. Y. Fang, X. Li, X. Wang, Synthesis of Polymeric Carbon Nitride Films with Adhesive Interfaces for Solar Water Splitting Devices, ACS Catal. 8 (2018) 8774-8780, DOI: $10.1021 /$ acscatal.8b02549.

[180]. Y. Fang, Y. Xu, X. Li, Y. Ma, X. Wang, Coating polymeric carbon nitride photoanodes on conductive $\mathrm{Y}$ : $\mathrm{ZnO}$ nanorod arrays for overall water splitting, Angew. Chem. Int. Ed. 130 (2018) 9897-9901, DOI: 10.1002/ange.201804530.

[181]. Q. Ruan, W. Luo, J. Xie, Y. Wang, X. Liu, Z. Bai, C. Carmalt, J. Tang, A nanojunction polymer photoelectrode for efficient charge transport and separation, Angew. Chem. Int. Ed. 56 (2017) 8221-8225, DOI: 10.1002/anie.201703372.

[182]. W. Cui, J. Li, Y. Sun, H. Wang, G. Jiang, S. Lee, F. Dong, Enhancing ROS generation and suppressing toxic intermediate production in photocatalytic $\mathrm{NO}$ oxidation on $\mathrm{O} / \mathrm{Ba}$ cofunctionalized amorphous carbon nitride, Appl. Catal., B, 237 (2018) 938-946, DOI: 10.1016/j.apcatb.2018.06.071. 
[183]. W. Cui, J. Li, F. Dong, Y. Sun, G. Jiang, W. Cen, S. Lee, Z. Wu, Highly efficient performance and conversion pathway of photocatalytic NO oxidation on SrO-clusters@ amorphous carbon nitride, Environ. Sci. Technol. 51 (2017) 10682-10690, DOI: 10.1021/acs.est.7b00974.

[184]. J. Li, Q. Xing, Y. Zhou, H. Huang, F. Dong, The activation of reactants and intermediates promotes the selective photocatalytic NO conversion on electron-localized Sr-intercalated g- ${ }_{3} \mathrm{~N}_{4}$, Appl. Catal., B, 232 (2018) 69-76, DOI: 10.1016/j.apcatb.2018.03.054.

[185]. J. Li, Z. Zhang, W. Cui, H. Wang, W. Cen, G. Johnson, G. Jiang, S. Zhang, F. Dong, The spatially oriented charge flow and photocatalysis mechanism on internal van der Waals heterostructures enhanced $\mathrm{g}_{-} \mathrm{C}_{3} \mathrm{~N}_{4}, \quad$ ACS $\quad$ Catal. $8 \quad$ (2018) 8376-8385, DOI: $10.1021 /$ acscatal.8b02459.

[186]. J. Li, Y. Sun, G. Jiang, Y. Chu, S. Lee, F. Dong, Tailoring the rate-determining step in photocatalysis via localized excess electrons for efficient and safe air cleaning, Appl. Catal., B, 239 (2018) 187-195, DOI: 10.1016/j.apcatb.2018.08.019.

[187]. F. Dong, Z. Zhao, Y. Sun, Y. Zhang, S. Yan, Z. Wu, An advanced semimetal-organic Bi spheres-g- $\mathrm{C}_{3} \mathrm{~N}_{4}$ nanohybrid with SPR-enhanced visible-light photocatalytic performance for NO purification, Environ. Sci. Technol. $49 \quad$ (2015) 12432-12440, DOI: $10.1021 /$ acs.est.5b03758.

[188]. P. Chen, F. Dong, M. Ran, J. Li, Synergistic photo-thermal catalytic NO purification of $\mathrm{MnO} \times / \mathrm{g}-\mathrm{C}_{3} \mathrm{~N}_{4}$ : Enhanced performance and reaction mechanism, Chin. J. Catal. 39 (2018) 619629, DOI: 10.1016/S1872-2067(18)63029-3. 


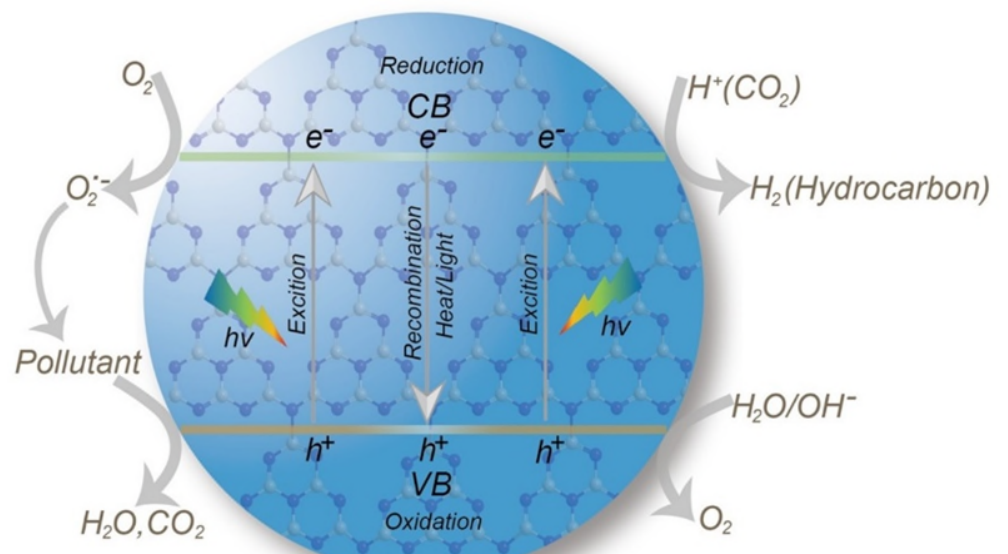

Figure 1. Mechanistic view of photocatalytic acivity of $\mathrm{g}-\mathrm{C}_{3} \mathrm{~N}_{4}$. Copyright with license Id;4537630117751. 


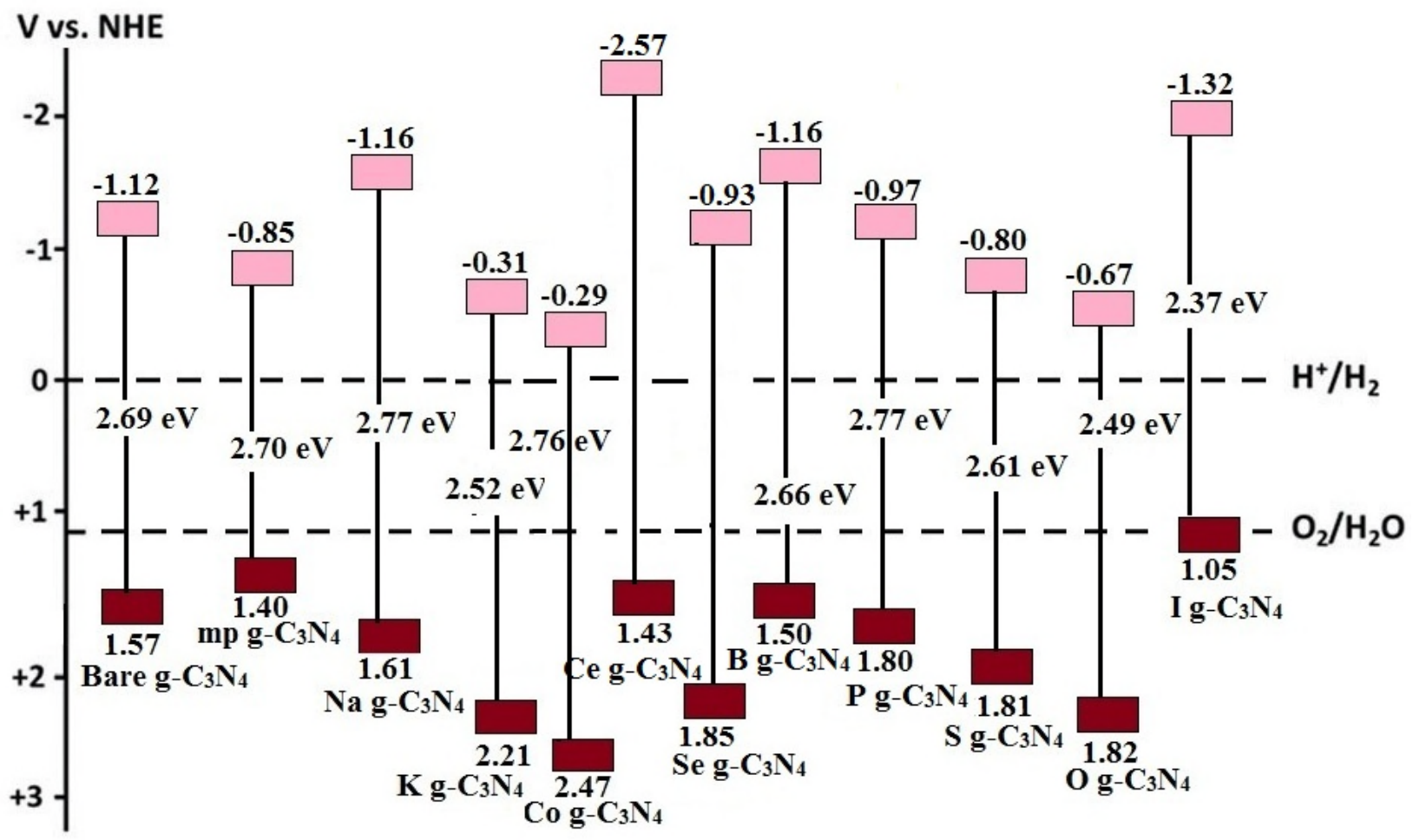

Figure 2. Band gap positioning with respect to conduction and valence band potentials of bare $g-\mathrm{C}_{3} \mathrm{~N}_{4}$ and non-precious metal doped $\mathrm{g}-\mathrm{C}_{3} \mathrm{~N}_{4}$.

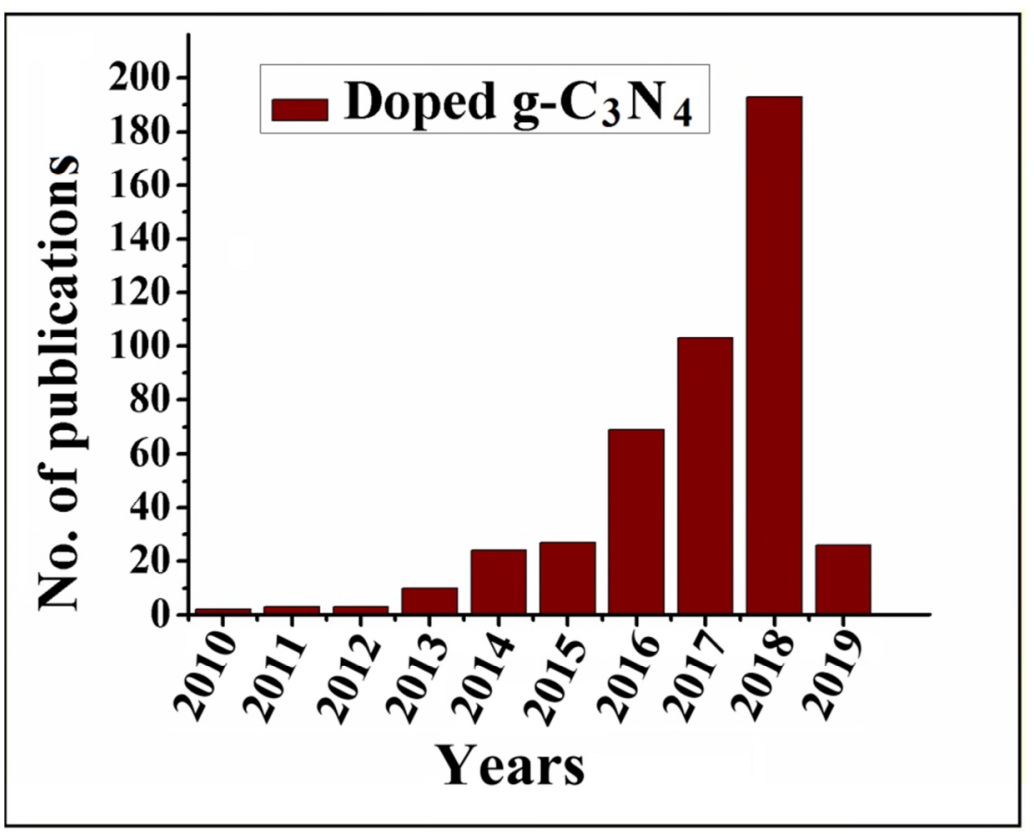

Figure 3. Annual publication details of doped g- $\mathrm{C}_{3} \mathrm{~N}_{4}$ from 2010 to 3 January 2019. 


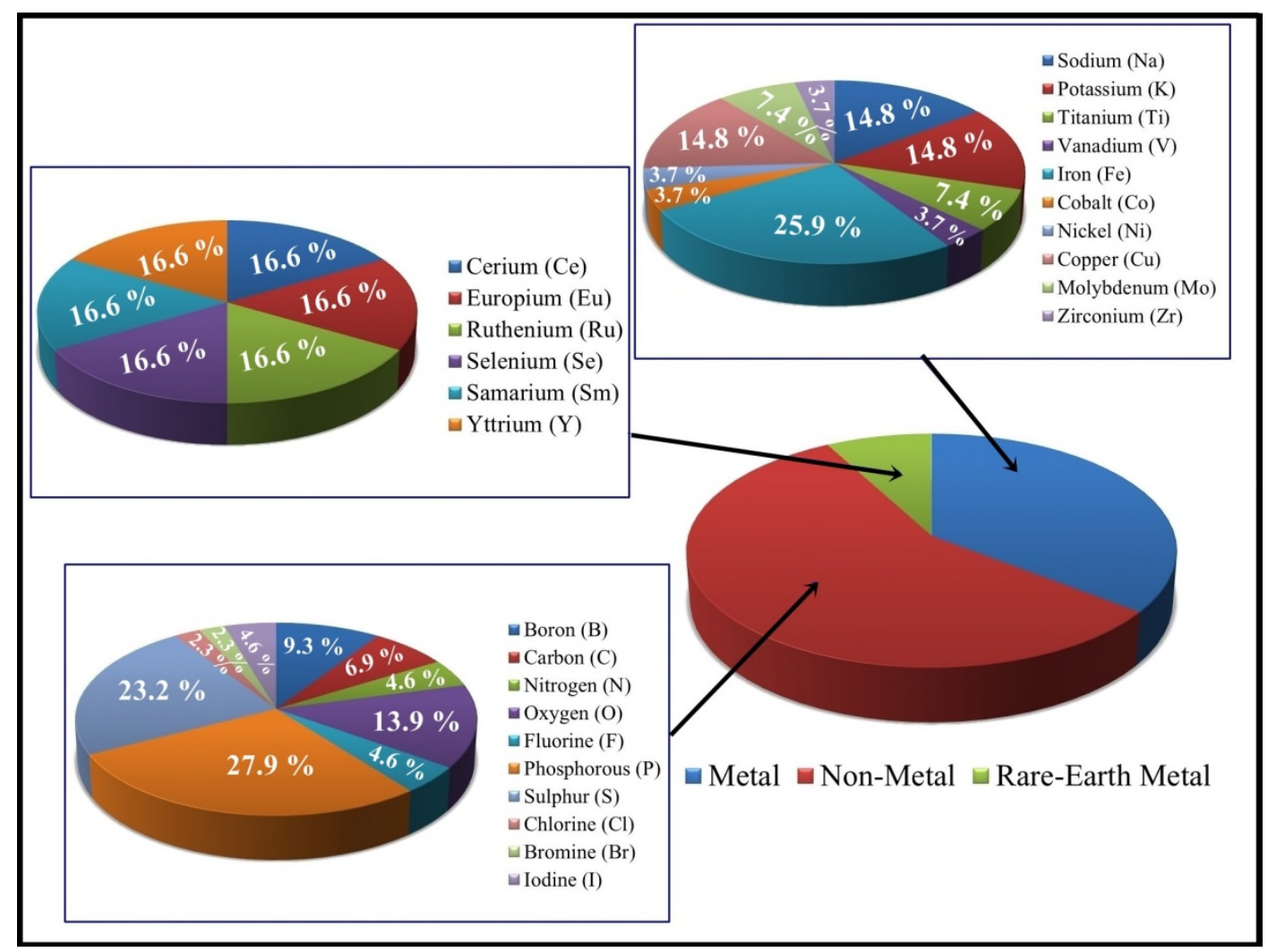

Figure 4. Pie diagram showing doping of $g-\mathrm{C}_{3} \mathrm{~N}_{4}$ with various noble metal free dopants using keyword (metal/non-metal/transition metal/ rare earth metal doped graphitic carbon nitride ) via SCOPUS search engine (Till 3 January 2019). 


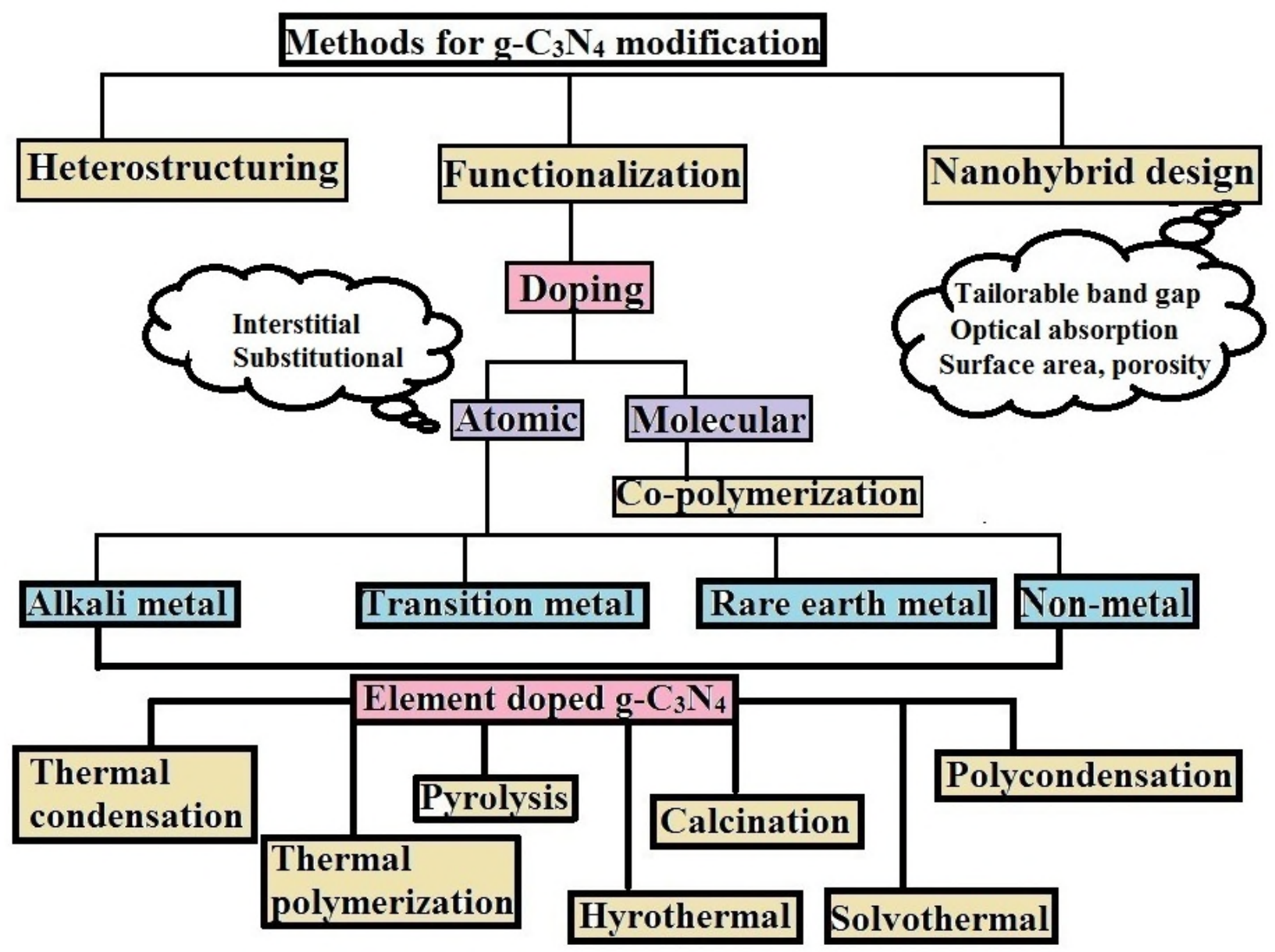

Figure 5. Flow chart showing modification methods for $\mathrm{g}-\mathrm{C}_{3} \mathrm{~N}_{4}$ and various doping strategies.

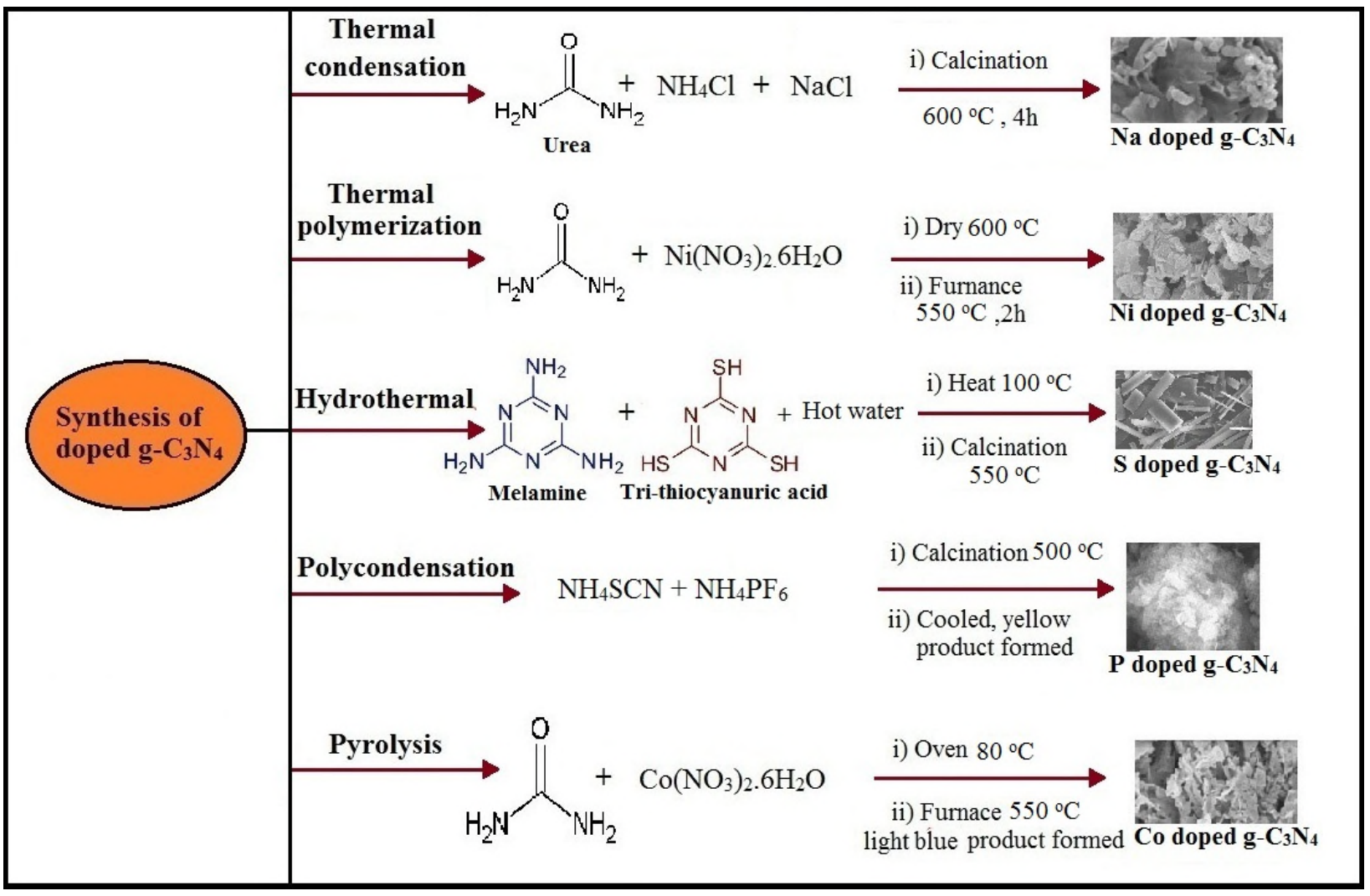


Recent advances in noble metal free doped graphitic carbon nitride based nanohybrids for photocatalysis of organic contaminants in water: A review

Hasija, Vasudha

Elsevier

Hasija V, Raizada P, Sudhaik A, et al., Recent advances in noble metal free doped graphitic carbon nitride based nanohybrids for photocatalysis of organic contaminants in water: A review. Applied Materials Today, Volume 15, June 2019, pp. 494-524

https://doi.org/10.1016/j.apmt.2019.04.003

Downloaded from Cranfield Library Services E-Repository 